\title{
Rational Design of MOF-Based Materials for Next-Generation Rechargeable Batteries
}

Cite as

Nano-Micro Lett.

(2021) 13:203

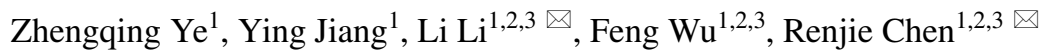

Received: 28 June 2021

Accepted: 16 August 2021

Published online: 6 October 2021

(C) The Author(s) 2021

\section{HIGHLIGHTS}

- This review summarizes recent progresses in pristine metal-organic frameworks (MOFs), MOF composites, and their derivatives for next-generation rechargeable batteries including lithium-sulfur batteries, lithium-oxygen batteries, sodium-ion batteries, potassiumion batteries, $\mathrm{Zn}$-ion batteries, and $\mathrm{Zn}$-air batteries.

- The design strategies for MOF-based materials as the electrode, separator, and electrolyte are outlined and discussed.

- The challenges and development strategies and of MOF-related materials for battery applications are highlighted.

ABSTRACT Metal-organic framework (MOF)-based materials with high porosity, tunable compositions, diverse structures, and versatile functionalities provide great scope for next-generation rechargeable battery applications. Herein, this review summarizes recent advances in pristine MOFs, MOF composites, MOF derivatives, and MOF composite derivatives for high-performance sodium-ion batteries, potassiumion batteries, Zn-ion batteries, lithium-sulfur batteries, lithium-oxygen batteries, and $\mathrm{Zn}$-air batteries in which the unique roles of MOFs as electrodes, separators, and even electrolyte are highlighted. Furthermore, through the discussion of MOFbased materials in each battery system, the key principles for controllable synthesis of diverse MOF-based materials and electrochemical performance improvement mechanisms are discussed in detail. Finally, the major challenges and perspectives of MOFs are also proposed for next-generation battery applications.

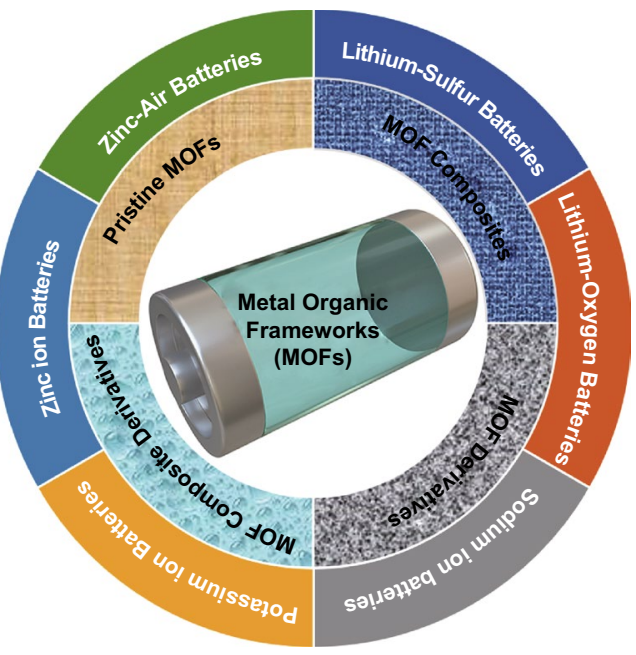

KEYWORDS Metal-organic frameworks; MOF composites; MOF derivatives; MOF composite derivatives; Batteries

Li Li, lily863@bit.edu.cn; Renjie Chen, chenrj@ bit.edu.cn

1 Beijing Key Laboratory of Environmental Science and Engineering, School of Materials Science and Engineering, Beijing Institute of Technology, Beijing 100081, People's Republic of China

2 Collaborative Innovation Center of Electric Vehicles in Beijing, Beijing 100081, People's Republic of China

3 Advanced Technology Research Institute, Beijing Institute of Technology, Jinan 250300, People's Republic of China 


\section{Introduction}

Over the past few decades, social attention in renewable energy storage systems has been rapidly increasing due to resource shortage and environmental degradation [1]. As one type of conventional energy storage technology, lithiumion batteries (LIBs) with high energy density are widely utilized in mobile phones, laptops, and portable electronics [2]. However, traditional LIBs constructed with a lithiated transition metal oxide (e.g., $\mathrm{LiCoO}_{2}$ and $\mathrm{LiFePO}_{4}$ ) as cathode and a graphite anode are reaching their specific energy density limits [3]. Besides, LIBs are still expensive to scale up owing to the limited Li reserves. The electric vehicles (EVs) and grid-based energy-storage markets demand a high energy density and a low cost at the rechargeable batteries $[4,5]$. Therefore, it is highly desirable to develop the nextgeneration batteries with high energy and low cost.

Lithium-sulfur ( $\mathrm{Li}-\mathrm{S})$ batteries have received considerable attention because of their high theoretical specific capacity $\left(1,675 \mathrm{mAh} \mathrm{g}^{-1}\right)$, energy density $\left(2,600 \mathrm{Wh} \mathrm{kg}^{-1}\right)$, and the use of nontoxic sulfur with natural abundance and low cost [5,6]. However, several major challenges hinder the commercialization including: (1) the depressed polysulfides conversion and low sulfur utilization resulting from the nonconductive nature of sulfur and discharged solid products $\left(\mathrm{Li}_{2} \mathrm{~S}_{2}\right.$ and $\left.\mathrm{Li}_{2} \mathrm{~S}\right)$, (2) the severe capacity fading and low Coulombic efficiency (CE) caused by the shuttle effect of soluble polysulfides, (3) the pulverization of the electrode structure originated from the volume variation $(80 \%)$, and (4) the safety issue of Li dendrite formation during the charge/ discharge process [7, 8]. Lithium-oxygen $\left(\mathrm{Li}-\mathrm{O}_{2}\right)$ batteries work broadly on the similar principle as the $\mathrm{Li}-\mathrm{S}$ batteries with the only difference being in the redox reaction between Li metal anode and $\mathrm{O}_{2}$ cathode. Despite high energy density $\left(3500 \mathrm{Wh} \mathrm{kg}^{-1}\right)$ and environmentally friendly nature, $\mathrm{Li}-\mathrm{O}_{2}$ batteries still face several issues. Firstly, the insulating and insoluble discharge product $\left(\mathrm{Li}_{2} \mathrm{O}_{2}\right)$ leads to sluggish kinetics of the oxygen reduction reaction (ORR) and oxygen evolution reaction (OER). Moreover, the undesirable generation of side products (e.g., $\mathrm{Li}_{2} \mathrm{CO}_{3}$ and $\mathrm{LiOH}$ ) results in inferior round trip efficiency and cycling performance $[4,9]$.

Advanced sodium-ion batteries (SIBs) and potassium-ion batteries (PIBs) have been regarded as one of the most promising candidates for grid-scale energy storage systems, due to the widespread distribution and low cost of sodium and potassium resources [10]. Unfortunately, the redox potential of $\mathrm{Na} / \mathrm{Na}^{+}(-2.71 \mathrm{~V}$ vs. standard hydrogen electrode) is higher than that of $\mathrm{Li}^{2} \mathrm{Li}^{+}(-3.04 \mathrm{~V})$ places, resulting in lower discharge voltage plateau and energy density of batteries [11]. Compared with $\mathrm{Na} / \mathrm{Na}^{+}, \mathrm{K} / \mathrm{K}^{+}$possesses a lower standard redox potential $(-2.93 \mathrm{~V})$, which ensures PIBs with higher energy density. However, the large ion radius of the $\mathrm{K}^{+}(1.38 \AA$ ) leads to slow diffusion kinetics, thus resulting in low capacity, inferior rate performance, and poor cycling stability during the insertion/deinsertion process [12]. Aqueous zinc ( $\mathrm{Zn}$ ) batteries (such as $\mathrm{Zn}$-ion batteries and $\mathrm{Zn}$-air batteries) have recently drawn considerable interest owing to their high theoretical capacity $\left(820 \mathrm{mAh} \mathrm{g}^{-1}\right)$, low toxicity, high safety, and low cost [13, 14]. However, they also suffer from several issues that need to be addressed. The development of aqueous $\mathrm{Zn}$-ion batteries (ZIBs) is plagued by the scarcity of suitable cathode materials for $\mathrm{Zn}$-ion storage. For $\mathrm{Zn}$-air batteries, the sluggish oxygen electrocatalytic kinetics usually cause a large overpotential and poor cycling stability. Moreover, $\mathrm{Zn}$ batteries face the problem of dendrite formation in anode resulted from uneven charge distribution and side reactions during plating/stripping. Dendrite growth is responsible for poor cycle life, capacity fade, and safety problems for aqueous $\mathrm{Zn}$ batteries [15].

To address the aforementioned challenges in each nextgeneration battery system, a large number of works have been devoted to exploring new materials with high electrochemical performance. Metal-organic frameworks (MOFs), constructed from metal ions or clusters and organic ligands, have attracted tremendous interest as a new class of porous materials in various fields, such as drug delivery [16, 17], gas adsorption, and separation [18, 19], energy storage and conversion [20,21]. MOFs possess topologically diverse and well-defined structures, resulting from their underlying topological nets. The combination of metal nodes (ions or clusters) and organic linkers endows MOFs' diverse structures with abundant elemental compositions and tunable porosity. The unique pore structure of MOFs ensures rapid electrolyte penetration and ion diffusion. The controllable structures and designable components could not only enable prominent electrochemical stability from their robust structure, but also guarantee a high capacity with their abundant electroactive sites. However, MOFs are rarely utilized directly as electrode materials for batteries due to their poor electrical 
conductivity [22]. Comparatively, MOF composites and MOF-derived materials not only inherit the structure, porosity, and composition advantages of MOFs, but also achieve improved electrical conductivity offered by the functional components. As a result, the electrochemical performances of the MOFs/MOF composites and their derivatives can be further improved, which opens up a new avenue for the rational design of battery materials for energy storage.

The present article focuses on the recent progress in pristine MOFs, MOF composites, MOF derivatives, and MOF composite derivatives for next-generation rechargeable batteries (SIBs, PIBs, ZIBs, Li-S, Li-O ${ }_{2}$, and $\mathrm{Zn}$-air batteries). We comprehensively discuss the unique advantages of components, structures, and properties in electrode materials, separators, electrolytes, and metal anodes for improved battery performance. The key factors for controllable preparation of various MOF-related materials and battery performance enhancement mechanisms are presented in detail. The main challenges and prospective solutions of these design strategies are proposed. We hope that this review will help guide and inspire the future design of advanced MOF-based materials for next-generation rechargeable batteries.

\section{Classification and Characteristics of MOF-based Materials}

\subsection{Classification of MOF-Based Materials}

Generally, pristine MOFs consisted of metal ions or clusters and organic ligands by coordination bonds. MOFs possess unique compositional and structural superiorities compared with conventional materials. In terms of component advantages, various metal nodes and organic linkers can be utilized to synthesize MOFs with different physical and chemical properties. In addition, pristine MOFs possess diverse nanoarchitectures such as 0D nanoparticles, 1D nanotubes, 2D nanosheets, and 3D nanoarrays with high porosity, which can provide high exposure of active sites and fast mass transport for high-performance batteries. Furthermore, MOFs can be incorporated with functional materials such as carbon, polymers, metal nanoparticles, and functional molecules to construct MOF composites. The synergistic effects between MOFs and the functional components can contribute to the enhanced electrochemical performance of the MOF composites. Besides, the transformation of MOFs into diverse MOF derivatives (e.g., carbon materials, metal/metal compounds, and single-atom sites) by post-synthetic strategies can result in novel properties over pristine MOFs. Similarly, MOF composite-derived (e.g., MOF/carbon, MOF/polymer, and $\mathrm{MOF} /$ metal compounds) multifunctional superstructures can further enrich their structural diversities, which are beneficial for the improved overall performance of batteries. Based on the above discussion, the MOF-based materials have been classified into four main groups: pristine MOFs, MOF composites, MOF derivatives, and MOF composite derivatives (Fig. 1). Furthermore, these MOF-related materials show great potential in many battery applications, including SIBs, PIBs, ZIBs, $\mathrm{Li}-\mathrm{S}, \mathrm{Li}-\mathrm{O}_{2}$, and $\mathrm{Zn}$-air batteries.

\subsection{Characteristics of MOF-Based Materials}

MOFs with tunable chemical compositions and crystalline porous structures display the following unique characteristics: (1) crystalline porous frameworks. Porosity is an intrinsic feature of MOFs because of the formation of open frameworks by coordination between metal nodes and organic linkers. Moreover, the original porous frameworks can also be converted into hierarchically porous structures after postsynthetic treatment. The unique porous frameworks ensure uniform distribution of the internal active sites, which is favorable to the continuous proceedings of electrochemical reaction. The encapsulation of other active species in the porous frameworks can also prevent the formation of severe agglomerates, thus resulting in enhanced electrochemical performance. (2) Tunable metal nodes. Metal nodes play a vital role in determining the porous frameworks and functional properties of MOFs [23]. For example, the MOFs with bimetallic active sites can also be synthesized via manipulating metal nodes, which can significantly facilitate electron transport and electron distribution, contributing to enhanced electrical conductivities and stabilities. Consideration of the atomic isolation of metal nodes is an intrinsic characteristic of MOFs, MOF-derived single-atom catalysts (SACs) with atomically dispersed metal active sites, which maximizes the catalytic activity of metal nodes. (3) Diverse organic ligands. Organic ligands can serve as "skeletons" in MOFs and isolate the metal nodes from each other, resulting in uniformly distributed metal active sites. Furthermore, rich functional groups in organic ligands promote the heterogeneous nucleation and uniform growth of MOFs on other 


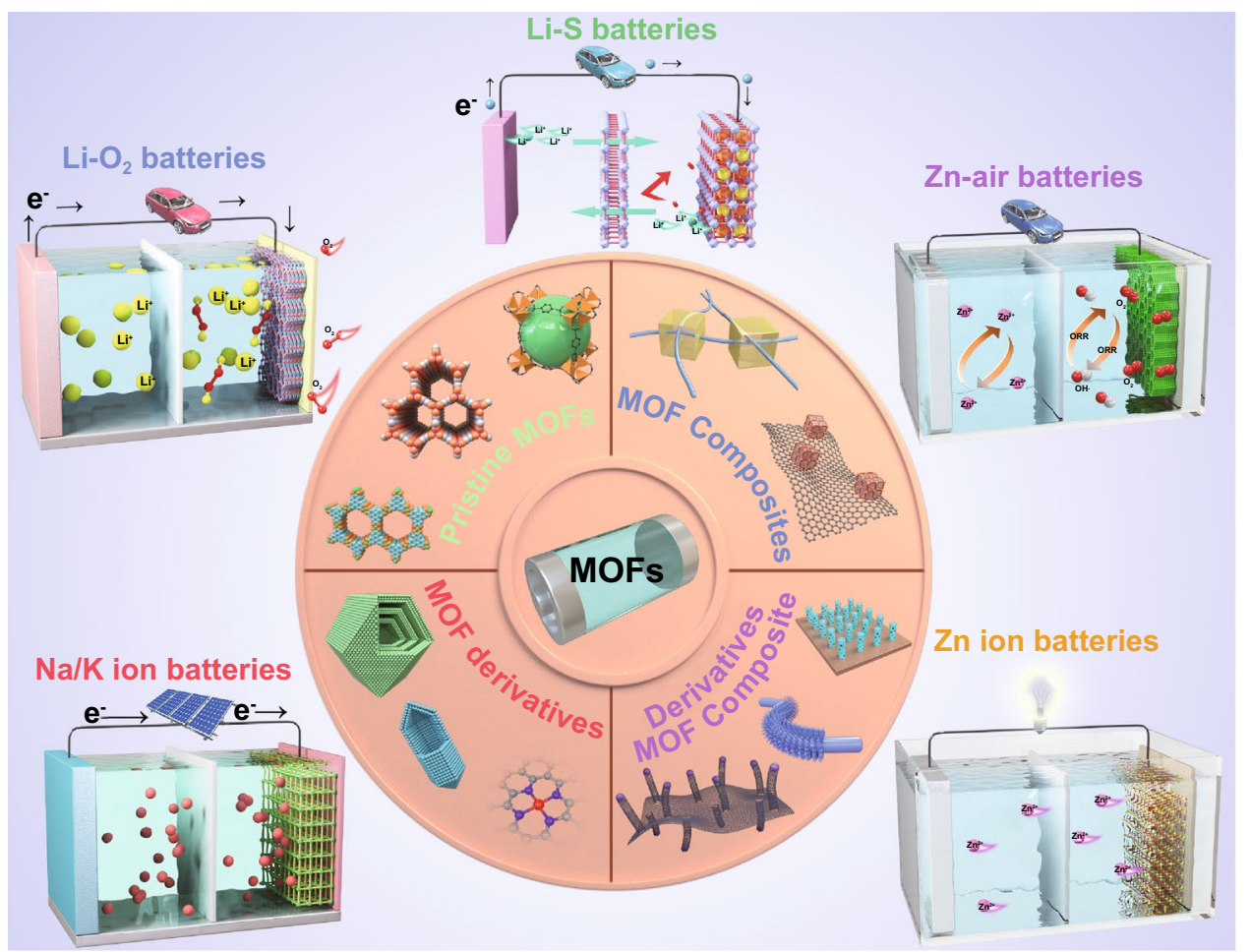

Fig. 1 Schematic illustration of MOF-related materials for next-generation batteries

functional materials through weak interactions in solutions [24]. For MOF derivatives, diverse organic ligands are not only the source of carbon, but also the source of other nonmetallic dopants, such as nitrogen, sulfur, and phosphorus [25]. Active dopants in the MOF derivatives further improve the electrochemical performance because of local electron transfer and redistribution. In addition, some nonmetal elements could also react with metal cations, partially converting metals into metal sulfides, metal phosphides, or metal- $\mathrm{N}_{\mathrm{x}}$ active species, which is beneficial for enhanced battery performance [26, 27]. These characteristics of MOFs demonstrate unique advantages when compared with other conventional materials, which is vital to achieving highperformance next-generation batteries.

\section{Lithium-Sulfur Batteries}

\subsection{Pristine MOFs}

Pristine MOFs with an abundant pore structure, well-defined morphology, and high polarity possess advantages in terms of accommodating active sulfur, alleviating volume variation, inhibiting polysulfides shuttling behavior, and protecting Li metal anode. The pioneering work of mesoporous MIL-100 (Cr) (MIL, Matérial Institut Lavoisier) as a sulfur host for Li-S batteries in 2011 was reported by Tarascon and co-workers [28]. Although the successful incorporation of 48 wt\% sulfur into the MIL-100 (Cr) with a high surface area, the battery delivered poor cycle stability due to the weak binding between the polysulfides and oxygenated MOF groups. In 2014, Xiao et al. [29] proposed interwoven microporous and mesoporous Ni-MOF $\left(\mathrm{Ni}_{6}(\mathrm{BTB})_{4}(\mathrm{BP})_{3}\right.$ ( $\mathrm{BTB}=$ benzene-1,3,5-tribenzoate and $\mathrm{BP}=4,4$ ' bipyridyl) in which $\mathrm{Ni}$ (II) served as a Lewis acid, while polysulfides acted as a Lewis base (Fig. 2a). The Ni-MOF can strongly confine polysulfides within the cathode side via physical and chemical interactions, leading to the excellent cycling stability (the capacity retention of $89 \%$ after 100 cycles at $0.1 \mathrm{C}$ ) of Ni-MOF sulfur cathode. However, the insulating nature of MOFs leads to poor sulfur utilization, and the framework could suffer from gradual degradation, especially after longterm cycling. 
MOFs with large surface area and tunable porosity could be appropriate candidates as ionic sieves to suppress these shuttling polysulfide ions. For example, Fang and co-workers [30] demonstrated that conductive and microporous MOF with the polysulfide-capturing ability $\left(\mathrm{Ni}_{3}(\mathrm{HITP})_{2}\right.$ (HITP = 2,3,6,7,10,11-hexaiminotriphenylene) ) was grown in situ on the separator for decreasing the polysulfide shuttling behavior (Fig. 2b). The Li-S batteries with MOFs' functional separator achieved a high area capacity of 7.24 $\mathrm{mAh} \mathrm{cm}^{-2}$ (capacity retention of $86 \%$ ) after 200 cycles at 0.5 $\mathrm{C}$ under high sulfur loading of $8.0 \mathrm{mg} \mathrm{cm}^{-2}$. Subsequently, a simple wet-chemistry method was developed for the preparation of ultrathin $\mathrm{MOF}\left(\mathrm{Cu}_{2}(\mathrm{CuTCPP})\right)$ nanosheets [31]. The as-obtained MOF nanosheets were used to assemble a highly oriented microporous membrane modified separator for inhibiting the polysulfide shuttling, which significantly enhanced cycling stabilities.

MOFs with narrow and uniform pore size can not only suppress the polysulfides shuttle in Li-S batteries, but also help to protect the Li metal anode for inhibiting the growth of Li dendrites. Zhou and co-workers designed MOF-based membrane by using copper benzene tricarboxylate (HKUST1) nanoparticles as assemble units and the PVDF-HFP as a binder [32]. The highly homogenous pore sizes of MOF particles boost uniform $\mathrm{Li}^{+}$fluxes, fundamentally suppressing the Li dendrites growth and leading to stable Li plating/striping even at a high current density of $10 \mathrm{~mA} \mathrm{~cm}^{-2}$. The Li-S batteries with a MOF-based separator displayed an ultralong cycle life with a low-capacity decay rate of $0.015 \%$ per cycle after 2000 cycles. Recently, Chen's group has demonstrated that MOF-199 could inhibit the growth of Li dendrites by serving as a robust shield and homogenize $\mathrm{Li}^{+}$concentration by their abundant porous structure (Fig. 2c) [33]. However, the intrinsic mechanical brittleness of the MOFs made them hardly meet the practical requirements of durable and stable Li-S batteries.

\subsection{MOF Composites}

Despite the attractive advantages, the application of the MOFs materials is hindered by several challenges, including the poor conductivity and detrimental electrochemical stability of MOFs [34, 35]. The combination of MOFs with various functional materials is a facile and effective way to further enhance MOF-based Li-S battery performance.
Numerous MOF/carbon composites have been presented by assembling MOFs, highly conductive and excellent mechanical carbon species, including carbon nanotubes (CNTs) and graphene, and act as sulfur host and separator for improved Li-S battery performance [35-38]. For example, the cerium (Ce)-MOF-2/CNT composites were fabricated as a modified separator material for high-performance $\mathrm{Li}-\mathrm{S}$ batteries [39]. The excellent performance is ascribed to the synergistic effect of strong adsorption and catalytic transformation of the Ce-MOF-2 toward polysulfides along with the highly conductive and robust CNT. In this regard, Liu et al. [40] synthesized a range of MOFs on graphene nanosheets including 2D Ni-2,6-NDC (2,6-NDC = 2,6-naphthalene dicarboxylate), zeolitic imidazolate framework-8 (ZIF-8), HKUST-1, and hybrid NiFe-BTC (BTC = benzene-1,3,5 tricarboxylate). Utilization of ZIF-67/graphene nanosheetbased membranes in $\mathrm{Li}-\mathrm{S}$ batteries results in higher long-term cycling stability compared to bare graphene and granular ZIF-67 + G membranes. Moreover, the construction of designed composites of MOFs with conductive polymers seems to be an effective strategy for the realization of excellent sulfur electrode materials [41]. For instance, a conductive polypyrrole (PPy) was applied to construct PPy-PCN-224 composite for a long-term cycle at a high rate (specific capacity of $780 \mathrm{mAh} \mathrm{g}^{-1}$ after 400 cycles at $5 \mathrm{C}$ ) in Li-S batteries (Fig. 2d) [22]. This method combines the polarity and cross-linked pore and tunnels of PCN-224 with the conductive gain of PPy; thus, their geometric advantages could be fully utilized. A substantially higher conductivity additive can be added to enhance the MOF conductivity, but resulting in a lower energy density in $\mathrm{Li}-\mathrm{S}$ batteries.

Functionalization strategy can be also used to design a variety of MOF composites [42, 43]. For example, Thoi and co-workers [44] proposed lithium thiophosphate $\left(\mathrm{Li}_{3} \mathrm{PS}_{4}\right)$-functionalized zirconium ( $\mathrm{Zr}$ )-MOFs with sulfur as cathode with enhanced rate capabilities (Fig. 2e). The incorporation of $\mathrm{Li}_{3} \mathrm{PS}_{4}$ in $\mathrm{Zr}$-MOFs enhances sulfur utilization and polysulfide confinement to maintain a high reversible capacity over prolonged cycling. The inorganic $\mathrm{Li}_{3} \mathrm{PS}_{4}$ with excellent stability and large surface area of MOFs also prevents battery damage under high rates and poor cycling conditions. The decorated MOF channels (pore size of 9.0 ̊, Ms-9.0) with negatively charged sulfonic polymer (NSP) were reported as a modified separator for enhanced cycling stability of Li-S batteries [45]. The Ms-9.0-NSP separator can form sulfurphobic interaction between NSP 


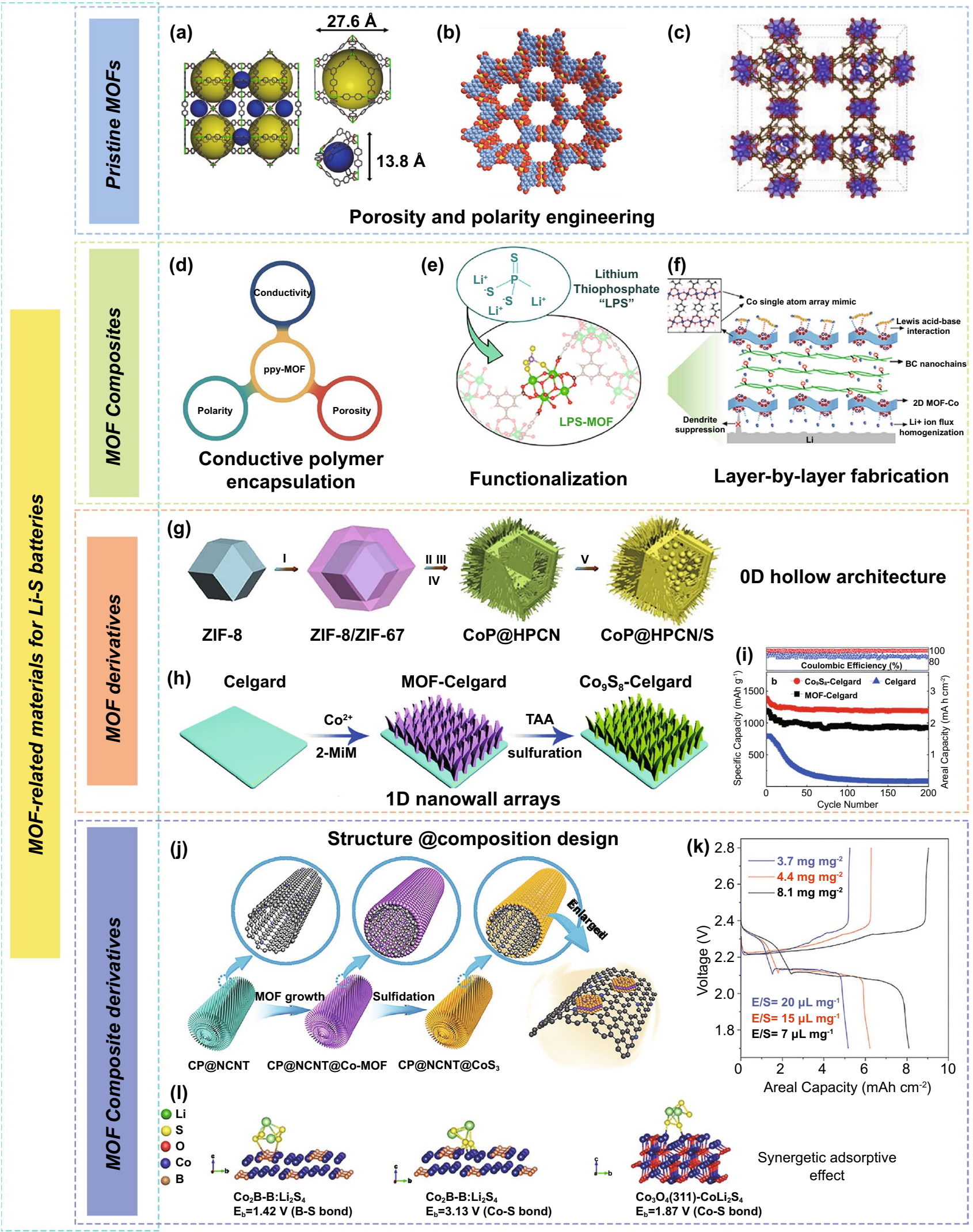


\Fig. 2 MOF-related materials for $\mathrm{Li}-\mathrm{S}$ batteries. a Structure of NiMOF (yellow and blue spheres represent pore volume; gray, C; red, O; blue, N; green, Ni) [29]. Copyright (C) 2014, American Chemical Society. b Crystal structure of $\mathrm{Ni}_{3}(\mathrm{HITP})_{2}$ [30]. Copyright (C) 2018, Wiley-VCH. c crystal structure of MOF-199 [33]. Copyright (C) 2019, Elsevier. d Three criteria of ppy-MOF structure [22]. Copyright (C) 2018, Wiley-VCH. e Scheme of $\mathrm{Li}_{3} \mathrm{PS}_{4}$-functionalized $\mathrm{Zr}$-MOFs host with encapsulation of polysulfides [44]. Copyright (c) 2019, American Chemical Society. f Schematic representation for Li-S batteries of the B/2D MOF-Co separator [47]. Copyright (C) 2020, Wiley-VCH. g Schematic illustration of synthesis process for CoP@ HPCN/S [56]. Copyright (C) 2019, Elsevier. h Schematic illustration of $\mathrm{Co}_{9} \mathrm{~S}_{8}$-Celgard preparation and $\mathbf{i}$ cyclic stability of the cells with the various separators [59]. Copyright (C) 2018, The Royal Society of Chemistry. j Schematic illustration of CP@NCNT@ $\mathrm{CoS}_{3}$ synthesis [69]. Copyright @ 2019, Wiley-VCH. k Charge-discharge profiles of CC@CS@HPP sulfur electrodes at 0.01 C [70]. Copyright @ 2020 , Wiley-VCH. I First-principles calculations of the chemical interaction of $\mathrm{Co}_{2} \mathrm{~B}$ and $\mathrm{Co}_{3} \mathrm{O}_{4}$ surfaces with polysulfides [78]. Copyright (C) 2019, American Chemical Society

and polysulfides, which could facilitate the $\mathrm{Li}^{+}$diffusion, reduce voltage polarizations, and relieve initial "sulfur loss."

An effective strategy to construct composite structures with MOFs and polymers assures both inhibiting shuttling effect and suppressing Li dendrite growth in $\mathrm{Li}-\mathrm{S}$ batteries simultaneously [46]. A layer-by-lawyer (LBL)-assembled bifunctional separator (B/2D MOF-Co) was prepared by employing bacterial cellulose (BC) and ultrathin MOFCo nanosheets [47]. The Co single-atom array mimic on 2D ultrathin MOF can not only homogenize $\mathrm{Li}^{+}$flux via strong $\mathrm{Li}^{+}$adsorption with $\mathrm{O}$ atoms, but also effectively trap polysulfides through Lewis acid-base interaction (Fig. 2f). Consequently, the B/2D MOF-Co can simultaneously regulate the Li stripping and plating behavior and migration of polysulfides, thus achieving the safety and life of Li-S batteries. Recently, Gao et al. [48] fabricated a MOF-based triple-layer kind of separator with stepped channels through the combination of multidimensional various MOFs and functional polymers. This MOF/polymer triple-layer separator with stepped channels can inhibit polysulfides shuttling, promote the efficient transfer of $\mathrm{Li}^{+} /$electrolyte, and suppress $\mathrm{Li}-\mathrm{S}$ battery polarization. As a powerful separator, it displays superior cycling performance compared to single-layer and double-layer membranes. Besides, a MOF-modified gel polymer electrolyte (GPE) was constituted of $\mathrm{Mg}$ (II)-based MOF material (Mg-MOF-74) and poly(vinylidene fluoride) (PVDF) polymer for high-performance quasi-solid-state $\mathrm{Li}-\mathrm{S}$ batteries [49]. Because of the unique pore structure, the Mg-MOF-74 material can not only inhibit the soluble polysulfides diffusion but also cage $\mathrm{TFSI}^{-}$anions, thus boosting a uniform flux of $\mathrm{Li}^{+}$and a stable $\mathrm{Li}$ metal anode.

\subsection{MOF Derivatives}

In addition to MOF composites, MOFs can be directly transformed into nanostructured porous carbon, metal compounds, and their composites. These MOF derivatives possess hierarchically porous structures, excellent conductivity, and abundant polar/catalytic sites that are beneficial for enhanced Li-S battery performance [50-52]. Specifically, the porous carbon substrate can efficiently promote ion/ electron transport and physically confine polysulfides, while elaborately designed hollow structures and core-shell structures can relieve volume expansion and preserve structural integrity during cycling [53, 54]. Furthermore, the incorporated metal compounds can offer polar/catalytic sites to chemically immobilize polysulfides and efficiently catalyze the sulfur species conversion reaction [55]. For example, Ye et al. [56] reported the hollow polyhedra/CNT confined CoP nanoparticles superstructures (CoP@HPCN) derived from core-shell ZIF-8/ZIF-67 as a sulfur host (Fig. 2g). It was proposed that smart hollow polyhedra/CNT architecture for alleviating volume variation and boosting ion/electron transport, together with the adsorption and catalysis effect of CoP nanoparticles for polysulfides transformation, contributed to an outstanding electrochemical performance in Li-S batteries.

MOF derivatives of modified separators can suppress polysulfides shuttle via chemical interaction and rapid redox kinetics $[57,58]$. The representative study of 2D ZIF-67-derived $\mathrm{Co}_{9} \mathrm{~S}_{8}$-Celgard separator was proposed by Manthiram and co-workers [59]. The 2D ZIF-67 was in situ grown on the Celgard and then was chemically converted into $\mathrm{Co}_{9} \mathrm{~S}_{8}$-Celgard via solvothermal sulfurization (Fig. $2 \mathrm{~h}$ ). The well-aligned $\mathrm{Co}_{9} \mathrm{~S}_{8}$ hollow nanowall arrays as a multifunctional polar barrier enabled a high capacity of 1385 $\mathrm{mAh} \mathrm{g}^{-1}$ with a capacity retention of $86 \%$ after 200 cycles for $\mathrm{Li}-\mathrm{S}$ batteries (Fig. 2i). In another case, Ni/Zn-bio-MOF100-derived bimetal carbide $\mathrm{Ni}_{3} \mathrm{ZnC}_{0.7}$ possesses both sulfophilic sites of $\mathrm{Ni}$ and lithiophilic sites of $\mathrm{Zn}$, resulting in strong adsorption toward polysulfides and reduced energy barriers for $\mathrm{Li}^{+}$diffusion [60]. When acting as the separator coating, the $\mathrm{Ni}_{3} \mathrm{ZnC}_{0.7}$ could effectively suppress the shuttle effect of polysulfides, leading to the excellent performance 
of Li-S batteries even at a high rate of $7 \mathrm{C}$ and high sulfur loading $\left(6.8 \mathrm{mg} \mathrm{cm}^{-2}\right)$. In addition, the use of MOF derivatives as separators to simultaneously suppress Li dendrite growth and inhibit polysulfides shuttle behavior has also been reported recently. The amorphous $\mathrm{TiO}_{2}$ embedded in benzene-1,4-dicarboxylic acid (denoted as a- $\mathrm{TiO}_{2}-\mathrm{BDC}$ ) derived from Ti-containing MOF (MIL-125-Ti) was coated on a commercial separator to stabilize Li metal anodes for $\mathrm{Li}-\mathrm{S}$ batteries [61]. The $\mathrm{a}-\mathrm{TiO}_{2}-\mathrm{BDC}$ not only induces the formation of robust solid electrolyte interphase (SEI) layer, but also strongly adsorbs polysulfides, which give an advantage to the anode and cathode of $\mathrm{Li}-\mathrm{S}$ batteries. However, the poor compatibility between the MOF derivatives and the separators could be unable to support the practical batteries for long-term cycling.

\subsection{MOF Composite Derivatives}

MOF composite derivatives have gained much attention owing to their applications in $\mathrm{Li}-\mathrm{S}$ batteries [62-65]. Combining MOF derivatives with conductive matrix (e.g., graphene, CNT, and carbon cloth) is a promising strategy to achieve an excellent electrochemical performance because of the reduced mechanical stress and prevented self-aggregation [66-68]. For instance, Sun and co-workers proposed [69] the use of amorphous $\mathrm{CoS}_{3}$ as an electrocatalyst to promote the transformation of $\mathrm{Li}_{2} \mathrm{~S}_{2}$ to $\mathrm{Li}_{2} \mathrm{~S}$. First, the nitrogendoped carbon nanotubes were grown on carbon paper (CP@ NCNT) as catalyst support (Fig. 2j). Then, Co-MOF was grown on the surface of $\mathrm{CP} @ \mathrm{NCNT}$ and further transformed into the CP@NCNT@CoS 3 . The $\mathrm{Li}_{2} \mathrm{~S}_{\mathrm{Li}} \mathrm{Li}_{2} \mathrm{~S}_{2}$ ratio in the discharge products increased to 5.60/1 from 1/1.63 with CP@ NCNT@ $\mathrm{CoS}_{3}$ via XPS analysis, contributing to $80 \%$ sulfur utilization and the high-capacity retention during cycling under high-sulfur-loading conditions. Recently, Ye et al. [70] constructed a high-efficiency CoSe electrocatalyst with hierarchical porous polyhedron on a carbon cloth framework (CC@CS@HPP) through simply immersing carbon cloth in the ZIF-67 precursors and followed by in situ selenization strategy. A freestanding CC@CS@HPP significantly accelerated polysulfide capture/diffusion and $\mathrm{Li}_{2} \mathrm{~S}$ precipitation/decomposition, which achieved a high areal capacity of $8.1 \mathrm{mAh} \mathrm{cm}^{-2}$ at high sulfur loading of $8.1 \mathrm{mg} \mathrm{cm}^{-2}$ under a lean electrolyte (Fig. 2k).
Developing fabrication strategies of metal compounds/ MOF composite derivatives is also of great importance [71-73]. By compositing with proper metal compounds, MOF composite derivatives could offer more exposed active sites for polysulfides regulation and tailorable structures for sulfur loading, thus improving the sulfur utilization and enhancing sulfur loading simultaneously. For example, the $\mathrm{TiO}_{2}$ and $\mathrm{Co}$ nanoparticle-decorated carbon polyhedra $\left(\mathrm{C}-\mathrm{Co} / \mathrm{TiO}_{2}\right)$ were prepared via titanium tetraisopropanolatecontaining ZIF67 as precursor through pyrolysis treatment as described in the previous study [74]. When serving as cathode materials for $\mathrm{Li}-\mathrm{S}$ batteries, $\mathrm{C}-\mathrm{Co} / \mathrm{TiO}_{2}$ polyhedras show significantly improved electrochemical performances due to high-efficiency conductive networks, robust architecture, abundant $\mathrm{TiO}_{2}$ - and Co-adsorption sites. In another study, Chen and co-workers reported a hollow nanocage-like layered double hydroxides $/ \mathrm{Co}_{9} \mathrm{~S}_{8}\left(\mathrm{H}-\mathrm{LDH} / \mathrm{Co}_{9} \mathrm{~S}_{8}\right)$ heterostructure by in situ construction and sulfurization of ZIF-67 templated NiCo-LDH [75]. The robust $\mathrm{H}-\mathrm{LDH} / \mathrm{Co}_{9} \mathrm{~S}_{8}$ sulfur host could inhibit the polysulfides diffusion and accommodate sufficient sulfur owing to abundant O-containing groups and $\mathrm{Co}-\mathrm{S}$ sites. Moreover, the intimated interfaces of NiCo$\mathrm{LDH}$ shell and $\mathrm{Co}_{9} \mathrm{~S}_{8}$ domains present greatly enhanced electron conductivity and $\mathrm{Li}^{+}$diffusivity.

Applying MOF composite derivatives as separators for Li-S batteries has the potential to block polysulfides [76, 77]. For example, $\mathrm{Co}_{2} \mathrm{~B} @ \mathrm{CNT}$ was prepared as a functional separator by employing ZIF-67 and CNT [78]. Interestingly, both $\mathrm{Co}$ and $\mathrm{B}$ in $\mathrm{Co}_{2} \mathrm{~B}$ could bond with the $\mathrm{S}_{4}{ }^{2-}$ anions and therefore exhibit higher adsorption capability when compared with $\mathrm{Co}_{3} \mathrm{O}_{4}$ (Fig. 21). By combining the synergetic adsorptive effect of $\mathrm{Co}_{2} \mathrm{~B}$ and the electron highway of CNT, the cell with modified separators exhibited prominent cycling life with a capacity decay rate of $0.0072 \%$ per cycle after 3000 cycles and ultrahigh-rate capability (1172.8 $\mathrm{mAh} \mathrm{g}^{-1}$ at $5 \mathrm{C}$ ). Also, MOF composite derivatives can serve as two-in-one hosts for both sulfur cathode and metallic Li anode to improve their performance simultaneously [79]. As an example, the use of bimetallic Co/Zn-ZIF and graphene nanosheet substrate was proposed as precursor for the synthesis of superhierarchical Co-embedded $\mathrm{N}$-doped porous carbon nanosheets (Co/N-PCNSs) [80]. The Co nanoparticles and doped $\mathrm{N}$ heteroatoms can work synergistically to confine soluble polysulfides and boost the 
conversion kinetics of sulfur cathode. Meanwhile, the hierarchical porous structure and the lithiophilic $\mathrm{N}$ heteroatoms in $\mathrm{Co} / \mathrm{N}-\mathrm{PCNSs}$ can regulate $\mathrm{Li}$ nucleation and inhibit $\mathrm{Li}$ dendrite growth in the anode. As a result, a full Li-S battery with $\mathrm{Co} / \mathrm{N}-\mathrm{PCNSs}$ as two-in-one hosts achieves excellent capacity retention and stable $\mathrm{CE}$.

\subsection{Summary}

$\mathrm{Li}-\mathrm{S}$ batteries as prominent candidates of next-generation batteries have been considered as rapid development. Because of the multielectron reaction mechanism, many issues still exist in Li-S batteries, including the low-sulfur utilization, sluggish sulfur conversion, polysulfides shuttle, and Li dendrite growth. As great as single MOFs, MOF composites and their derivatives perform in $\mathrm{Li}-\mathrm{S}$ batteries. However, the poor conductivity of MOFs, the self-agglomeration and low tap density of MOF derivatives, the lack of diversity of the MOF composites, and their derivatives are worth to be comprehensive consideration. The emerging MOF composites ion sieve and 3D MOF composite derivatives for freestanding sulfur cathodes are very likely to be good choices for high-performance Li-S batteries.

\section{Lithium-Oxygen Batteries}

\subsection{Pristine MOFs}

MOFs are a viable option for $\mathrm{Li}-\mathrm{O}_{2}$ batteries owing to the tunable pore structure, accessible metal sites, and robust framework structure. Wu et al. [81] demonstrated that MOFs with accessible metal sites could contribute to a significant $\mathrm{O}_{2}$ enrichment/diffusion in the framework (Fig. 3a). Five MOFs (MOF-5, HKUST-1, Co-MOF-74, Mn-MOF-74, and Mg-MOF-74) were studied, among which Mn-MOF-74 with $1 \mathrm{D}$ regular channels and open metal sites delivered the highest discharge capacity of $9420 \mathrm{mAh} \mathrm{g}^{-1}$ at $50 \mathrm{~mA} \mathrm{~g}^{-1}$, which was more than four times for MOF-free cathode (Fig. 3b). Moreover, robust Mn-MOF-74 exhibited excellent structural stability without obvious decomposition after discharge/ charge. A bimetallic MOF (MnCo-MOF-74) was presented to further enhance the performance of $\mathrm{Li}-\mathrm{O}_{2}$ batteries [82]. Benefitting from both Mn-metal and Co-metal clusters, MnCo-MOF-74 enhanced reversibility and efficiency during repeated cycles.
Recently, a single-ion conductor in the liquid electrolyte was prepared by coordinating the anions in the electrolyte on the abundant metal sites of a Cu-MOF-74 rod-like substrate [83]. Further investigations demonstrate that the $\mathrm{Li}^{+}$migrate within the pores of the Cu-MOF-74 by a Grotthuss-like mechanism that the charge is transferred by coordinated hopping of solvated $\mathrm{Li}^{+}$between the lithiophilic $\mathrm{ClO}^{4-}$ groups (Fig. 3c). The single-ion electrolyte can contribute to homogeneous single $\mathrm{Li}^{+}$transport in the electrolyte and effectively suppress Li dendrites growth. When the single ion electrolyte is applied for $\mathrm{Li}-\mathrm{O}_{2}$ batteries, an enhanced cycle performance with low overpotential is achieved.

\subsection{MOF Composites}

Considering most MOFs possess low electrical conductivity, it is desired to develop strategies to improve the conductivity of MOFs, such as hybridization with conductive matrix and functionalization with guest molecules. Mn-MOF-74 nanoparticles were directly grown on 1D CNTs by a simple additive-mediated synthesis as cathode materials for Li- $\mathrm{O}_{2}$ batteries [84]. The Mn-MOF-74@CNTs could provide conductive networks and prevent the agglomeration of MOF nanoparticles, thus exhibiting fewer side reactions and improved cycling performance in a humid oxygen environment. Recently, dinuclear $\mathrm{Co}(\mathrm{OH})_{2}$ sub-nanometric particles (SNP) within multishell hollow ZIF-8 (H-ZIF-8[nS], where $\mathrm{n}$ is the number of shells) were autogenously synthesized by Kang and co-workers (Fig. 3d) [85]. First, the stable MOF (ZIF-8) layers effectively transferred ethylene glycol (EG) isolated water molecules to the decomposable MOF (ZIF67) layers through hydrophobic micropores. Subsequently, SNPs derived from the decomposable ZIF-67 were stabilized inside the pore channels of H-ZIF-8 (Fig. 3e). The hopping charge transport between SNPs stabilized by $\pi$-back bonding introduces high electrical conduction in MOFs, thus leading to high capacities and low overpotentials in $\mathrm{Li}-\mathrm{O}_{2}$ batteries.

For more practical lithium-air batteries (LABs), MOF composites could be applied as an $\mathrm{O}_{2}$-permeable membrane to protect cathodes from moisture and $\mathrm{CO}_{2}$ in ambient air atmosphere. In one example, a mixed matrix membrane (MMM) was constructed by introducing a polydopaminecoated AI-based MOF (CAU-1- $\mathrm{NH}_{2}$ ) into a polymethylmethacrylate (PMMA) substrate (Fig. 3f) [86]. The abundant 
(a)

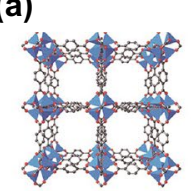

MOF-5 $\left(\mathrm{Zn}_{4} \mathrm{O}(\mathrm{BDC})_{3}\right)$

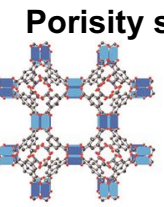

HKUST-1 $\left(\mathrm{Cu}_{3}(\mathrm{BTC})_{2}\right)$

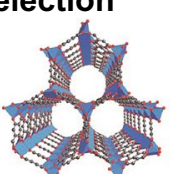

M-MOF-74(M M $_{2}$ DOBDC)) 1D channel in M-MOF-7

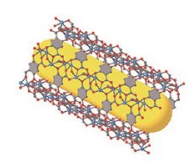

(b)

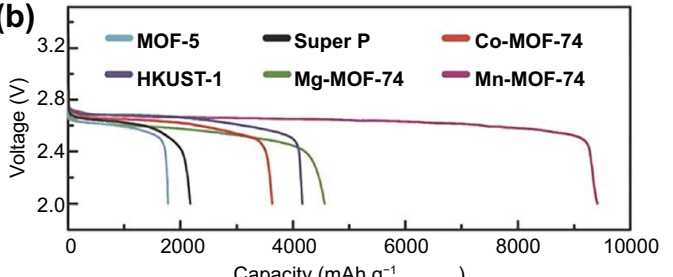

(c)

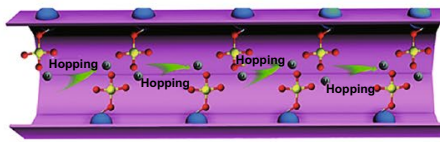

Coordinated hopping (d)

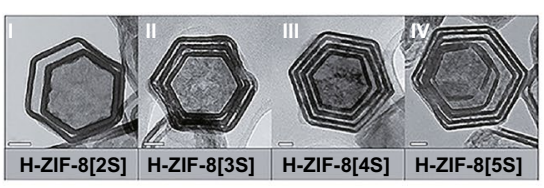

(e) Stable MOFs Decomposable MOFs Stable MOFs

(e) Stable mors Decomposable mors

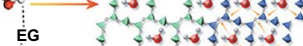

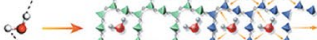

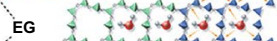

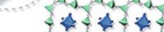

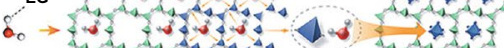

Molecular water transfer SNP production $\quad$ SNPs $\subset$ MOFs

strategy

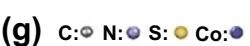

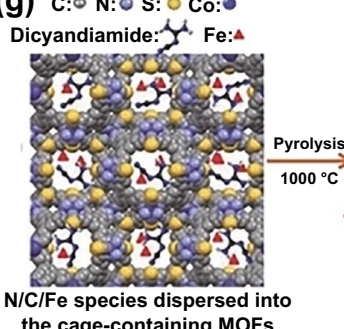

\section{Synergistic effect}

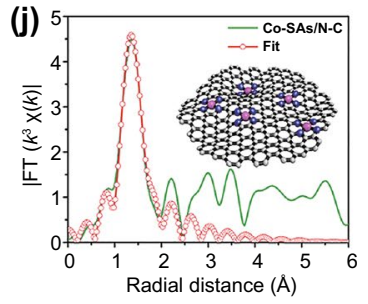

Single-atom catalysis

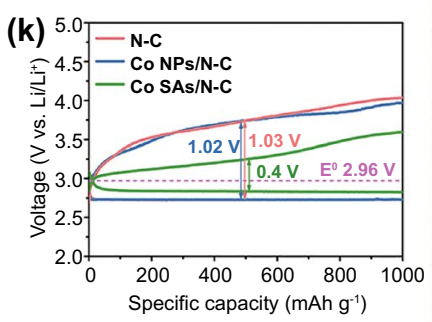

Specific capacity $\left(\mathrm{mAh} \mathrm{g}^{-1}\right)$

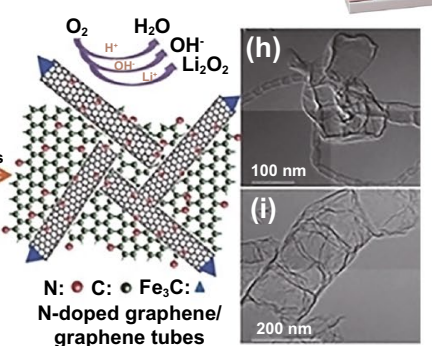

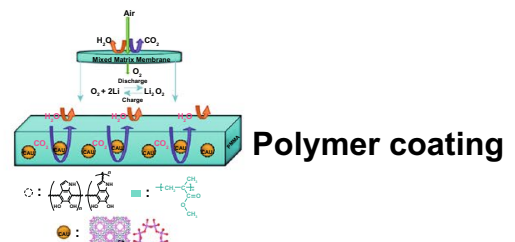

๑) : 80,4

MOF composites

MOF composite derivatives

(f)

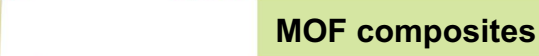

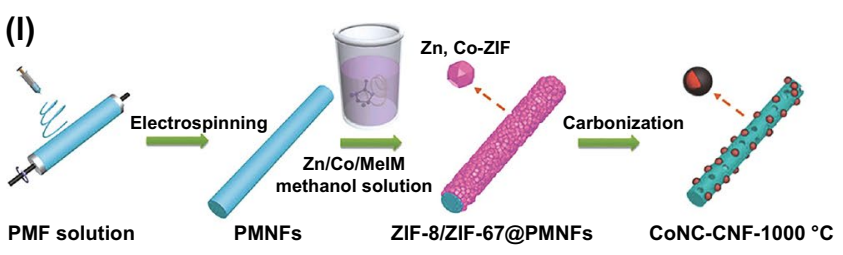

Electrospinning

(m)

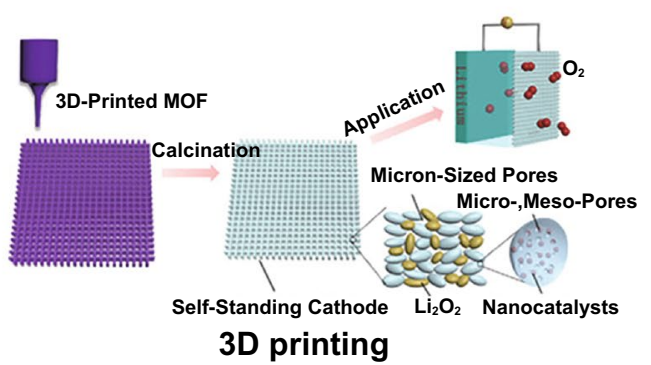

Fig. 3 MOF-based materials for $\mathrm{Li}-\mathrm{O}_{2}$ batteries. a Crystal structures and $\mathbf{b}$ discharge profiles of pristine MOFs [81]. Copyright $\odot$ 2014, Wiley$\mathrm{VCH}$. c Schematic illustration of Li diffusion path in pore channel of Cu-MOF-74. (O atom: red, $\mathrm{Cl}$ atom: yellow, $\mathrm{Cu}$ atom: blue) [83]. Copyright (C) 2019, The Royal Society of Chemistry. d TEM images of H-ZIF-8[2S, 3S, 4S, 5S]. All scale bars: $50 \mathrm{~nm}$. e Schematic illustration of the formation process of SNP-embedded H-ZIF-8[nS] (green: Zn, violet: Co) [85]. Copyright @ 2020, Wiley-VCH. f Schematic illustration of the MMM based on MOF composites for rebelling $\mathrm{H}_{2} \mathrm{O}$ and $\mathrm{CO}_{2}$ molecules in $\mathrm{Li}-\mathrm{O}_{2}$ batteries (Al, pink; $\mathrm{O}$, red; $\mathrm{C}$, gray; $\mathrm{H}$, blue) [86]. Copyright $\odot$ ( 2015, Royal Society of Chemistry. g Schematic illustration and h, i TEM images of N-doped graphene/graphene-tube [88]. Copyright @ 2014, Wiley-VCH. j XAFS measurements and $\mathbf{k}$ discharge-charge curves of Co-SAs/N-C. Reproduced with permission. [95] Copyright 2020, Nature Publishing Group. 1 Synthesis process for CoNC-CNFs [97]. Copyright @ 2018, Wiley-VCH. m Schematic illustration of 3DP-NC-Co $\mathrm{O}_{2}$ cathode for $\mathrm{Li}-\mathrm{O}_{2}$ batteries [98]. Copyright $\odot$ 2019, Wiley-VCH 
$-\mathrm{NH}_{2}$ groups in CAU-1-NH $\mathrm{N}_{2}$ can efficiently capture $\mathrm{CO}_{2}$ while the PMMA endowed the MMM with excellent hydrophobic nature. Therefore, the LABs with MMM achieved high discharge capacity and excellent cycling stability under a real ambient atmosphere (humidity $=30 \%$ ). In addition, the MOF@PVDF-HFP composite separator acts as a dual redox mediator molecule sieve to suppress the shuttling and protect $\mathrm{Li}$ metal for $\mathrm{Li}-\mathrm{O}_{2}$ batteries [87]. The $\mathrm{Li}-\mathrm{O}_{2}$ batteries achieved a superior cycled life over 100 cycles $\left(5000 \mathrm{mAh} \mathrm{g}^{-1}\right)$ at high current rate of $1000 \mathrm{~mA} \mathrm{~g}^{-1}$.

\subsection{MOF Derivatives}

MOF derivatives with high electrical conductivities, hierarchical porous structure, and well-distributed catalysts are favorable to the mass transport, oxygen redox reactions, and storage of discharged products. The earliest work on MOFderived cathode catalyst for $\mathrm{Li}-\mathrm{O}_{2}$ batteries was proposed by $\mathrm{Wu}$ and co-workers [88]. The in situ formation of $\mathrm{Fe}$ and $\mathrm{N}$-doped graphene/graphene-tube nanocomposites were prepared by from the cage-containing MOF (Fig. 3g-i). The designed Co-MOF is used as a precursor to be further annealed with dicyandiamide and iron acetate to prepare a Fe- and N-doped graphene/graphene tube catalyst. The doping of pyridinic- and quaternary- $\mathrm{N}$ and coordination with iron $\left(\mathrm{Fe}-\mathrm{N}_{\mathrm{x}}\right)$ creates more active sites for boosting the adsorption of $\mathrm{O}_{2}$ and the dissociation of $\mathrm{O}-\mathrm{O}$ bonds. Besides this, $\mathrm{N}$-doping Co@graphene [89], $\mathrm{Co}_{3} \mathrm{O}_{4}$-carbon [90], $\mathrm{NiCo}_{2} \mathrm{O}_{4}$ nanoflake arrays [91], $\mathrm{ZnO} / \mathrm{ZnFe}_{2} \mathrm{O}_{4} /$ carbon nanocages [92], and $\mathrm{Co}_{9} \mathrm{~S}_{8} @$ carbon porous nanocages [93] have also been reported as cathode catalyst for $\mathrm{Li}-\mathrm{O}_{2}$ batteries.

Dual MOF-derived (MIL-100(Fe) and ZIF-8) $\mathrm{Fe}_{-} \mathrm{Fe}_{3} \mathrm{C}$ embedded $\mathrm{Fe}-\mathrm{N}$-codoped carbon was proposed as an excellent ORR electrocatalyst for aprotic $\mathrm{Li}-\mathrm{O}_{2}$ batteries [94]. The $\mathrm{Fe}-\mathrm{Fe}_{3} \mathrm{C} @ \mathrm{Fe}-\mathrm{N}-\mathrm{C}$ dual active sites improve oxygen affinity and accelerate $* \mathrm{OH}$ desorption. The partial graphitization carbon with hierarchical porosities (micro-/macropores) maximized the active sites and promote mass transport. Recently, Yin's group synthesized desirable Co single atoms embedded in 2D MOF-derived ( $\mathrm{Zn}$-hexamine complex) N-doped carbon substrate $(\mathrm{Co}-\mathrm{SAs} / \mathrm{N}-\mathrm{C})$ as a catalyst for $\mathrm{Li}-\mathrm{O}_{2}$ batteries (Fig. 3j) [95]. Taking advantages from both 2D MOFs and uniformly distributed atomic Co sites, the elaborately designed Co-SAs/ $\mathrm{N}-\mathrm{C}$ catalyst is to help for accelerating formation/decomposition of nanosized $\mathrm{Li}_{2} \mathrm{O}_{2}$.
As a result, the Co-SAs/N-C cathode can afford superior discharge capacity, ultra-low charge/discharge polarization $(0.40 \mathrm{~V})$ (Fig. 3k), and excellent cyclability (260 cycles at $\left.400 \mathrm{~mA} \mathrm{~g}^{-1}\right)$.

\subsection{MOF Composite Derivatives}

The construction of MOF/conductive matrix derivatives is conducive to further improve electronic conductivity and prevent aggregation of MOFs, thus maximizing catalytic active sites for ORR and OER reaction in $\mathrm{Li}-\mathrm{O}_{2}$ batteries. A dual-phasic carbon cathode for enhanced $\mathrm{Li}-\mathrm{O}_{2}$ batteries was prepared by adopting ZIF8/CNT composite [96]. The dual-phasic nanoarchitecture combines the advantages of both components: MOF-derived carbon endows a high surface area for the oxygen reactions and a large pore volume for $\mathrm{Li}_{2} \mathrm{O}_{2}$ accommodation, and CNTs provide rapid electron $/ \mathrm{O}_{2}$ transport pathways and additional void spaces for $\mathrm{Li}_{2} \mathrm{O}_{2}$ storage. Moreover, a bimetallic ZIF-8/ZIF-67 and polyacrylonitrile nanofibers composite-derived, Co- $\mathrm{N}_{\mathrm{x}}-$ confined porous carbon nanofibers (CNFs) with graphitic carbon-embedded Co nanoparticles (CoNC-CNFs) were prepared and used as an efficient dual catalyst for both ORR and OER (Fig. 31) [97]. The excellent catalyst performance is attributed to the high graphitized $1 \mathrm{D}$ carbon structure for fast electronic mobility, hierarchical porosities for mass transport, and uniformly dispersed $\mathrm{CoN}_{\mathrm{x}} \mathrm{C}$ active sites for functionalized carbon network.

In another interesting study, Wang and co-workers reported two MOF composite-derived cathodes for $\mathrm{Li}-\mathrm{O}_{2}$ batteries, namely the Co-MOF/carbon paper derived Co nanoparticles assembled in $\mathrm{N}$-doped porous carbon flakes (CPNC-Co), and 3D-printing Co-MOF/Pluronic F127 derivative (3DP-NC-Co) [98]. The hierarchical porous framework of MOF composite derivatives significantly promotes the deposition of $\mathrm{Li}_{2} \mathrm{O}_{2}$ particles and accelerates their decomposition because of the confinement of nonconductive $\mathrm{Li}_{2} \mathrm{O}_{2}$ within the pores and the existence of Co electrocatalysts. Moreover, they found that 3DP-NC-Co exhibited a higher discharge capacity, a lower overpotential, and longer cycle performance than that of $\mathrm{CP}-\mathrm{NC}-\mathrm{Co}$, which resulted from a light-weight and unique hierarchically porous framework of 3DP-NC-Co (Fig. 3m). Recently, Hu et al. synthesized Ru single atoms distributing in $\mathrm{N}$-doped porous carbon on carbon cloth (Ru SAs-NC/CC) by ionic substitution and spatial 
confinement strategies [99]. Importantly, single atomic catalysts could maximize the redox efficiency and reversibility of $\mathrm{Li}-\mathrm{O}_{2}$ batteries using the $\mathrm{Ru}-\mathrm{N}_{4}$ catalytic active centers, while the carbon cloth with sufficient electronic conductivity can promote mass transfer and with enough porous channels can accommodate the discharge product $\mathrm{Li}_{2} \mathrm{O}_{2}$. As expected, the Ru SAs-NC/CC electrode can deliver the lowest overpotential $\left(0.55 \mathrm{~V}\right.$ at $\left.0.02 \mathrm{~mA} \mathrm{~cm}^{-2}\right)$ compared with pyrolyzed ZIF-8 and Ru nanoparticles' counterparts.

\subsection{Summary}

In summary, MOF/MOF composites and their derivatives show great potentials for $\mathrm{Li}-\mathrm{O}_{2}$ batteries due to their unique pore channels, open metal active sites, and structural stability. However, many fundamental and technical challenges need to be overcome before MOF-based materials can meet the requirements of practical $\mathrm{Li}-\mathrm{O}_{2}$ batteries. At the current stage of research, MOF/MOF composite derivatives show high electric conductivities and good chemical stabilities, which can be directly used as the bifunctional catalyst for $\mathrm{Li}-\mathrm{O}_{2}$ batteries. A better understanding of catalytic mechanisms in $\mathrm{Li}-\mathrm{O}_{2}$ chemistry is highly desirable to guide and explore more MOF-derived cathode materials. The pore structure and functional active sites of MOFs require to be optimized for application as separator and electrolyte framework in $\mathrm{Li}-\mathrm{O}_{2}$ batteries. The development of MOF-based materials with high polarity, hierarchal structure, and abundant lithiophilic sites is also expected to protect $\mathrm{Li}$ metal anodes in $\mathrm{Li}-\mathrm{O}_{2}$ batteries.

\section{Sodium-Ion Batteries}

\subsection{Pristine MOFs}

MOFs such as Prussian blue and its analogues (PB and PBAs) with open framework and interstitial sites ensuring facile insertion/extraction of $\mathrm{Na}^{+}$have received considerable attention for cathode materials in SIBs. Previous studies on $\mathrm{KMFe}(\mathrm{CN})_{6}(\mathrm{M}=\mathrm{Fe}, \mathrm{Mn}, \mathrm{Ni}, \mathrm{Cu}, \mathrm{Co}$, and $\mathrm{Zn})$ [100] and rhombohedral $\mathrm{Na}_{1.72} \mathrm{MnFe}(\mathrm{CN})_{6}$ [101], have demonstrated that a reversible phase transition incurred upon $\mathrm{Na}^{+}$insertion/extraction. However, these PBAs suffer from poor cyclability and low CE due to their vast vacancies and crystalline water in the lattice, causing large lattice distortions and inefficient $\mathrm{Na}^{+}$storage during cycling. Many strategies have been proposed to optimize crystallization structures, such as high-quality $\mathrm{Na}_{0.61} \mathrm{Fe}\left[\mathrm{Fe}(\mathrm{CN})_{6}\right]_{0.94}[102]$, dehydrated $\mathrm{Na}_{2} \mathrm{MnFe}(\mathrm{CN})_{6}$ [103], single-crystal $\mathrm{FeFe}(\mathrm{CN})_{6}$ [104], and high-entropy $\mathrm{Na}_{\mathrm{x}}(\mathrm{FeMnNiCuCo})\left[\mathrm{Fe}(\mathrm{CN})_{6}\right]$ [105], which result in enhanced electrochemical performance of SIB cathodes. Moreover, multiple electron transfer-type $\mathrm{Na}_{2} \mathrm{Mn}^{\mathrm{II}}\left[\mathrm{Mn}^{\mathrm{II}}(\mathrm{CN})_{6}\right]$ [106], mesoporous $\mathrm{NiFe}(\mathrm{II})$ PBA [107], and cubic $\mathrm{Na}_{x} \mathrm{MnFe}(\mathrm{CN})_{6}$ [108] were reported to achieve high specific capacities, superior rate capability, and excellent cycle stability.

MOFs were also reported as anode materials for SIBs recently. It was demonstrated that the ultrathin cobalt terephthalate-based MOF nanosheets (u-CoOHtp) with oxygen vacancies could induce a local built-in electric field, which is beneficial for accelerating ion diffusion rate and thus improve the reversible $\mathrm{Na}^{+}$storage [109]. To enhance the conductivity of the electrode material, a novel cobaltbased 2D conductive MOF (Co-HAB, consisted of Co(II) ion node and redox active hexaaminobenzene (HAB) linker) has been proposed for SIBs (Fig. 4a) [110]. As a SIB anode material, Co-HAB presents a high rate capability of 214 $\mathrm{mAh} \mathrm{g}^{-1}$ within $7 \mathrm{~min}$ or $152 \mathrm{mAh} \mathrm{g}^{-1}$ in $45 \mathrm{~s}$, corresponding to a redox process of three electrons. Besides, Huang and co-workers designed a stable 3D wavy-layered structure of MOF, zinc perylenetetracarboxylates (Zn-PTCA), which enables aromatic rings activated as sodium storage sites (Fig. 4b) [111]. Such Zn-PTCA anode achieves a high discharge capacity of $357 \mathrm{mAh} \mathrm{g}^{-1}$ at a rate of $50 \mathrm{~mA} \mathrm{~g}^{-1}$, corresponding to the eight electrons transfer process. This work can provide an efficient strategy to design 3D MOF structures for high-capacity electrode materials.

\subsection{MOF Composites}

In many cases, as a MOF material, low conductivity and poor structural stability seriously limit the electrochemical performance of PB and PBAs. To tackle these issues, several unique nanostructures of MOF composites with conductive carbon, such as Ketjen black [112], CNTs [113], and graphene [114], have been developed. In particular, the $3 \mathrm{D}$ conductive carbon networks have attracted special attention on account of their high specific surface area, excellent electrical conductivity, and superior thermal/ chemical stability. For example, a metal-organic cuprous 


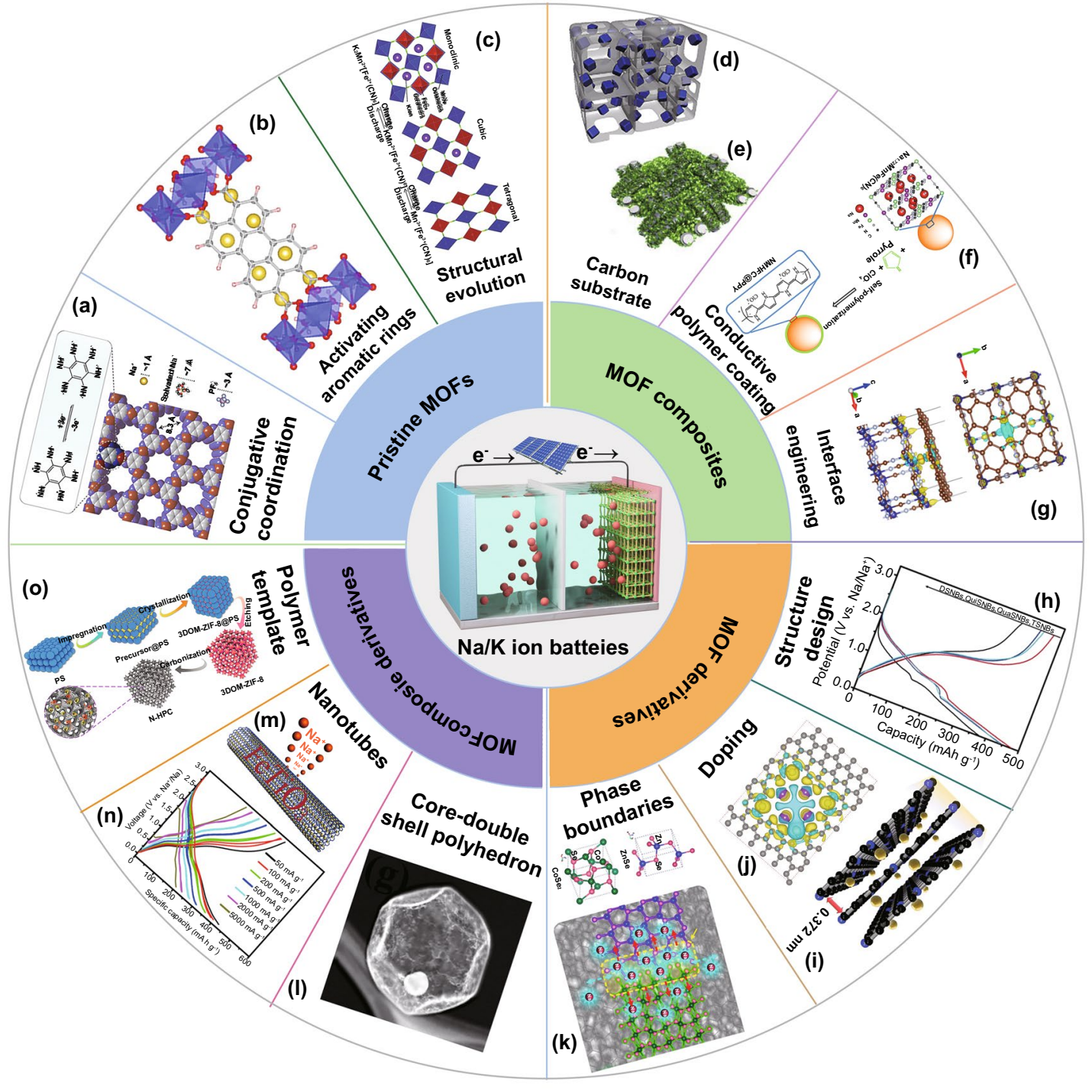

Fig. 4 MOF-related materials for SIBs and PIBs. a Expected three electron reversible reaction and calculated structure of Co-HAB [110]. Copyright (C) 2018, American Chemical Society. b The most stable position of $\mathrm{Na}^{+}$insertion in Zn-PTCA [111]. Copyright (C) 2018, Elsevier. c Crystal structures and phase transition during charging/discharging processes [145]. Copyright (c) 2017, Royal Society of Chemistry. d Schematic illustration of NaK-MnHCF@3DNC [116]. Copyright @ 2019, Elsevier. e Schematic illustration of preparation NiCo-MOF cathode [151]. Copyright () 2019, Elsevier. f Schematic for synthesis process the NMHFC@PPy preparation [118]. Copyright @ 2015, Elsevier. g Top and side views of the charge density difference (CDD) of the Co-MOF-RGO composite. The yellow and blue regions refer positive (electron accumulation) and negative (electron depletion) values (in 0.001 e/bohr ${ }^{3}$ ), respectively [152]. Copyright () 2020, American Chemical Society. h Discharge-charge curves of MSNBs with different shell numbers [130]. Copyright @ 2018, Wiley-VCH. i Schematic illustration $\mathrm{K}^{+}$insertion in NPC [153]. Copyright (C) 2018, Royal Society of Chemistry. j CDD map of four potassium ions embedded into the O/F dual-doped porous carbon [154]. Copyright (C) 2019, Wiley-VCH. k Schematic for the phase-boundary effect in CoZn-Se [135]. Copyright (C) 2019, American Chemi-

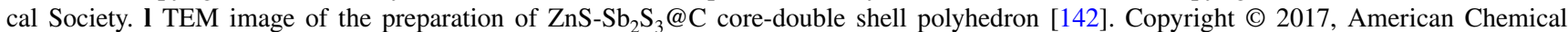
Society. $\mathbf{m}$ Schematic illustration and $\mathbf{n}$ discharge-charge voltage profiles of FTO C CNTs [143]. Copyright @ 2017, American Chemical Society. o Schematic illustration of N-HPC preparation [159]. Copyright (C) 2019, American Chemical Society

tetracyanoquinodimethane in situ grown on 3D carbon nanofiber network (CuTCNQ/CNFs) has been prepared and used as a freestanding cathode for SIBs [115]. The highly interconnected CNFs enabled rapid electron transfer and maintained the integrity of the electrode during cycling. In another case, a 3D cathode material for SIBs was fabricated by compounding $\mathrm{Na}_{x} \mathrm{~K}_{y} \mathrm{MnFe}(\mathrm{CN})_{6}(x+y \leq 2$, NaK$\mathrm{MnHCF}$ ) with hierarchical porous 3D N-doped ultrathin 
carbon networks (3DNC) (Fig. 4d) [116]. The 3DNC not only provides large specific surface and abundant active sites to inhibit the aggregation of NaK-MnHCF particles, but also enhances the electrical conductivity of the NaKMnHCF, which boosted the sodium storage of the NaKMnHCF@3DNC composite.

Another possible strategy is to integrate MOFs with conductive polymers, especially the polypyrrole (PPy) [117]. Dou and co-workers synthesized $\mathrm{ClO}^{4-}$ doped conducting polypyrrole-coated $\mathrm{Na}_{1+x} \mathrm{MnFe}(\mathrm{CN})_{6}$ composite (NMHFC@ PPy) for SIBs cathode material via a simple and one-step chemistry approach (Fig. 4f) [118]. The authors only used the intrinsic oxidation capacity of the NMHFC to form conductive PPy on the surfaces of NMHFC particles. In this study, PPy plays multiple significant roles in the overall electrochemical performance of the NMHFC@PPy composite. Specifically, PPy as a conducting polymer can improve the electronic conductivity of NMHFC to enhance the rate capability. Next, PPy can act as a protective layer to prevent the dissolution of Mn in the NMHFC structure to increase the cycling stability. Finally, the PPy doped with $\mathrm{ClO}^{4-}$ can provide redox active sites to improve the capacity of the NMHFC@PPy composite.

\subsection{MOF Derivatives}

MOF-derived carbon materials with porous structure, abundant heteroatoms doping, and desirable electrical conductivity have exhibited remarkable application prospects for SIBs. In this regard, Qu et al. prepared ZIF-8-derived microporous carbon (ZIF-C) with a uniform pore size of $0.5 \mathrm{~nm}$. ZIF-C exhibited a higher capacity and superior reversibility than mesoporous carbon (CMK-3) [119]. Also, Zhang's group developed sulfur-doped mesoporous carbons via pyrolysis and sulfuration of MOF-5 [120]. Sulfur doping can enlarge the interlayer distance of carbon and provide more active sites for sodium storage. It is important to develop MOFderived carbon anode with desirable morphology, especially the 2D ones. Therefore, Liu et al. synthesized 2D Zn-hexamine MOF-derived $\mathrm{N}$-rich porous carbon nanosheets (NPCNs) as an anode material for SIBs [121]. The as-prepared 2D NPCNs can provide large surface area and abundant accessible active sites for superior sodium storage. As a result, a high reversible capacity $\left(318 \mathrm{mAh} \mathrm{g}^{-1}\right.$ at $100 \mathrm{~mA} \mathrm{~g}^{-1}$ ) and ultrafast sodium storage capability $\left(194 \mathrm{mAh} \mathrm{g}^{-1}\right.$ at
$10 \mathrm{~A} \mathrm{~g}^{-1}$ ) were achieved by these carbon nanosheets. In addition, carbon/metal hybrid resulting from transformation of single MOF can improve the sodiophilic for sodium nucleation/deposition and accommodate huge volume change, achieving the dendrite-free Na metal anodes [122, 123].

MOF-derived metal oxides such as $\mathrm{TiO}_{2}$ [124], $\mathrm{Co}_{3} \mathrm{O}_{4}$ [125], and $\mathrm{V}_{2} \mathrm{O}_{3}$ [126] are considered to be attractive anode materials for SIBs because of their high specific capacities and environmental friendliness. However, they may suffer from poor rate performance and cycling stability owing to low electrical conductivity and poor structure stability during the charging/discharging process. Transforming MOFs into metal sulfides, phosphides, and selenides with high electrical conductivity and desirable architecture/components would be favorable [127-129]. Lou's group developed ZIF67-derived $\mathrm{CoS}_{2}$ multi-shelled nanoboxes through solvothermal treatment with complex anion conversion and exchange reaction [130]. The $\mathrm{CoS}_{2}$ with double, triple, quadruple, and quintuple shells (denoted as $\mathrm{CoS}_{2}$ with DSNBs, TSNBs, QuaSNBs, and QuiSNBs, respectively) delivered high discharge capacities of 478.1, 449.6, 442.2, and $380.0 \mathrm{mAh} \mathrm{g}^{-1}$ at $500 \mathrm{~mA} \mathrm{~g}^{-1}$, respectively (Fig. 4h). The as-prepared triple-shelled $\mathrm{CoS}_{2}$ nanoboxes maintained a high specific capacity of $438 \mathrm{mAh} \mathrm{g}^{-1}$ over 100 cycles at $500 \mathrm{~mA} \mathrm{~g}^{-1}$. The multi-shelled nanostructures not only provided large specific surface area and adequate active sites for sodium storage, but also alleviated the volume expansion during sodiation/desodiation process, which enhanced the overall electrochemical performance of the $\mathrm{CoS}_{2}$ multi-shelled nanoboxes. In addition to the conversion-type anodes, MOFderived alloy-type anodes have been developed for fast and efficient sodium storage [131]. Recently, Bi-MOF is loaded with Sb salts within its pores and is applied as the precursor for the preparation of $\mathrm{Bi}-\mathrm{Sb}$ alloy nanoparticles by the nanoscale laser metallurgy strategy [132]. The obtained $\mathrm{Bi}_{0.70} \mathrm{Sb}_{0.30}$ anode exhibited excellent rate performance and cycle stability due to $1 \mathrm{D}$ nanostructure with proper $\mathrm{Bi} / \mathrm{Sb}$ atomic ratios, effectively facilitating the permeation of electrolyte and movement of electron/ion, as well as the mitigation of volume expansion.

Compared to single MOF derivatives, dual MOF derivatives possess higher electrical conductivity and richer redox reactions due to their abundant phase boundaries. Previous works have demonstrated that MOF-derived bimetal compounds could accelerate reaction kinetics, thus enhancing 
sodium storage performance $[133,134]$. As an example, a bimetallic selenide heterostructure $\left(\mathrm{CoSe}_{2} / \mathrm{ZnSe}\right)$ was developed through a facile oil-bath treatment and selenization of 2D CoZn-MOFs [135]. It is documented that heterointerface with high electron density in $\mathrm{ZnSe}$ crystalline side is more favorable to the adsorption of $\mathrm{Na}^{+}$ions (Fig. 4k), therefore accelerating reaction kinetics for SIBs. The excellent capacity retention of $93 \%$ after 100 cycles was achieved for CoZnSe anode, while the mono-metal selenides exhibit fast decay in capacity.

\subsection{MOF Composite Derivatives}

Constructing MOF composite derivatives could provide an opportunity to achieve synchronous advantages between different components. The MOF/carbon (i.e., CNTs, graphene, and carbon cloth) composite derivatives have been widely applied as anode materials for SIBs [131, 136, 137]. Chen et al. prepared $\mathrm{N}$-doped porous carbon nanocomposites (NPCNs) derived from ZIF-8 and carbon (1D CNT and/or 2D graphene) composites [138]. Because of the synergistic effect of N-doped porous carbon, CNTs and graphene, the optimized NPCNs exhibited superior sodium storage performance among the other NPCNs. In another case, Co, $\mathrm{N}$-doped mesoporous $\mathrm{TiO}_{2} / \mathrm{C}$ frameworks transformed from the Ti-MOFs/graphene oxide composite were developed to boost fast sodium storage [124]. The high reversible capacities of 174,121 , and $100 \mathrm{mAh} \mathrm{g}^{-1}$ were yielded at 6,15 , and $30 \mathrm{C}$ for over 5000, 10,000, and 3000 cycles, respectively. The dual-doping incorporates abundant oxygen vacancies into the $\mathrm{TiO}_{2}$ nanoparticles, significantly enhancing their electrical conductivity. The interwoven graphene porous networks facilitate electron conduction and $\mathrm{Na}^{+}$transport through the overall electrode.

The development of MOFs/polymeric composite derivatives is of great importance in order to fabricate anode materials for SIBs [139]. In one interesting study, a bimetallic $\mathrm{Zn}$-Co-ZIF shell was formed by fixing two $\mathrm{Co}(\mathrm{Ac})_{2}$ and $\mathrm{Zn}(\mathrm{Ac})_{2}$ into polyacrylonitrile (PAN) electrospun nanofibers [140]. The subsequent annealing in inert gas under $700{ }^{\circ} \mathrm{C}$, the Zn-Co-ZIF shell converted into well-graphitized carbon, while the carbon core (carbonized from the PAN) was etched by ZIF-8-derived $\mathrm{ZnO}$ nanoparticles. The asprepared $\mathrm{N}$-doped carbon hollow tubules exhibited a high reversible capacity of $346 \mathrm{mAh} \mathrm{g}^{-1}$ and ultralong cycling life over 10,000 cycles. Similarly, nitrogen- and oxygen-doped porous carbon nanofibers (PCNFs) were synthesized through thermal decomposition of the bimetallic $\mathrm{ZnNi}-\mathrm{MOF} / \mathrm{PAN}$ electrospun nanofibers [141]. The PCNFs can reduce the $\mathrm{Na}$ adsorption energy barrier as well as enhance the nucleation and deposition of $\mathrm{Na}$, which can achieve the dendritefree and ultrastable Na metal anodes. Polymers engineered on the surface of MOFs can also serve as a stabilization layer for the composite derivatives. Yin's group developed a resorcinol-formaldehyde (RF)-coated ZIF-8 polyhedron composite [142]. After the sulfurization with thioacetamide (TAA) and the cation exchange process with $\mathrm{Sb}^{3+}$, a $\mathrm{ZnS}-\mathrm{Sb}_{2} \mathrm{~S}_{3} @ \mathrm{C}$ core-double-shell polyhedron was finally obtained (Fig. 41). When evaluated as alloy-type anode for SIBs, the $\mathrm{ZnS}-\mathrm{Sb}_{2} \mathrm{~S}_{3} @ \mathrm{C}$ exhibited a high specific capacity of $630 \mathrm{mAh} \mathrm{g}^{-1}$ after 120 cycles at $100 \mathrm{~mA} \mathrm{~g}^{-1}$.

Metal compound/MOF composite derivative is another effective strategy for constructing multicomponent electrode materials. Ilmenite $\mathrm{FeTiO}_{3}$ nanoparticles embedded in carbon nanotubes (FTO $\subset$ CNTs) were synthesized by a facile annealing process of $\mathrm{TiO}_{2}$ coating $\mathrm{Fe}-\mathrm{MOF}$ nanorods (Fig. $4 \mathrm{~m}$ ) [143]. Benefiting from the distinct advantages of hollow 1D nanostructure, ultrafine electroactive sites, and flexible conductive carbon substrate, FTO $\subset$ CNT electrode achieved high capacities for sodium storage (Fig. 4n). Besides, Kang and co-workers fabricated ZIF-67 shells on the $\mathrm{MoO}_{3}$ nanobelts, followed by the sulfidation process [144]. The obtained $\mathrm{CoMoS}_{3}$ nanobackbones were coated with polydopamine and then carbonized under inert conditions, leading to the generation of $\mathrm{CoMoS}_{3} @ \mathrm{~N}$-doped carbon nanobackbones $\left(\mathrm{CoMoS}_{3} @ \mathrm{NC}\right)$. The $\mathrm{CoMoS}_{3} @$ $\mathrm{NC}$ anode delivered improved sodium storage performance because of their hierarchical nanostructure, conductive $\mathrm{N}$-doped carbon shell, and the synergistic effect between multiple components.

\subsection{Summary}

MOF/MOF composite cathodes and MOF/MOF compositederived anodes have been regarded as promising candidates for electrode materials in SIBs. Although great progress on the development of MOF electrode materials for SIBs has been demonstrated, several challenges still exist and limit their electrochemical applications. The low electrical conductivity, structural instability, and the low tap density of 
MOFs lead to poor rate capability, low cycling stability, and volumetric energy density. These challenging issues may be addressed to some extent by the aforementioned approaches. However, more efforts need to be done to explore storage mechanisms and optimize the structure, compositions, and properties of MOF materials in SIBs.

\section{Potassium-Ion Batteries}

\subsection{Pristine MOFs}

Apart from the applications as electrode materials for SIBs, MOFs could be applied for PIBs. Komada and co-workers proposed Prussian blue analogues, $\mathrm{K}_{1.75} \mathrm{Mn}\left[\mathrm{Fe}(\mathrm{CN})_{6}\right]_{0.93} \cdot 0.16 \mathrm{H}_{2} \mathrm{O}$ (K-MnHCFe), and $\mathrm{K}_{1.64} \mathrm{Fe}\left[\mathrm{Fe}(\mathrm{CN})_{6}\right]_{0.89} \cdot 0.15 \mathrm{H}_{2} \mathrm{O}(\mathrm{K}-\mathrm{FeHCFe})$, as affordable cathode materials for PIBs (Fig. 4c) [145]. In particular, $\mathrm{K}-\mathrm{MnHCFe}$ displayed a high capacity of $141 \mathrm{mAh} \mathrm{g}^{-1}$ and good cycling stability because of its open and flexible framework structure. Recently, Chen and co-workers proposed a low-strain potassium-rich $\mathrm{K}_{1.84} \mathrm{Ni}\left[\mathrm{Fe}(\mathrm{CN})_{6}\right]_{0.88^{\bullet}} \cdot 0.49 \mathrm{H} 2 \mathrm{O}$ (KNiHCF) as a cathode material for PIBs [146]. The KNi$\mathrm{HCF}$ exhibited an excellent rate performance $\left(45.8 \mathrm{mAh} \mathrm{g}^{-1}\right.$ at $5000 \mathrm{~mA} \mathrm{~g}^{-1}$ ) due to the low $\mathrm{K}^{+}$diffusion barrier. Besides, a vanadium-based MOF material $\mathrm{K}_{2}\left[(\mathrm{VO})_{2}\left(\mathrm{HPO}_{4}\right)_{2}\left(\mathrm{C}_{2} \mathrm{O}_{4}\right)\right]$ with large interplanar lattice spacing was synthesized as a cathode for PIBs [147]. Highly reversible $\mathrm{K}^{+}$extraction/ insertion in the layers was realized, with good cycling stability (capacity retention of $83 \%$ ) after 200 cycles.

MOFs are also promising anode materials for PIBs because of their abundant electroactive components and regular ion diffusion channels. For example, a MOF (MIL125(Ti)) with high porosity, unique ligand, and low toxicity was synthesized and probed as the anode material for PIBs [148]. Benefiting from porous structure, active carboxylate groups, and reversible potassiation/depotassiation process in MIL-125(Ti), the electrode delivered a high-capacity retention of $90.2 \%$ over 2000 cycles with a Coulombic efficiency of $100 \%$. Hu's group reported cobalt(II) terephthalate-based layered MOF $\left(\mathrm{L}-\mathrm{Co}_{2}(\mathrm{OH})_{2} \mathrm{BDC}, \mathrm{BDC}=1,4\right.$-benzenedicarboxylate) as an anode material for PIBs with high reversible capacity of $246 \mathrm{mAh} \mathrm{g}^{-1}$ at $100 \mathrm{~mA} \mathrm{~g}^{-1}$ and excellent cycling stability (188 $\mathrm{mAh} \mathrm{g}^{-1}$ after 600 at $1 \mathrm{~A} \mathrm{~g}^{-1}$ ) [149]. They found that coordination between cobalt and oxygen ions greatly ensures a reversible $\mathrm{K}^{+}$insertion/deinsertion process.

\subsection{MOF Composites}

Among the major issues that limit MOF applications are both its low stability and poor electrical conductivity. The fabrication of nanocomposites between MOFs and various carbonaceous materials is an effective way to improve the stability and electrical conductivity of MOF. The singlewalled carbon nanotubes (SWCNTs) or multi-walled carbon nanotubes (MWCNTs) have been demonstrated as a reactant to the electrosynthesis of $\mathrm{PB}$, yielding $\mathrm{CNT} / \mathrm{PB}$ nanocomposite thin films as cathodes for PIBs [150]. In another case, a $\mathrm{Ni} / \mathrm{Co}$-oxygen octahedron layers pillared by NiCo-2,6-NDC nanosheets were grown on carbon cloth as a good candidate for PIBs (Fig. 4e) [151]. In this MOF, the carboxylate layer enlarges the interplanar space for fast ion transportation to expose $\mathrm{Ni}$ and Co redox centers, which makes great contributions to its high capacity and excellent rate performance $\left(225 \mathrm{mAh} \mathrm{g}^{-1}\right.$ at $1 \mathrm{~A} \mathrm{~g}^{-1}$ and $185 \mathrm{mAh} \mathrm{g}^{-1}$ at $20 \mathrm{~A} \mathrm{~g}^{-1}$ ). Recently, Xu and co-workers constructed CoMOF nanocrystals encapsulated in a 3D graphene network (Co-MOF-RGO) via strong chemical interaction as freestanding anodes for PIB (Fig. 4g) [152]. It is demonstrated that the strong chemical-bonded interface can significantly enhance charge transfer, adsorption, and diffusion of the potassium ion within the MOF nanocrystals compared to the physical mixture of Co-MOF nanocrystals and reduced graphene oxide (RGO).

\subsection{MOF Derivatives}

MOF-derived carbon materials and metal compounds/carbon composites have been demonstrated impressive performances in PIBs. Compared with MOFs, MOF-derived porous carbon materials are very attractive for PIBs anodes due to their high conductivity, abundant surface defects, and stable carbon skeleton structure. For this, Li et al. prepared high pyridine N-doped porous carbon (NPC) derived from the ZIF-67 as an anode material for PIBs [153]. The high content of pyridinic $\mathrm{N}$ and negligible change of interlayer space (Fig. 4i) can offer additional adsorption sites of $\mathrm{K}^{+}$ and thus ensure structure stability. Therefore, the NPC-600 can deliver a high reversible capacity $\left(587.6 \mathrm{mAh} \mathrm{g}^{-1}\right.$ at $\left.50 \mathrm{~mA} \mathrm{~g}^{-1}\right)$ and long lifespan (231.6 $\mathrm{mAh} \mathrm{g}^{-1}$ at $500 \mathrm{~mA} \mathrm{~g}^{-1}$ after 2000 cycles). Multiple heteroatoms' doping is also a promising strategy to enhance the electrochemical properties 
of carbon materials. A kind of oxygen/fluorine dual-doped porous carbon nanopolyhedra (OFPCN) was synthesized from carbonization, etching and annealing UiO-66 ( $\mathrm{Zr}$ ) MOF as a novel anode material for PIBs [154]. The obtained OFPCN electrode achieved a high specific capacity of $481 \mathrm{mAh} \mathrm{g}^{-1}$ at $0.05 \mathrm{~A} \mathrm{~g}^{-1}$ and ultralong cycling stability of $111 \mathrm{mAh} \mathrm{g}^{-1}$ over 5000 cycles at $10 \mathrm{~A} \mathrm{~g}^{-1}$. Oxygen/fluorine co-doping can effectively tune the electronic structure of carbon atoms and enhance the $\mathrm{K}$ atoms adsorption ability (Fig. 4j), which could account for such excellent performance of the OFPCN electrode.

MOF-derived metal species/carbon has been developed and used as electrode materials for PIBs because of its desirable conductivity, high theoretical capacity, and good electrochemical activities. The $\mathrm{Co}_{0.85}$ Se nanoparticles embedded in $\mathrm{N}$-doped carbon polyhedrons $\left(\mathrm{Co}_{0.85} \mathrm{Se}-\mathrm{NC}\right)$ were prepared by carbonization and selenization of ZIF-67 [155]. Due to the uniform distribution of $\mathrm{Co}_{0.85}$ Se together with the high specific surface area from mesoporous structures and improved electric conductivity of $\mathrm{N}$-doped carbon, the $\mathrm{Co}_{0.85} \mathrm{Se}-\mathrm{NC}$ exhibited a specific capacity of $114.7 \mathrm{mAh} \mathrm{g}^{-1}$ after 250 cycles at $1000 \mathrm{~mA} \mathrm{~g}^{-1}$. Besides, Lu's group reported ultrathin carbon film@carbon nanorods@Bi nanoparticle (UCF@CNs@BiN) composites by pyrolysis of Bi-MOFs as anodes for PIBs [156]. The UCF@CN matrix can not only direct most solid electrolyte interphase (SEI) film formation on the carbon film surface, but also provide a fast channel for ion transport and accommodate the volume variation of Bi nanoparticles during many potassiation/ depotassiation cycles. As a result, the UCF@CNs@BiN anodes delivered an outstanding capacity of $425 \mathrm{mAh} \mathrm{g}^{-1}$ at $100 \mathrm{~mA} \mathrm{~g}^{-1}$ and a capacity decay rate of $0.038 \%$ per cycle after 600 cycles.

\subsection{MOF Composite Derivatives}

Building elaborately designed composites of MOF with carbon or polymer material and the subsequent conversion to metal species/carbon derivatives are effective approaches in achieving excellent potassium storage performance. For example, Mai and co-workers proposed MOF-74/graphene oxide composite-derived $\mathrm{NiCo}_{2.5} \mathrm{~S}_{4}$ microrods wrapped in reduced graphene oxide (NCS@RGO) for potassium-ion storage [157]. The introduction of RGO enhanced excellent electrical conductivity and fast $\mathrm{K}^{+}$diffusion kinetics in the NCS@RGO. Moreover, NCS@RGO electrode with organic potassium salt-containing electrolyte reduced byproduct formation and enhanced the mechanical stability of electrode due to the formation of a robust SEI layer. The NCS@RGO anode displayed a high initial reversible capacity (602 mAh $\mathrm{g}^{-1}$ at $50 \mathrm{~mA} \mathrm{~g}^{-1}$ ), excellent rate capability (402 $\mathrm{mA} \mathrm{h} \mathrm{g}^{-1}$ at $\left.2 \mathrm{~A} \mathrm{~g}^{-1}\right)$, and ultralong cycle life (495 $\mathrm{mAh} \mathrm{g}^{-1}$ at $200 \mathrm{~mA} \mathrm{~g}^{-1}$ after 1900 cycles).

Electrospinning MOF/PAN nanofiber derivatives have also been developed for PIBs. As an example, Zhang's group reported a simple method for the preparation of MOF/PAN composite by using a mixture of ZIF-67 nanocubes, PAN, and DMF as electrospun precursors [158]. The subsequent carbonization-selenylation process led to the confinement of $\mathrm{Co}_{0.85} \mathrm{Se} @ \mathrm{C}$ nanoboxes within carbon nanofibers $\left(\mathrm{Co}_{0.85} \mathrm{Se} @ \mathrm{CNFs}\right)$. In this derivative, $\mathrm{Co}_{0.85} \mathrm{Se} @ \mathrm{C}$ nanoboxes with high surface area and adequate void space alleviate the volume expansion for improved cycling stability. Furthermore, the robust CNFs network enhanced the electronic conductivity and stabilized the integral structure upon repeated potassiation/depotassiation process. As a result, this unique nanoarchitecture exhibited good cycling stability (353 $\mathrm{mAh} \mathrm{g}^{-1}$ at $0.2 \mathrm{~A} \mathrm{~g}^{-1}$ after 100 cycles) as an anode material for PIBs.

Polystyrene (PS) spheres are commonly utilized templates for the fabrication of porous or hollow structures by removed PSs. Yu and co-workers fabricated 3D MOF/PS composite for PIBs by in situ growth of ZIF-8 between the clearances of 3D PS monolith (Fig. 4o) [159]. Subsequently, the hierarchical porous carbon with N-doped (N-HPC) was obtained by removed PS template and heat-treated at $900{ }^{\circ} \mathrm{C}$ in $\mathrm{Ar}$ atmosphere. The as-prepared N-HPC anode achieved high reversible capacity $\left(292 \mathrm{mAh} \mathrm{g}^{-1}\right.$ at $\left.0.1 \mathrm{~A} \mathrm{~g}^{-1}\right)$, superior rate performance ( $94 \mathrm{mAh} \mathrm{g}^{-1}$ at $10.0 \mathrm{~A} \mathrm{~g}^{-1}$ ), and extraordinary long cycle life $\left(157 \mathrm{~mA} \mathrm{~g}^{-1}\right.$ after 12,000 cycles at $\left.2.0 \mathrm{~A} \mathrm{~g}^{-1}\right)$. The 3D hierarchical porous structure reduced the transportation distance for both ions/electrons, while N-doping enhanced the active sites and electronic conductivity through forming more defects. Moreover, the bicontinuous structure with a high specific surface area could decrease the current density and enhance the rate performance. 


\subsection{Summary}

Applying MOFs as cathodes and MOF derivatives as anodes for PIBs has been demonstrated in recent years. However, they may suffer from several issues, such as structural instability, intrinsically high surface area, and poor electric conductivity, which could result in poor cycling stability, low initial CE and volumetric energy density, and inferior rate capability. It is highly desirable to achieve symmetry among the porosity, structure, and conductivity for applications of MOF-based electrodes in PIBs. In addition, the detailed structural transformation and potassium storage processes of MOF-based materials are still unclear. These challenges may be mitigated to some extent by the aforementioned strategies. However, more research in this area needs to be done to reveal and optimize the basic electrochemical mechanism by in situ characterizations and theoretical simulations and further optimize MOF-based materials' potassium-ion storage performances.

\section{Aqueous Zn-Ion Batteries}

\subsection{Pristine MOFs}

Among the various cathode materials for ZIBs, PBAs have been investigated due to their open framework structures, which could contribute to the excellent cycling performance [160-162]. As an example, Liu and co-workers found that zinc hexacyanoferrates $\left(\mathrm{Zn}_{3}\left[\mathrm{Fe}(\mathrm{CN})_{6}\right]_{2}, \mathrm{ZnHCFs}\right)$ can provide reversible insertion/extraction of $\mathrm{Zn}^{2+}$ and keep stable in aqueous $\mathrm{ZnSO}_{4}$ electrolytes [163]. Consequently, the $\mathrm{Zn} / \mathrm{ZnSO}_{4} / \mathrm{ZnHCF}$ battery delivered an average operation voltage of $1.7 \mathrm{~V}$, good rate capability $\left(32.2 \mathrm{mAh} \mathrm{g}^{-1}\right.$ at $20 \mathrm{C}$ ), and cycle stability (the capacity retention of $81 \%$ after 100 cycles). Besides, Stoddart's group reported a conductive $2 \mathrm{D} \mathrm{Cu}{ }_{3}(\mathrm{HHTP})_{2}(\mathrm{HHTP}=2,3,6,7,10,11$-hexahydroxytriphenylene) with large open channels as cathode for ZIBs (Fig. 5a) [164]. They found that hydrated $\mathrm{Zn}^{2+}$ ions can insert directly into the $\mathrm{Cu}_{3}(\mathrm{HHTP})_{2}$ pores, allowing fast diffusion rate and small interfacial resistance, which

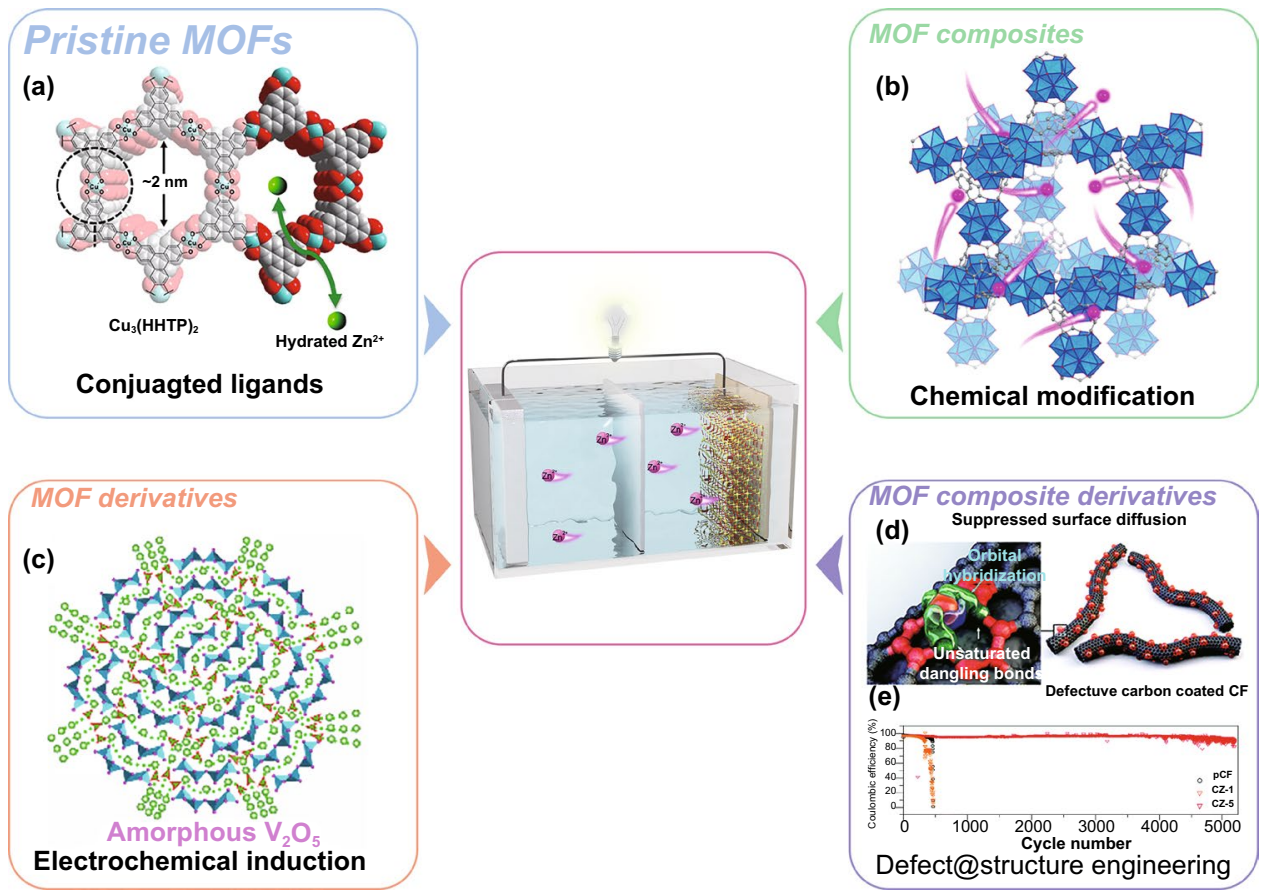

Fig. 5 MOF-based materials for ZIBs. a Crystal structure (the cyan, red, and gray spheres represent $\mathrm{Cu}$, O, and $\mathrm{C}$ atoms, respectively) of $\mathrm{Cu}_{3}(\text { HHTP })_{2}$ [164]. Copyright ( $)$ 2019, Nature Publishing Group. b Crystal structure of ZnMOF-808. Blue polyhedrons represent Zr-O clusters and pink balls represent $\mathrm{Zn}^{2+}$ ions [168]. Copyright (C) 2019, Elsevier. c Schematic illustration of $\mathrm{Zn}^{2+}$ diffusion pathways and $\mathrm{Zn}^{2+}($ de)intercalation energy in amorphous $\mathrm{V}_{2} \mathrm{O}_{5}$ [170]. Copyright (c) 2020, Wiley-VCH. d Schematic of uniform Zn deposit and lateral growth on the defective carbon layer-coated 3D CF. e Columbic efficiencies of pristine CF (Pcf), non-defective CF (CZ-1), and defective CF (CZ-5) [175]. Copyright @ 2020, Royal Society of Chemistry 
provide enhanced rate capability and cyclability. Moreover, both copper and the quinoid structures in $\mathrm{Cu}_{3}(\mathrm{HHTP})_{2}$ can serve as redox active sites to increase the specific capacity of the cathode material. The reversible shifts of (100) peaks in XRD and the high capacitive contribution suggest that $\mathrm{Cu}_{3}(\mathrm{HHTP})_{2}$ follows an intercalation pseudocapacitive charge storage mechanism. As a result, $\mathrm{Cu}_{3}(\mathrm{HHTP})_{2}$ achieved a high reversible capacity of $228 \mathrm{mAh} \mathrm{g}^{-1}$ at $50 \mathrm{~mA} \mathrm{~g}^{-1}$ and capacity retention of $75.0 \%$ over 500 cycles at a high current density of $4000 \mathrm{~mA} \mathrm{~g}^{-1}$.

Developing a regular porous MOF coating on $\mathrm{Zn}$ anode can also guide homogenous deposition and suppress $\mathrm{Zn}$ dendrite formation. For example, MOF (ZIF 7) was coated on $\mathrm{Zn}$ anode surface as a super-saturated electrolyte layer for stable aqueous ZIBs [165]. ZIF 7 channels (2.94 $\AA$ ) would reject large-sized charged ion complexes and form a super-saturated electrolyte in ZIF 7 channel under electric field. Moreover, MOF-coated $\mathrm{Zn}$ anode exhibited roundedged and dense-packed electrodeposits without byproduct accumulation. Taking advantage from the super-saturated front surface, symmetric $\mathrm{Zn}$ cells delivered ultralong cycle life over $3000 \mathrm{~h}$ at $0.5 \mathrm{~mA} \mathrm{~cm}{ }^{-2}$. When fabricated with $\mathrm{MnO}_{2}$ cathode, $\mathrm{ZIBs}$ achieved a high reversible capacity (180.3 $\mathrm{mAh} \mathrm{g}^{-1}$ ) and excellent cycle stability (capacity retention of $88.9 \%$ after 600 cycles) under $\mathrm{MnO}_{2}$ loading of $4.2 \mathrm{mg} \mathrm{cm}^{-2}$. Recently, Pu et al. reported all-MOF-based integrated high-performance aqueous ZIBs constructed by Mn(BTC) MOF cathodes and ZIF-8-coated Zn (ZIF-8@Zn) anodes [166]. The unique porous structure of ZIF-8 coating was applied to protect $\mathrm{Zn}$ metal anodes, which resulted in a uniform electrolyte flux and effectively suppressed the formation of $\mathrm{Zn}$ protuberances/dendrites.

\subsection{MOF Composites}

MOF composites incorporating highly conductive carbon materials can improve MOF-based cathode performance in ZIBs. 3D conductive vanadium-based MOFs (V-MOFs, MIL-47) nanowire-bundle arrays were recently developed by growing on carbon nanotube fibers (CNTFs) as binderfree cathodes for ZIBs [167]. During the synthetic process, V-MOF nanowire-bundle arrays were engineered on the surface of CNTFs, which were then immersed into the $\mathrm{VOSO}_{4}$ and p-phthalic acid-containing DMF solutions for the hydrothermal reaction. By virtue of their desirable conductivity, rich active sites, and hierarchical porosity, a fiber-shaped V-MOF-CNTFs cathode displayed an excellent volumetric capacity of $101.8 \mathrm{mAh} \mathrm{cm}^{-3}$ at $0.1 \mathrm{~A} \mathrm{~cm}^{-3}$ and superior rate capability $\left(65.5 \mathrm{mAh} \mathrm{cm}^{-3}\right.$ at $\left.5.0 \mathrm{~A} \mathrm{~cm}^{-3}\right)$.

Modification strategy can construct MOF functional composites to provide fast ion transportation and protect $\mathrm{Zn}$ metal anode. Pan's group described a single-ion $\mathrm{Zn}^{2+}$ solidstate electrolyte (SSE) through a post-synthetic modified MOF-808 $\left(\left[\mathrm{Zr}_{6} \mathrm{O}_{4}(\mathrm{OH})_{4}(\mathrm{HCOO})_{6}(\mathrm{BTC})_{2}\right]\right)$ [168]. Specifically, MOF- 808 was turned negative by $\mathrm{HCl}$ treatment to obtain HMOF-808 (Fig. 5b). The counter $\mathrm{H}^{+}$ions in the pores were replaced by $\mathrm{Zn}\left(\mathrm{H}_{2} \mathrm{O}\right)_{6}{ }^{2+}$ by immersing HMOF808 in zinc acetate solution. Owing to the confined highly concentrated $\mathrm{Zn}\left(\mathrm{H}_{2} \mathrm{O}\right)_{6}{ }^{2+}$ ions within pores of MOF host, water@ZnMOF-808 (WZM) SSE demonstrates high ionic conductivity $\left(2.1 \times 10^{-4} \mathrm{~S} \mathrm{~cm}^{-1}\right.$ at $\left.30^{\circ} \mathrm{C}\right)$, low activation energy $(0.12 \mathrm{eV})$, and high $\mathrm{Zn}^{2+}$ transference number (0.93). WZM-SSE also shows good compatibility with Zn metal anode and stable $\mathrm{Zn}$ plating/stripping free from dendrite by virtue of its solid microporous structure with nanowetted $\mathrm{SSE} / \mathrm{Zn}$ metal interface. The $\mathrm{VS}_{2} / \mathrm{SSE} / \mathrm{Zn}$ batteries exhibited a reversible capacity of $125 \mathrm{mAh} \mathrm{g}^{-1}$ after 250 cycles at $0.2 \mathrm{~A} \mathrm{~g}^{-1}$.

\subsection{MOF Derivatives}

Metal compounds are often mixed with carbon materials to assemble the conventional cathodes of ZIBs because of their poor conductivity. However, the connections between metal compounds and conductive carbon are usually just the simple physical contact in traditional cathodes, limiting the rapid electron transport and thus resulting in poor rate performance. MOF derivatives with uniform distribution of metal compounds and carbon would hold great promise to achieve high-performance ZIBs [169]. As an example, Niu and co-workers developed a MIL-88B(V)-derived amorphous $\mathrm{V}_{2} \mathrm{O}_{5}$ /carbon material $\left(\mathrm{a}-\mathrm{V}_{2} \mathrm{O}_{5} @ \mathrm{C}\right)$ by carbonization and in situ electrochemical induction strategy (Fig. 5c) [170]. The amorphous $\mathrm{V}_{2} \mathrm{O}_{5}$ enables more isotropic $\mathrm{Zn}^{2+}$ diffusion routes and reaction sites, leading to a faster $\mathrm{Zn}^{2+}$ diffusion than that of crystalline $\mathrm{V}_{2} \mathrm{O}_{5}\left(\mathrm{c}-\mathrm{V}_{2} \mathrm{O}_{5}\right)$. Moreover, the porous carbon framework offers a continuous electron transfer pathway and ion diffusion channels. As a result, the $\mathrm{a}-\mathrm{V}_{2} \mathrm{O}_{5} @ \mathrm{C}$ ZIB cathode exhibits superior rate performance compared with $\mathrm{a}-\mathrm{V}_{2} \mathrm{O}_{5}$ and $\mathrm{c}-\mathrm{V}_{2} \mathrm{O}_{5}$ materials. 
MOF derivative-based $\mathrm{Zn}$ anodes have been presented recently. Wang and co-workers reported ZIF-8-derived Zn/ carbon nanoparticles as a host matrix for electrodeposited $\mathrm{Zn}$ [171]. The optimized MOF derivative (ZIF-8 annealed at $500{ }^{\circ} \mathrm{C}$, ZIF-8-500) is an attractive host material for highly stable CE (close to $100 \%$ ) and dendrite-free $\mathrm{Zn}$ plating and stripping behavior. Moreover, $\mathrm{I}_{2} / / \mathrm{Zn} @$ ZIF-8-500 battery exhibited long cycle stability and good rate capability, which is a great improvement compared to the $\mathrm{I}_{2} / / \mathrm{Zn}$ cell. The excellent electrochemical performances can be attributed to abundant porous structure and amount of $\mathrm{Zn}$ species in the ZIF-8-500 framework, which offers homogeneous nuclei for $\mathrm{Zn}$ plating and large overpotential for hydrogen evolution to alleviate $\mathrm{H}_{2} \mathrm{O}$ decomposition side reaction. MOFs can also be directly grown on $\mathrm{Zn}$ metal, whose derivatives can be utilized as integrated anodes for ZIBs. Ruoff's group engineered ZIF-8 layer directly on the surface of Zn foil by successively dipping foil in an ammonium persulfate solution and 2-methylimidazole solution, and the derived $\mathrm{Zn}$ / carbon layer on $\mathrm{Zn}$ foil was demonstrated to be an excellent integrated anode for ZIBs [172]. The MOF-based integrated anode suppressed $\mathrm{Zn}$ dendrite formation and side reactions due to its hydrophilic and porous surface. Thus, ZIBs with modified $\mathrm{Zn}$ anode achieved improved performance including reversible capacity, rate capability, and cycle stability relative to the pure $\mathrm{Zn}$ anode.

\subsection{MOF Composite Derivatives}

Combining cathode material with MOF to form composite derivative could be an effective strategy for improving the overall performance of ZIBs. In one example, ZIF-8 nanoparticles were fabricated on the surface of polyvinylpyrrolidone-modified $\mathrm{MnO}_{2}$ nanorods by Sun and coworkers to obtain a robust composite [173]. The subsequent annealing process transformed $\mathrm{ZIF}-8 / \mathrm{MnO}_{2}$ composite into $\mathrm{MnO}_{\mathrm{x}} @ \mathrm{~N}$-carbon nanorods. With the advantages of abundant porous structure, and conductive carbon shell, the $\mathrm{MnO}_{\mathrm{x}} @ \mathrm{~N}-\mathrm{C}$ delivered a much higher capacity of $385 \mathrm{mAh} \mathrm{g}^{-1}$ after 120 cycles relative to those of $\mathrm{MnO}_{2}$ and $\mathrm{M}_{\mathrm{n}} \mathrm{O}_{\mathrm{y}}$ cathode materials. In addition, MOF-based materials can be grown on carbon substrates for high-performance ZIBs cathode. For example, flexible carbon cloth was found to be an excellent support for the growth of MnMOF nanorod arrays with the solvothermal method. The fabricated Mn-MOF nanorod arrays/carbon cloth composite was then calcinated in the air atmosphere under target temperature, finally obtaining bulk oxygen defects $\mathrm{Mn}_{3} \mathrm{O}_{4} @ \mathrm{C}$ nanorod arrays $\left(\mathrm{O}_{\mathrm{d}}-\mathrm{Mn}_{3} \mathrm{O}_{4} @ \mathrm{C}\right.$ NA/CC $)$ cathode material, which exhibited better ZIBs performance than the $\mathrm{Mn}_{3} \mathrm{O}_{4}$ nanosheets/carbon cloth electrode [174]. Bulk oxygen defects can change the $\left(\mathrm{MnO}_{6}\right)$ octahedron structure, which enhances structural stability and prevents the dissolution of $\mathrm{Mn}^{2+}$. Moreover, the $\mathrm{O}_{\mathrm{d}}-\mathrm{Mn}_{3} \mathrm{O}_{4} @ \mathrm{C}$ NA/CC electrodes also assembled flexible quasi-solid-state ZIBs with high energy density and power density because of the adhesive-free nature.

Constructing MOF/carbon substrate composite derivatives can also serve as a scaffold for dendrite-free $\mathrm{Zn}$ deposition. For example, Kim and co-workers proposed a highly porous and defective carbon structure by the direct carbonization of ZIF-8-coated 3D carbon felt (CF) [175]. A single vacancy carbon defect $\left(\mathrm{SV}_{1}\right)$ resulting from the transformation of ZIF-8 prevents the surface diffusion and subsequent aggregation of $\mathrm{Zn}$ by inducing a strong orbital hybridization between $\mathrm{Zn}$ adatoms and unsaturated dangling bonds of the defect (Fig. 5d). The $\mathrm{Zn}$ adsorption energies between the $\mathrm{SV}_{1}$ and $\mathrm{Zn}$ crystal planes indicated $\mathrm{Zn}$ tendency to nucleate on the defect. The consequent growth of $\mathrm{Zn}$ nuclei results in the connection of nearby nuclei, coating the whole carbon fiber surfaces and leading to a dense packing of $\mathrm{Zn}$ electrodeposits in the 3D carbon framework. As a result, the Zn-Br battery with CZ-5 achieved stable CEs (>97\%) over 5000 cycles (Fig. 5e).

\subsection{Summary}

Although PBAs as cathode for ZIBs delivered excellent rate and cycling performances, the quite low specific capacity limits their further application. Making more vacancy sites and nanocomposites could be feasible approaches to improve the overall performance of PBAs cathode. Designing electrically conducting MOFs using graphene like extended $\pi$-conjugation systems is highly desirable for enhanced ZIBs cathode performance. Utilizing MOFs' modified electrolytes and anodes is also effective strategy for suppressing $\mathrm{Zn}$ dendritic formation and enhancing overall performance ZIBs. However, MOFs are chemically unstable for electrochemical applications, especially in acidic/alkaline aqueous conditions. Until now, the development of MOFs for ZIBs 
remains in its infancy. Thus, efforts must be made to explore MOF-based materials and devise solutions to realize the full potential of MOFs for ZIBs.

\section{Zn-air Batteries}

\subsection{Pristine MOFs}

As tunable pore structure and abundant active redox sites, MOF is a promising cathode material in the area of rechargeable $\mathrm{Zn}$-air batteries. For example, Lee and co-workers synthesized 3D dual-linked hexaiminobenzene MOF (Mn/ Fe-HIB-MOF) hollow spheres by isolated reactions between $\mathrm{Mn}(\mathrm{II})$ and $\mathrm{Fe}$ (II) nitrates and hexaaminobenzene ligands under room atmosphere, followed by a thermal process
(Fig. 6a) [176]. The Mn/Fe-HIB-MOF possesses a high surface area, rapid electron and mass transport pathways, and abundant $\mathrm{Mn} / \mathrm{Fe}-\mathrm{N}_{4}$ active redox sites as compared to conventional MOFs. The $\mathrm{Zn}$-air batteries with $\mathrm{Mn} / \mathrm{Fe}-\mathrm{HIB}-$ MOF exhibited a long cycle life over 6000 cycles $(1000 \mathrm{~h})$ at $10 \mathrm{~mA} \mathrm{~cm}^{-2}$ with a narrow voltage gap of $0.75 \mathrm{~V}$.

In another study, Ni/Fe-BTC MOF nanorods were electrochemically prepared via utilizing a two-electrode system containing $\mathrm{Ni}$ (II) and Fe(II) chlorides, and BTC linker [177]. When the Ni/Fe-BTC MOF was applied as a cathode in $\mathrm{Zn}$-air batteries, the excellent cycle stability for 5262 cycles (over 594 h) with round trip efficiency (65.80\%) at a current density of $10 \mathrm{~mA} \mathrm{~cm}^{-2}$ was delivered. The improved electrochemical performance of $\mathrm{Ni} / \mathrm{Fe}-\mathrm{BTC} \mathrm{MOF}$ is attributed to its

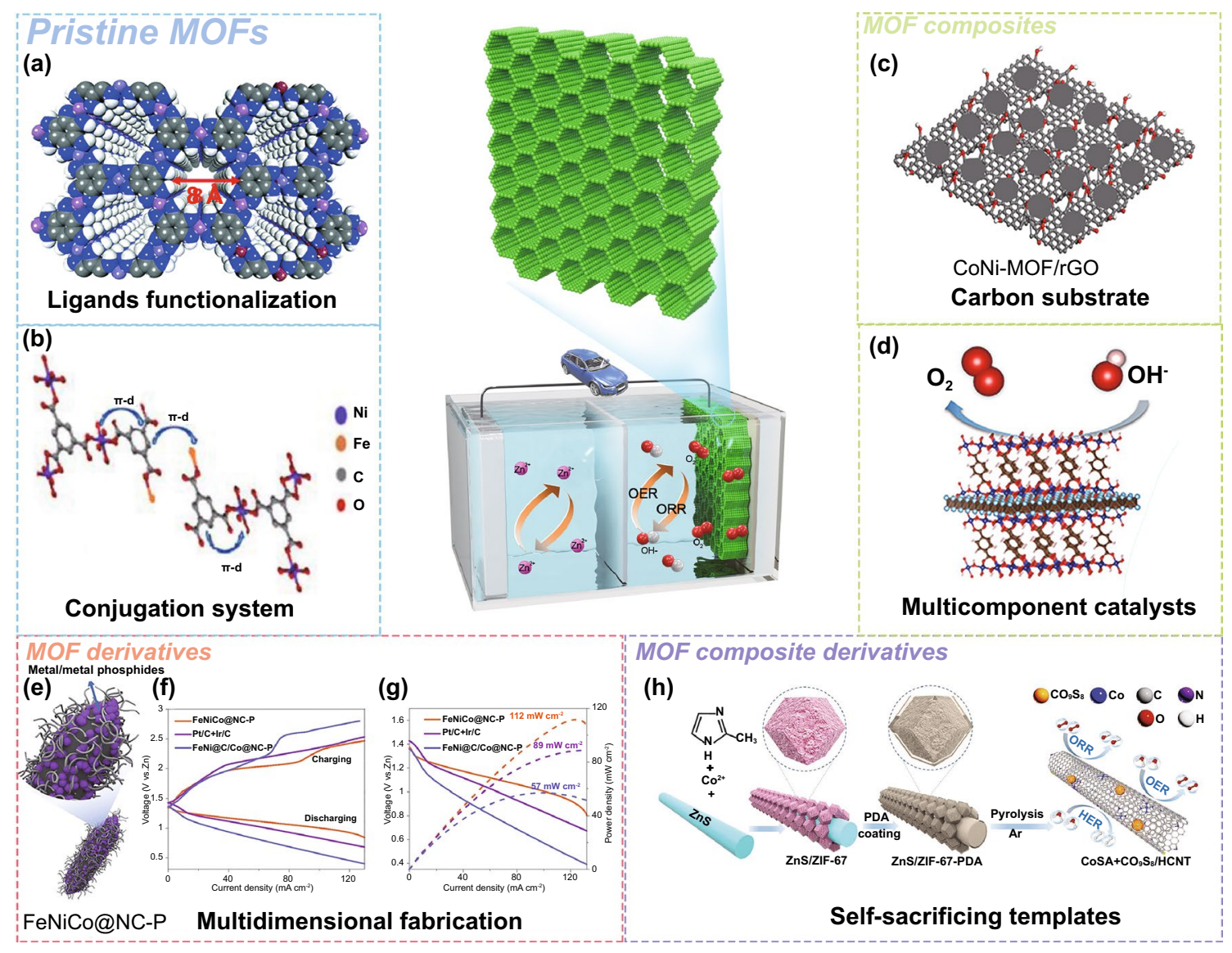

Fig. 6 MOF-based materials for Zn-air batteries. a Structure illustration of 3D M-HIB-MOFs [176]. Copyright (C) 2019, Royal Society of Chemistry. b Illustration of conjugation system of Ni/Fe-BTC MOFs [177]. Copyright @ 2019 , Elsevier. c Structure illustration of the CoNiMOF/RGO catalyst [179]. Copyright (C) 2019, American Chemical Society. d Structure of $\mathrm{Ti}_{3} \mathrm{C}_{2} \mathrm{~T}_{\mathrm{x}}-\mathrm{CoBDC}$ hybrid [182]. Copyright @ 2017 , American Chemical Society. e Schematics of preparation of FeNiCo@ NC-P. f Charge-discharge profiles, $\mathbf{g}$ discharge curves and the corresponding power density curves of FeNiCo@NC-P, FeNi@C/Co@NC-P and the mixture of Pt/C + Ir/C, respectively. [189]. Copyright @ 2019, WileyVCH. h Illustration of synthetic strategy of CoSA $+\mathrm{Co}_{9} \mathrm{~S}_{8} / \mathrm{HCNT}$ [27]. Copyright $@$ 2020 , Wiley-VCH 
unique pore structure, intrinsic electrical conductivity, and adequate covalent coordination redox active sites (Fig. 6b).

\subsection{MOF Composites}

Combining MOFs and conductive carbon is expected to achieve further improved electronic conductivity and catalytic performance in $\mathrm{Zn}$-air batteries. For example, the CoMOF $\left(\mathrm{Co}(\mathrm{bpdc})\left(\mathrm{H}_{2} \mathrm{O}\right)_{4}\right.$ (bpdc = biphenyl-4, 4'-dicarboxylic acid), arrays were in situ grown on a 3D graphite foam (GF) via hydrothermal reaction [178]. The obtained Co-MOF/ GF presented excellent bifunctional oxygen activity with a greatly reduced overpotential, which endows the as-assembled $\mathrm{Zn}$-air batteries with good power density and cycling performance. Similarly, a composite with bimetallic CoNiMOF nanosheets embedded in RGO was also synthesized by a simple mixture of CoNi-MOF and RGO, displaying the adequate exposed active sites and the improved electron conductivity (Fig. 6c) [179]. The Zn-air batteries with CoNiMOF/RGO-based air electrodes achieved a power density of $97 \mathrm{~mW} \mathrm{~cm}{ }^{-2}$, an energy density of $711 \mathrm{Wh} \mathrm{kg}_{\mathrm{Zn}}{ }^{-1}$, and excellent cycling stability with negligible decline over $120 \mathrm{~h}$. In addition, the direct growth of CoZn-ZIF nanosheet arrays on Ni foam support and its hierarchical porosity can ensure fast electron transfer and mass transportation in $\mathrm{Zn}$-air batteries [180, 181].

2D MXene with high electrical conductivity, surface electronegativity, and good stability are potential substrates that may alter the electrophilicity of the active centers of MOFs and therefore tune their catalytic properties. For instance, Huang and co-workers in situ hybridized cobalt 1,4-benzenedicarboxylate (CoBDC) nanosheets with 2D MXene $\left(\mathrm{Ti}_{3} \mathrm{C}_{2} \mathrm{~T}_{\mathrm{x}}\right)$ by an interdiffusion reaction strategy (Fig. 6d) [182]. The CoBDC layer offered a highly porous structure and large active surface area. The electrically conductive and hydrophilic $\mathrm{Ti}_{3} \mathrm{C}_{2} \mathrm{~T}_{x}$ nanosheets enabled the fast charge and ion transfer and promoted the easy access of aqueous electrolytes to the catalytically active CoBDC surfaces. The hybrid $\mathrm{Ti}_{3} \mathrm{C}_{2} \mathrm{~T}_{x}-\mathrm{CoBDC}$ nanosheets were assembled into air cathodes for $\mathrm{Zn}$-air batteries, exhibiting small overpotential and good cycling stability. Considering the multiple benefits of using MOFs as supports, Cao and coworkers reported grafted Co porphyrins on MOF surfaces through ligand exchange. $\mathrm{Zn}$-air batteries assembled with
MOF-supported Co porphyrins catalyst achieved comparable performance to that with $\mathrm{Pt} / \mathrm{C}$ [183].

\subsection{MOF Derivatives}

MOF-derived metal-free carbon electrocatalysts with atomically dispersed heteroatoms, abundant porous structure, and high conductivity have been developed as air-cathode for $\mathrm{Zn}$-air batteries. As one example, Zhao and co-workers developed a Zn-MOF, which was synthesized by using 1,4-benzenebicarboxlic acid and sodium tetrakis(1-imidazolyl) borate as organic linkers [184]. During the process of pyrolysis, $\mathrm{Zn}$ was evaporated and $\mathrm{B}, \mathrm{N}$ heteroatoms were retained leading to $\mathrm{B}-\mathrm{N}$ dual-doped highly porous carbon (BNPC). Benefiting from high porous structure and good oxygen catalytic activities of the $\mathrm{N}$ dopants (particularly pyridinic N) and B dopants, the $\mathrm{Zn}$-air batteries with BNPC exhibited initial charge and discharge potentials at 2.19 and $1.16 \mathrm{~V}\left(2 \mathrm{~mA} \mathrm{~cm}^{-2}\right)$, respectively, and stable performance even after $100 \mathrm{~h}$ ( 600 cycles).

MOF derivatives with uniformly dispersed metal species and rich nitrogen/carbon sources are also taken into account as significant platform materials in the field of $\mathrm{Zn-air} \mathrm{batteries} \mathrm{[185,} \mathrm{186].} \mathrm{As} \mathrm{an} \mathrm{example,} \mathrm{Zhang}$ et al. synthesized $\mathrm{N}$-doped graphitic carbon with embedded Co nanoparticles (C-MOF-C2-900) transformed from a pair of enantiotopic chiral 3D Co-based MOF $\left(\left[\mathrm{Co}_{6}(\mathrm{MIDPPA})_{3}(1,2,4-\mathrm{btc})_{3}\left(\mathrm{NO}_{2}\right)_{3}\left(\mathrm{H}_{2} \mathrm{O}\right)_{3}\right]\left(\mathrm{H}_{2} \mathrm{O}\right)_{7}\right)$, $1 \mathrm{~L}$ and $1 \mathrm{R}$, where MIDPPA $=4,4^{\prime}-\operatorname{di}(4-$ pyridine $)-4^{\prime \prime}-$ imidazoletriphenylamine and 1,2,4-btc $=1,2,4$-benzenetricarboxylic acid, via thermal treatment at temperature $900{ }^{\circ} \mathrm{C}$ [187]. The C-MOF-C2-900 with a hierarchical rodlike structure and multiple active sites (metallic $\mathrm{Co}, \mathrm{CoN}_{x}$, $\mathrm{CoO}_{x}$, and $\mathrm{N}$ species) exhibits high electrocatalytic activities for both ORR and OER. The Zn-air batteries based on C-MOF-C2-900 air-cathode delivered excellent initial potentials $(1.81 \mathrm{~V}$ for charge and $1.28 \mathrm{~V}$ for discharge) and stability with almost no decline over $120 \mathrm{~h}$ (300 cycles) at $2 \mathrm{~mA} \mathrm{~cm}^{-2}$.

Except for single MOF derivatives, bimetallic MOF and multiple MOF-derived metal species/carbon materials have drawn special attention due to their optimized electronic configuration and enhanced intrinsic activity. Lou and coworkers reported $\mathrm{MnO} / \mathrm{Co}$ hybrid with porous graphitic 
carbon (MnO/Co/PGC) polyhedrons by a hydrothermal-calcination strategy with a bimetal MOF containing cobalt and manganese (Co/Mn-MIL-100) as the precursor [188]. Interface engineering of highly active $\mathrm{MnO}$ for ORR and high conductive $\mathrm{Co}$ for OER endows the $\mathrm{MnO} / \mathrm{Co} / \mathrm{PGC}$ with excellent bifunctional electrocatalytic performance. The $\mathrm{Zn}$-air batteries using the $\mathrm{MnO} / \mathrm{Co} / \mathrm{PGC}$ cathode achieved a high-power density $\left(172 \mathrm{~mW} \mathrm{~cm}^{-2}\right)$ and specific capacity ( $872 \mathrm{mAh} \mathrm{g}_{\mathrm{Zn}}{ }^{-1}$ at $5 \mathrm{~mA} \mathrm{~cm}{ }^{-2}$ ) with long-term durability (350 cycles). Moreover, dual-MOFs ( $\mathrm{Fe}_{2} \mathrm{Ni}$-MIL-88@ ZnCo_ZIF) were recently developed through self-assembly with PVP-functionalized $\mathrm{Fe}_{2} \mathrm{Ni}$ _MIL-88 (Fig. 6e), $\mathrm{Zn}(\mathrm{NO})_{2} \cdot 6 \mathrm{H}_{2} \mathrm{O}, \mathrm{Co}(\mathrm{NO})_{2} \cdot 6 \mathrm{H}_{2} \mathrm{O}$, and 2-methylimidazole in an ethanol solution, the derived CNT-grafted, and N-doped carbon nanorod embedded with $\mathrm{Fe}-\mathrm{Ni}-\mathrm{Co}$ metal/metal phosphide nanoparticles (FeNiCo@NC-P) enhanced the porous structure and intrinsic activity of the oxygen catalysts [189]. The Zn-air batteries with FeNiCo@NC-P realized a low voltage gap and a maximum power density of $112 \mathrm{~mW} \mathrm{~cm} \mathrm{~cm}^{-2}$ (Fig. 6f, g).

\subsection{MOF Composite Derivatives}

During the pyrolysis process, the severe aggregation and structural collapse of MOF derivatives are inevitable, which greatly limit the catalytic performance. Rational construction of MOFs and carbon composite derivatives seem to be an effective strategy in achieving robust bifunctional oxygen electrocatalysts. For example, ZIF-67 was grown on a graphene oxide (GO) substrate, where the composite was then reduced in an $\mathrm{H}_{2}$-Ar atmosphere to produce $2 \mathrm{D} \mathrm{N}$-doped carbon nanotubes/graphene (GNCNTs) hybrid as an electrocatalyst for Zn-air batteries [190]. The Zn-air batteries assembled by this hybrid catalyst delivered a high power density of $253 \mathrm{~mW} \mathrm{~cm}^{-2}$ and a specific capacity of $801 \mathrm{mAh} \mathrm{g}_{\mathrm{Zn}}{ }^{-1}$, as well as a long lifespan of 9000 cycles (over $3000 \mathrm{~h}$ at $5 \mathrm{~mA} \mathrm{~cm}^{-2}$ ). The superior performance of the hybrid could be ascribed by the hierarchical structure with high specific surface area and rich heteroatoms active sites, which endow high catalytic activity and stability for the oxygen reactions. In addition, Guan et al. proposed a simple solution method to grow Co-MOF arrays directly on the surface of carbon cloth (CC) support [191]. The Co-MOF/CC composite was then converted into hollow $\mathrm{Co}_{3} \mathrm{O}_{4}$ nanosphereembedded nitrogen-doped carbon arrays $\left(\mathrm{NC}-\mathrm{Co}_{3} \mathrm{O}_{4} / \mathrm{CC}\right)$ under pre-carbonized and post-oxidized processes, which exhibited excellent catalytic activities toward both OER and ORR. A solid-state $\mathrm{Zn}$-air battery was assembled using the $\mathrm{NC}-\mathrm{Co}_{3} \mathrm{O}_{4} / \mathrm{CC}$ as a flexible air cathode, which demonstrated high open-circuit potential $(1.44 \mathrm{~V})$, satisfactory specific capacity (387.2 $\mathrm{mAh} \mathrm{g}^{-1}$ ), and good cycling stability.

The polymer can not only serve as a template to guide structure design, but also be converted into conductive carbon materials to protect unstable electrode materials. Recently, a bifunctional catalyst consisting of Co nanoparticles encapsulated in hollow nitrogen-doped carbon tubes (Co@hNCTs) is synthesized by simple polypyrrole (PPy) tube-directed templating method [192]. Typically, surfactant-treated PPy nanotubes act as the structure-guiding templates for efficient capture of $\mathrm{Co}^{2+}$, achieving the in situ growth of ZIF-67 nanocrystals on the surface of PPy nanotubes. The fabricated ZIF-67/PPy nanotubes composite was then carbonized in $\mathrm{Ar}$ atmosphere at $800{ }^{\circ} \mathrm{C}$, finally obtaining Co@hNCTs, which achieved long-term cyclability (over $500 \mathrm{~h}$ ) when using as an air cathode in $\mathrm{Zn}$-air batteries. Polyacrylonitrile (PAN) is a well-known soft electrospun substrate for designing 1D interconnected N-containing nanofibers. PAN nanofiber film was spun by Guo and coworkers, which was then immersed into $\mathrm{Co}\left(\mathrm{NO}_{3}\right)_{2}$ and 2-methylimidazole containing aqueous solution to finally form Co-ZIF on the surface of nanofiber [193]. The subsequent carbonization-acidification process resulted in the formation of Co single-atom supported by $\mathrm{N}$-doped carbon flake arrays grown on carbon nanofibers (Co SA@NCF/ $\mathrm{CNF}$ ). The wearable solid-state $\mathrm{Zn}$-air batteries based on $\mathrm{Co}$ SA@NCF/CNF air cathode delivered high specific capacity (530.17 $\mathrm{mAh} \mathrm{g}_{\mathrm{zn}}{ }^{-1}$ ) and superior stability (900 cycles). The excellent performance of the Co SA@NCF/CNF air-cathode stems from the following merits: (1) single-atomic Co sites exhibit low reaction barriers for oxygen catalysis, (2) the hierarchical porous architecture of hybrid endows it to possess adequate accessibility for single atom catalytic sites, (3) the robust carbon nanofiber framework enables high conductivities for rapid electron transfer and provides excellent mechanical properties for structural stability and flexibility in the device.

Developing fabrication strategies of metal compounds/ MOF composite derivatives is also important for enhanced oxygen catalysis performance [194, 195]. For example, $\mathrm{MnO}_{2} @ \mathrm{ZIF}-67$ composite was achieved via engineering 
ZIF-67 shell on the surface of hollow $\mathrm{MnO}_{2}$ nanowires [196]. Highly porous MnO@Co-N/C nanowires were then successfully formed after the subsequent pyrolysis process, which exhibited good cycling stability as air-cathode for $\mathrm{Zn}$-air batteries. The excellent performances originate from the synergistic effect of $\mathrm{MnO}$ and porous $\mathrm{Co}-\mathrm{N} / \mathrm{C}$ in $1 \mathrm{D}$ hollow nanowires, maximizing the catalytic ability of $\mathrm{MnO}$ and preventing the aggregation of carbon frameworks. Some metal compounds (i.e., $\mathrm{ZnO}$ and $\mathrm{SiO}_{2}$ ) can also be used as self-sacrificing templates for the MOF-based derivatives [185]. Recently, $\mathrm{ZnS}$ nanorods were utilized as templates for the growth of ZIF-67 and followed by coating polydopamine (PDA) to obtain ZnS/ZIF-67-PDA composite (Fig. 6h) [27]. Then after pyrolysis at $1000{ }^{\circ} \mathrm{C}$, the $\mathrm{ZnS}$ nanorods were reduced to $\mathrm{Zn}$ vapors and simultaneously saved as a sulfur source to form $\mathrm{Co}_{9} \mathrm{~S}_{8}$ nanoparticles from ZIF-67, finally reaching hollow carbon nanotube embedded single atomic cobalt with $\mathrm{Co}_{9} \mathrm{~S}_{8}$ nanoparticles $\left(\mathrm{CoSA}+\mathrm{Co}_{9} \mathrm{~S}_{8} /\right.$ $\mathrm{HCNT})$. The synergistic effects between $\mathrm{Co}_{9} \mathrm{~S}_{8}$ and single atomic cobalt can optimize the electronic structure of the active sites to low the catalytic barrier and promoting the ORR and OER simultaneously. Consequently, $\mathrm{Zn}$-air batteries based on $\mathrm{CoSA}+\mathrm{Co}_{9} \mathrm{~S}_{8} / \mathrm{HCNT}$ displayed good stability and a high-power density of $177.33 \mathrm{~mW} \mathrm{~cm}^{-2}$.

\subsection{Summary}

MOF, MOF composite, and their derivatives have been explored for $\mathrm{Zn}$-air batteries because of their abundant porous structures, operative active sites, and high surface area. However, most of the MOFs suffer from low electrical conductivities and poor stabilities in basic/acidic electrolytes. The incorporation of multi-metal active sites in MOFs or the design of MOF composites should be more encouraged in the next stage of research. In addition, although MOF derivatives possess high conductivities and oxygen catalytic activities, these particles would happen self-aggregation and structural collapse during the operation of $\mathrm{Zn}$-air batteries. It is also important to develop MOF composite derivatives so as to fabricate efficient catalytic materials for high-performance $\mathrm{Zn}$-air batteries. Moreover, MOF-based anodes with hydrophilic and porous surface hold great promise for the development of stable and dendrite-free $\mathrm{Zn}$-air batteries.

\section{Conclusions and Perspectives}

This review provides an overview of recent advances of pristine MOFs, MOF composites, MOF derivatives, and MOF composite derivatives for next-generation batteries (including SIBs, PIBs, ZIBs, AIBs, Li-S, Na-S, Li-Se, Li-O $\mathrm{Na}$-air, and $\mathrm{Zn}$-air batteries), demonstrating that MOFs are promising candidates for these energy storage applications due to their highly porous structures, controllable morphologies/structures, and tunable chemical compositions. A detailed information of MOFs along with their battery performance parameters is summarized in Table 1.

Despite their beneficial features, there are still several issues and challenges on MOFs for various new-generation rechargeable batteries so far (Fig. 7). (1) The poor conductivity and structural stability of pristine MOFs are the major obstacles for battery applications. Although some 2D conductive MOFs have been developed in recent years, they are still unsatisfactory when used as high-rate electrode materials in batteries. Moreover, most of the MOFs suffer from structural collapse, especially in water/moisture, acidic or alkaline environments, which leads to poor cycling stability during the operation of batteries. Apart from developing new MOFs with high conductivity and stability, it is expected that the functionalized strategy by grafting desired atoms/ groups or introducing structural stabilizers inside MOFs may also enhance the conductivity or stability of pristine MOFs. Comparatively, MOF derivatives with enhanced conductivity and better stability are considered to be great potential materials for different batteries. However, the self-aggregation and poor microstructures of MOF-derived particles would cause inferior electrochemical performance during the prolonged cycling process in the batteries. In addition, pristine MOFs and their derivatives with high porous structures and large surface areas lead to a low CE and low tap density. Considering these issues, engineering microstructure by combining MOF derivatives with various substrates and adjustment ratio of hybrid electrode components are expected to improve overall battery performances (i.e., CE, gravimetric/volumetric energy density, rate performance, and cycling stability). A significant progress regarding the fabrication of MOF composite and their derivatives has been proposed to achieve better battery performances via the synergistic effect between various components. It should be 
Table 1 Summary of the representative MOF-related materials for next-generation batteries

\begin{tabular}{|c|c|c|c|c|c|c|}
\hline Materials & MOF utilized & Application & $\begin{array}{l}\text { Rate capability } \\
\left(\mathrm{DC}^{\mathrm{a}} / \mathrm{CD}^{\mathrm{b}}\right)\end{array}$ & $\begin{array}{l}\text { Reversible capacity } \\
\text { (DC/CD) }\end{array}$ & $\begin{array}{l}\text { Cycling Stability } \\
\left(\mathrm{DC} / \mathrm{CD} / \mathrm{CN}^{\mathrm{c}}\right)\end{array}$ & Refs. \\
\hline Ni-MOF/S & Ni-MOF & Li-S cathode & $287 / 2 \mathrm{C}$ & $689 / 0.1 \mathrm{C}$ & $611 / 0.1 \mathrm{C} / 100$ & [29] \\
\hline $\mathrm{Ni}_{3}(\mathrm{HITP})_{2}$ & $\mathrm{Ni}_{3}(\mathrm{HITP})_{2}$ & $\mathrm{Li}-\mathrm{S}$ separator & $589 / 5 \mathrm{C}$ & $1244 / 0.2 \mathrm{C}$ & $1139 / 0.2 \mathrm{C} / 100$ & [30] \\
\hline $\mathrm{Cu}_{2}(\mathrm{CuTCPP})$ & $\mathrm{Cu}_{2}(\mathrm{CuTCPP})$ & $\mathrm{Li}-\mathrm{S}$ separator & $437 / 5 \mathrm{C}$ & $1200 / 0.2 \mathrm{C}$ & $1020 / 0.2 \mathrm{C} / 100$ & [31] \\
\hline HKUST-1 & HKUST-1 & $\mathrm{Li}-\mathrm{S}$ separator & $633 / 3 \mathrm{C}$ & $1196 / 0.5 \mathrm{C}$ & $802 / 0.5 \mathrm{C} / 600$ & [32] \\
\hline Ce-MOF-2/CNT & Ce-MOF-2 & $\mathrm{Li}-\mathrm{S}$ separator & $663 / 4 \mathrm{C}$ & $1022 / 1 \mathrm{C}$ & $839 / 1 \mathrm{C} / 800$ & [39] \\
\hline CuBTC-NSP & CuBTC & $\mathrm{Li}-\mathrm{S}$ separator & $963 / 2 \mathrm{C}$ & $1316 / 0.5 \mathrm{C}$ & $1128 / 0.5 \mathrm{C} / 500$ & [45] \\
\hline B/2D MOF-Co & 2D MOF-Co & $\mathrm{Li}-\mathrm{S}$ separator & $478 / 5 \mathrm{C}$ & $1138 / 0.1 \mathrm{C}$ & $703 / 0.5 \mathrm{C} / 200$ & [47] \\
\hline $\begin{array}{l}\text { ppy-S-in- } \\
\text { PCN-224 }\end{array}$ & PCN-224 & Li-S cathode & $640 / 5 \mathrm{C}$ & $680 / 10 \mathrm{C}$ & $440 / 10 \mathrm{C} / 1000$ & [22] \\
\hline LPS-UiO-66/S & Zr-MOFs & $\mathrm{Li}-\mathrm{S}$ cathode & - & 1040/0.1 C & $835 / 0.2 \mathrm{C} / 100$ & [44] \\
\hline $\begin{array}{l}\text { Mg-MOF-74 } \\
\text {-PVDF }\end{array}$ & Mg-MOF-74 & $\mathrm{Li}-\mathrm{S}$ electrolyte & $861 / 2 \mathrm{C}$ & $1383 / 0.1 \mathrm{C}$ & $981 / 0.1 \mathrm{C} / 200$ & [49] \\
\hline $\begin{array}{l}\text { CoP@HPCN- } \\
\text { MWCNT }\end{array}$ & ZIF-8/ZIF-67 & Li-S cathode & $528 / 3 \mathrm{C}$ & $887 / 0.2 \mathrm{C}$ & $753 / 0.2 \mathrm{C} / 200$ & [56] \\
\hline $\mathrm{Co}_{9} \mathrm{~S}_{8}$ & 2D-MOF & $\mathrm{Li}-\mathrm{S}$ separator & $428 / 2 \mathrm{C}$ & $1385 / 0.1 \mathrm{C}$ & $1190 / 0.1 \mathrm{C} / 200$ & [59] \\
\hline $\begin{array}{l}\mathrm{CP} @ \mathrm{NCNT} @ \\
\mathrm{CoS}_{3}\end{array}$ & Co-MOF & $\mathrm{Li}-\mathrm{S}$ cathode & - & $1601 / 0.13 \mathrm{C}$ & $1047 / 0.13 \mathrm{C} / 70$ & [69] \\
\hline CC@CS@HPP & ZIF-67 & Li-S cathode & - & $1223 / 1 \mathrm{C}$ & $1005 / 1 \mathrm{C} / 200$ & [70] \\
\hline $\mathrm{Co} / \mathrm{N}-\mathrm{PCNSs}$ & $\mathrm{Co} / \mathrm{Zn}-\mathrm{ZIF}$ & $\mathrm{Li}-\mathrm{S}$ cathode & $520 / 5 \mathrm{C}$ & $1234 / 0.2 \mathrm{C}$ & $913 / 0.2 \mathrm{C} / 100$ & [80] \\
\hline $\mathrm{Co}_{2} \mathrm{~B} @ \mathrm{CNT}$ & ZIF-67 & $\mathrm{Li}-\mathrm{S}$ separator & $1137 / 5 \mathrm{C}$ & $1430 / 0.2 \mathrm{C}$ & $1283 / 0.2 \mathrm{C} / 200$ & [78] \\
\hline Mn-MOF-74 & Mn-MOF-74 & $\mathrm{Li}-\mathrm{O}_{2}$ cathode & $\begin{array}{l}9420 / 50 \\
\mathrm{~mA} \mathrm{~g}^{-1}\end{array}$ & - & - & [81] \\
\hline MnCo-MOF-74 & MnCo-MOF-74 & $\mathrm{Li}-\mathrm{O}_{2}$ cathode & - & $11,150 / 200 \mathrm{~mA} \mathrm{~g}^{-1}$ & $\begin{array}{l}1000 / 200 \\
\mathrm{~mA} \mathrm{~g}^{-1} / 44\end{array}$ & [82] \\
\hline MOF-74@CNTs & MOF-74 & $\mathrm{Li}-\mathrm{O}_{2}$ cathode & - & $2500 / 125 \mathrm{~mA} \mathrm{~g}^{-1}$ & $\begin{array}{l}500 / 125 \\
\mathrm{~mA} \mathrm{~g}^{-1} / 60\end{array}$ & [84] \\
\hline $\begin{array}{l}\text { CAU-1-NH2- } \\
\text { PMMA }\end{array}$ & CAU-1-NH2 & Li-air cathode & - & $1480 / 200 \mathrm{~mA} \mathrm{~g}^{-1}$ & $\begin{array}{l}450 / 450 \\
\mathrm{~mA} \mathrm{~g}^{-1} / 66\end{array}$ & [86] \\
\hline $\begin{array}{l}\mathrm{Fe}-\mathrm{Fe}_{3} \mathrm{C} @ \\
\mathrm{Fe}-\mathrm{N}-\mathrm{C}\end{array}$ & MIL-100(Fe)/ ZIF-8 & $\mathrm{Li}-\mathrm{O}_{2}$ cathode & $2878 / 300 \mathrm{~mA} \mathrm{~g}^{-1}$ & $\begin{array}{l}8749 / 50 \\
\mathrm{~mA} \mathrm{~g}^{-1}\end{array}$ & - & [94] \\
\hline $\mathrm{Co}-\mathrm{SAs} / \mathrm{N}-\mathrm{C}$ & Zn-hexamine complex & $\mathrm{Li}-\mathrm{O}_{2}$ cathode & $\begin{array}{l}11,098 / 1000 \\
\mathrm{~mA} \mathrm{~g}^{-1}\end{array}$ & $\begin{array}{l}20,105 / 200 \\
\mathrm{~mA} \mathrm{~g}^{-1}\end{array}$ & $\begin{array}{l}1000 / 400 \\
\mathrm{~mA} \mathrm{~g}^{-1} / 260\end{array}$ & [95] \\
\hline $\mathrm{MOF}-\mathrm{C} / \mathrm{CNT}$ & ZIF-8 & $\mathrm{Li}-\mathrm{O}_{2}$ cathode & $\begin{array}{l}500 / 600 \\
\mathrm{~mA} \mathrm{~g}^{-1}\end{array}$ & $\begin{array}{l}10,050 / 50 \\
\mathrm{~mA} \mathrm{~g}^{-1}\end{array}$ & $500 / 200 / 75$ & [96] \\
\hline 3DP-NC-Co & Co-MOF & $\mathrm{Li}-\mathrm{O}_{2}$ cathode & $\begin{array}{l}525 / 0.8 \\
\mathrm{~mA} \mathrm{~cm}\end{array}$ & $1124 / 0.05 \mathrm{~mA} \mathrm{~cm}^{-2}$ & - & [98] \\
\hline $\mathrm{Na}_{1.72} \mathrm{MnFe}(\mathrm{CN})_{6}$ & $\mathrm{Na}_{1.72} \mathrm{MnFe}(\mathrm{CN})_{6}$ & SIB cathode & $\begin{array}{l}45 / 4800 \\
\mathrm{~mA} \mathrm{~g}^{-1}\end{array}$ & $\begin{array}{l}134 / 120 \\
\mathrm{~mA} \mathrm{~cm}\end{array}$ & $\begin{array}{l}120 / 120 \\
\mathrm{~mA} \mathrm{~g}^{-1 / 30}\end{array}$ & [101] \\
\hline $\begin{array}{l}\mathrm{Na}_{0.61} \mathrm{Fe} \\
{\left[\mathrm{Fe}(\mathrm{CN})_{6}\right]_{0.94}}\end{array}$ & $\begin{array}{l}\mathrm{Na}_{0.61} \mathrm{Fe} \\
{\left[\mathrm{Fe}(\mathrm{CN})_{6}\right]_{0.94}}\end{array}$ & SIB cathode & $\begin{array}{l}70 / 600 \\
\mathrm{~mA} \mathrm{~g}^{-1}\end{array}$ & $\begin{array}{l}170 / 25 \\
\mathrm{~mA} \mathrm{~g}^{-1}\end{array}$ & $\begin{array}{l}170 / 25 \\
\mathrm{~mA} \mathrm{~g}^{-1} / 150\end{array}$ & [102] \\
\hline cubic $\mathrm{Na}_{\mathrm{x}} \mathrm{MnFe}(\mathrm{CN})_{6}$ & Cubic $\mathrm{Na}_{\mathrm{x}} \mathrm{MnFe}(\mathrm{CN})_{6}$ & SIB cathode & $\begin{array}{l}74 / 600 \\
\mathrm{~mA} \mathrm{~g}^{-1}\end{array}$ & $\begin{array}{l}124 / 25 \\
\mathrm{~mA} \mathrm{~g}^{-1}\end{array}$ & $\begin{array}{l}84 / 200 \\
\mathrm{~mA} \mathrm{~g}^{-1} / 500\end{array}$ & [108] \\
\hline u-CoOHtp & u-CoOHtp & SIB anode & $\begin{array}{l}215 / 2000 \\
\mathrm{~mA} \mathrm{~g}^{-1}\end{array}$ & $\begin{array}{l}418 / 50 \\
\mathrm{~mA} \mathrm{~g}^{-1}\end{array}$ & $\begin{array}{l}371 / 50 \\
/ \mathrm{mA} \mathrm{g}^{-1} / 50\end{array}$ & [109] \\
\hline Co-HAB & Сo-HAB & SIB anode & $\begin{array}{l}152 / 12000 \\
\mathrm{~mA} \mathrm{~g}^{-1}\end{array}$ & $\begin{array}{l}291 / 50 \\
\mathrm{~mA} \mathrm{~g}^{-1}\end{array}$ & $\begin{array}{l}226 / 500 \\
\mathrm{~mA} \mathrm{~g}^{-1} / 50\end{array}$ & [110] \\
\hline Zn-PTCA & Zn-PTCA & SIB anode & $\begin{array}{l}256 / 1000 \\
\mathrm{~mA} \mathrm{~g}^{-1}\end{array}$ & $\begin{array}{l}450 / 50 \\
\mathrm{~mA} \mathrm{~g}^{-1}\end{array}$ & $\begin{array}{l}302 / 200 \\
\mathrm{~mA} \mathrm{~g}^{-1} / 50\end{array}$ & [111] \\
\hline CuTCNQ/CNFs & CuTCNQ & SIB cathode & $\begin{array}{l}89 / 600 \\
\mathrm{~mA} \mathrm{~g}^{-1}\end{array}$ & $\begin{array}{l}161 / 300 \\
\mathrm{mAg}^{-1}\end{array}$ & $\begin{array}{l}137 / 300 \\
\mathrm{~mA} \mathrm{~g}^{-1 / 300}\end{array}$ & [115] \\
\hline
\end{tabular}


Table 1 (continued)

\begin{tabular}{|c|c|c|c|c|c|c|}
\hline Materials & MOF utilized & Application & $\begin{array}{l}\text { Rate capability } \\
\left(\mathrm{DC}^{\mathrm{a}} / \mathrm{CD}^{\mathrm{b}}\right)\end{array}$ & $\begin{array}{l}\text { Reversible capacity } \\
\text { (DC/CD) }\end{array}$ & $\begin{array}{l}\text { Cycling Stability } \\
\left(\mathrm{DC} / \mathrm{CD} / \mathrm{CN}^{c}\right)\end{array}$ & Refs. \\
\hline $\begin{array}{l}\text { NaK-MnHCF- } \\
\text { 3DNC }\end{array}$ & NaK-MnHCF & SIB cathode & $\begin{array}{l}110 / 500 \\
\mathrm{~mA} \mathrm{~g}^{-1}\end{array}$ & $\begin{array}{l}190 / 40 \\
\mathrm{~mA} \mathrm{~g}^{-1}\end{array}$ & $\begin{array}{l}137 / 40 \\
\mathrm{~mA} \mathrm{~g}^{-1} / 100\end{array}$ & [116] \\
\hline NMHFC@PPy & NMHFC & SIB cathode & $\begin{array}{l}56 / 4800 \\
\mathrm{~mA} \mathrm{~g}^{-1}\end{array}$ & $\begin{array}{l}113 / 240 \\
\mathrm{~mA} \mathrm{~g}^{-1}\end{array}$ & $\begin{array}{l}76 / 240 \\
\mathrm{~mA} \mathrm{~g}^{-1} / 200\end{array}$ & [118] \\
\hline NPCNs & Zn-hexamine MOF & SIB anode & $\begin{array}{l}\text { 194/10000 } \\
\mathrm{mA} \mathrm{g}^{-1}\end{array}$ & $\begin{array}{l}318 / 100 \\
\mathrm{~mA} \mathrm{~g}^{-1}\end{array}$ & $\begin{array}{l}280 / 100 \\
\mathrm{~mA} \mathrm{~g}^{-1} / 100\end{array}$ & [121] \\
\hline $\mathrm{CoS}_{2}$ & ZIF-67 & SIB anode & $\begin{array}{l}346 / 5000 \\
\mathrm{~mA} \mathrm{~g}^{-1}\end{array}$ & $\begin{array}{l}478 / 200 \\
\mathrm{~mA} \mathrm{~g}^{-1}\end{array}$ & $\begin{array}{l}454 / 200 \\
\mathrm{~mA} \mathrm{~g}^{-1} / 100\end{array}$ & [130] \\
\hline $\mathrm{CoSe}_{2} / \mathrm{ZnSe}$ & 2D CoZn-MOFs & SIB anode & $\begin{array}{l}263 / 10000 \\
\mathrm{~mA} \mathrm{~g}^{-1}\end{array}$ & $\begin{array}{l}575 / 100 \\
\mathrm{~mA} \mathrm{~g}^{-1}\end{array}$ & - & [135] \\
\hline NPCNs & ZIF-8 & SIB anode & $\begin{array}{l}146 / 2000 \\
\mathrm{~mA} \mathrm{~g}^{-1}\end{array}$ & $\begin{array}{l}295 / 100 \\
\mathrm{~mA} \mathrm{~g}^{-1}\end{array}$ & $\begin{array}{l}257 / 100 \\
\mathrm{~mA} \mathrm{~g}^{-1} / 100\end{array}$ & [138] \\
\hline $\mathrm{ZnS}-\mathrm{Sb}_{2} \mathrm{~S}_{3} @ \mathrm{C}$ & ZIF-8 & SIB anode & $\begin{array}{l}391 / 800 \\
\mathrm{~mA} \mathrm{~g}^{-1}\end{array}$ & $\begin{array}{l}1043 / 100 \\
\mathrm{~mA} \mathrm{~g}^{-1}\end{array}$ & $\begin{array}{l}630 / 100 \\
\mathrm{~mA} \mathrm{~g}^{-1 / 120}\end{array}$ & [142] \\
\hline FTO $\subset$ CNTs & Fe-MOF & SIB anode & $\begin{array}{l}202 / 5000 \\
\mathrm{~mA} \mathrm{~g}^{-1}\end{array}$ & $\begin{array}{l}465 / 100 \\
\mathrm{~mA} \mathrm{~g}^{-1}\end{array}$ & $\begin{array}{l}376 / 100 \\
\mathrm{~mA} \mathrm{~g}^{-1 / 200}\end{array}$ & [143] \\
\hline $\begin{array}{l}\mathrm{K}_{2}\left[(\mathrm{VO})_{2}\right. \\
\left.\left(\mathrm{HPO}_{4}\right)_{2}\left(\mathrm{C}_{2} \mathrm{O}_{4}\right)\right]\end{array}$ & $\begin{array}{l}\mathrm{K}_{2}\left[(\mathrm{VO})_{2}\right. \\
\left.\left(\mathrm{HPO}_{4}\right)_{2}\left(\mathrm{C}_{2} \mathrm{O}_{4}\right)\right]\end{array}$ & PIB cathode & - & $\begin{array}{l}65 / 21.8 \\
\mathrm{~mA} \mathrm{~g}^{-1}\end{array}$ & $\begin{array}{l}54 / 21.8 \\
\mathrm{~mA} \mathrm{~g}^{-1} / 200\end{array}$ & [145] \\
\hline MIL-125(Ti) & MIL-125(Ti) & PIB anode & $\begin{array}{l}56 / 200 \\
\mathrm{~mA} \mathrm{~g}^{-1}\end{array}$ & $\begin{array}{l}155 / 50 \\
\mathrm{~mA} \mathrm{~g}^{-1}\end{array}$ & $\begin{array}{l}157 / 50 \\
\mathrm{~mA} \mathrm{~g}^{-1} / 200\end{array}$ & [148] \\
\hline $\mathrm{L}-\mathrm{Co}_{2}(\mathrm{OH})_{2} \mathrm{BDC}$ & $\begin{array}{l}\mathrm{L}-\mathrm{Co}_{2}(\mathrm{OH})_{2} \\
\mathrm{BDC}\end{array}$ & PIB anode & $131 / 1000 \mathrm{~mA} \mathrm{~g}^{-1}$ & $\begin{array}{l}352 / 50 \\
\mathrm{~mA} \mathrm{~g}^{-1}\end{array}$ & $\begin{array}{l}246 / 100 \\
\mathrm{~mA} \mathrm{~g}^{-1} / 50\end{array}$ & [149] \\
\hline CC-Ni- NiCo-MOF & NiCo-MOF & PIB cathode & $\begin{array}{l}185 / 20000 \\
\mathrm{~mA} \mathrm{~g}^{-1}\end{array}$ & $218 / 2000 \mathrm{~mA} \mathrm{~g}^{-1}$ & - & [151] \\
\hline OFPCN & UiO-66 (Zr) & PIB anode & $78 / 20000 \mathrm{~mA} \mathrm{~g}^{-1}$ & $\begin{array}{l}405 / 100 \\
\mathrm{~mA} \mathrm{~g}^{-1}\end{array}$ & $\begin{array}{l}286 / 100 \\
\mathrm{~mA} \mathrm{~g}^{-1} / 200\end{array}$ & [154] \\
\hline $\mathrm{Co}_{0.85} \mathrm{Se}-\mathrm{NC}$ & ZIF-67 & PIB anode & $111 / 2000 \mathrm{~mA} \mathrm{~g}^{-1}$ & $\begin{array}{l}320 / 50 \\
\mathrm{~mA} \mathrm{~g}^{-1}\end{array}$ & $\begin{array}{l}115 / 1000 / \\
\mathrm{mA} \mathrm{g}^{-1} / 250\end{array}$ & [155] \\
\hline UCF@CNs@BiN & Bi-MOFs & PIB anode & $\begin{array}{l}140 / 1000 \\
\mathrm{~mA} \mathrm{~g}^{-1}\end{array}$ & $\begin{array}{l}665 / 100 \\
\mathrm{~mA} \mathrm{~g}^{-1}\end{array}$ & $\begin{array}{l}425 / 100 \\
\mathrm{~mA} \mathrm{~g}^{-1} / 50\end{array}$ & [156] \\
\hline NCS@RGO & MOF-74 & PIB anode & $\begin{array}{l}402 / 2000 \\
\mathrm{~mA} \mathrm{~g}^{-1}\end{array}$ & $\begin{array}{l}585 / 50 \\
\mathrm{~mA} \mathrm{~g}^{-1}\end{array}$ & $\begin{array}{l}495 / 200 \\
\mathrm{~mA} \mathrm{~g}^{-1} / 1900\end{array}$ & [157] \\
\hline $\mathrm{Co}_{0.85} \mathrm{Se} @ \mathrm{CNFs}$ & ZIF-67 & PIB anode & $\begin{array}{l}166 / 5000 \\
\mathrm{~mA} \mathrm{~g}^{-1}\end{array}$ & $\begin{array}{l}364 / 200 \\
\mathrm{~mA} \mathrm{~g}^{-1}\end{array}$ & $\begin{array}{l}353 / 200 \\
\mathrm{~mA} \mathrm{~g}^{-1} / 100\end{array}$ & [158] \\
\hline N-HPC & ZIF-8 & PIB anode & $\begin{array}{l}94 / 10 \\
\mathrm{~mA} \mathrm{~g}^{-1}\end{array}$ & $\begin{array}{l}345 / 0.1 \\
\mathrm{~mA} \mathrm{~g}^{-1}\end{array}$ & $\begin{array}{l}157 / 2000 \\
\mathrm{~mA} \mathrm{~g}^{-1} / 12000\end{array}$ & [159] \\
\hline $\mathrm{Cu}_{3}(\mathrm{HHTP})_{2}$ & $\mathrm{Cu}_{3}(\mathrm{HHTP})_{2}$ & ZIB cathode & $\begin{array}{l}125 / 4000 \\
\mathrm{~mA} \mathrm{~g}^{-1}\end{array}$ & $\begin{array}{l}124 / 4000 \\
\mathrm{~mA} \mathrm{~g}^{-1}\end{array}$ & $\begin{array}{l}93 / 4000 \\
\mathrm{~mA} \mathrm{~g}^{-1} / 500\end{array}$ & [164] \\
\hline ZIF 7 & ZIF 7 & ZIB anode & - & $\begin{array}{l}192 / 500 \\
\mathrm{~mA} \mathrm{~g}^{-1}\end{array}$ & $\begin{array}{l}187 / 500 \\
\mathrm{~mA} \mathrm{~g}^{-1} / 180\end{array}$ & [165] \\
\hline ZnMOF-808 & MOF-808 & ZIB electrolyte & - & $140 / 200$ & $\begin{array}{l}125 / 200 \\
\mathrm{~mA} \mathrm{~g}^{-1} / 250\end{array}$ & [168] \\
\hline ZIF-8-500 & ZIF-8 & ZIB anode & $\begin{array}{l}80 / 8000 \\
\mathrm{~mA} \mathrm{~g}^{-1}\end{array}$ & $\begin{array}{l}183 / 200 \\
\mathrm{~mA} \mathrm{~g}^{-1}\end{array}$ & - & [171] \\
\hline $\mathrm{a}-\mathrm{V}_{2} \mathrm{O}_{5} @ \mathrm{C}$ & MIL-88B(V) & ZIB cathode & $\begin{array}{l}72.8 / 200000 \\
\mathrm{~mA} \mathrm{~g}^{-1}\end{array}$ & $\begin{array}{l}620 / 300 \\
\mathrm{~mA} \mathrm{~g}^{-1}\end{array}$ & $\begin{array}{l}249 / 40000 \\
\mathrm{~mA} \mathrm{~g}^{-1} / 20000\end{array}$ & [170] \\
\hline $\mathrm{MnO}_{\mathrm{x}} @ \mathrm{~N}-\mathrm{C}$ & ZIF-8 & ZIB cathode & - & - & $\begin{array}{l}305 / 500 \\
\mathrm{~mA} \mathrm{~g}^{-1} / 600\end{array}$ & [173] \\
\hline $\mathrm{O}_{\mathrm{d}}-\mathrm{Mn}_{3} \mathrm{O}_{4} @ \mathrm{C} \mathrm{NA} / \mathrm{CC}$ & Mn-MOFs & ZIB cathode & $\begin{array}{l}133 / 5000 \\
\mathrm{~mA} \mathrm{~g}^{-1}\end{array}$ & $\begin{array}{l}396 / 200 \\
\mathrm{~mA} \mathrm{~g}^{-1}\end{array}$ & $\begin{array}{l}84 / 5000 \\
\mathrm{~mA} \mathrm{~g}^{-1} / 12000\end{array}$ & [174] \\
\hline $\mathrm{Mn} / \mathrm{Fe}-\mathrm{HIB}$ & $\mathrm{Mn} / \mathrm{Fe}-\mathrm{HIB}$ & Zn-air cathode & $\begin{array}{l}702 / 50 \\
\mathrm{~mA} \mathrm{~cm}^{-2}\end{array}$ & $\begin{array}{l}769 / 5 \\
\mathrm{~mA} \mathrm{~cm}\end{array}$ & $\begin{array}{l}-/ 10 \\
\mathrm{~mA} \mathrm{~cm}-2 / 6000\end{array}$ & [176] \\
\hline
\end{tabular}


Table 1 (continued)

\begin{tabular}{|c|c|c|c|c|c|c|}
\hline Materials & MOF utilized & Application & $\begin{array}{l}\text { Rate capability } \\
\left(\mathrm{DC}^{\mathrm{a}} / \mathrm{CD}^{\mathrm{b}}\right)\end{array}$ & $\begin{array}{l}\text { Reversible capacity } \\
\text { (DC/CD) }\end{array}$ & $\begin{array}{l}\text { Cycling Stability } \\
\left(\mathrm{DC} / \mathrm{CD} / \mathrm{CN}^{\mathrm{c}}\right)\end{array}$ & Refs. \\
\hline Ni/Fe-BTC & $\mathrm{Ni} / \mathrm{Fe}-\mathrm{BTC}$ & Zn-air cathode & $\begin{array}{l}706 / 50 \\
\mathrm{~mA} \mathrm{~cm}\end{array}$ & $\begin{array}{l}775 / 10 \\
\mathrm{~mA} \mathrm{~cm}\end{array}$ & $\begin{array}{l}-/ 10 \\
\mathrm{~mA} \mathrm{~cm} \mathrm{~cm}^{-2} / 5262\end{array}$ & [177] \\
\hline $\mathrm{Ti}_{3} \mathrm{C}_{2} \mathrm{~T}_{\mathrm{x}}-\mathrm{CoBDC}$ & CoBDC & Zn-air cathode & - & - & $\begin{array}{l}-/ 0.8 \\
\mathrm{~mA} \mathrm{~cm} / 25\end{array}$ & [182] \\
\hline C-MOF-C2-900 & Co-based MOF & Zn-air cathode & $\begin{array}{l}741 / 10 \\
\mathrm{~mA} \mathrm{~cm}\end{array}$ & $\begin{array}{l}768 / 5 \\
\mathrm{~mA} \mathrm{~cm}\end{array}$ & $\begin{array}{l}-/ 2 \\
\mathrm{~mA} \mathrm{~cm}\end{array}$ & [187] \\
\hline $\mathrm{MnO} / \mathrm{Co} / \mathrm{PGC}$ & $\begin{array}{l}\text { Co/Mn- } \\
\text { MIL-100 }\end{array}$ & Zn-air cathode & - & $\begin{array}{l}873 / 5 \\
\mathrm{~mA} \mathrm{~cm}\end{array}$ & $\begin{array}{l}-/ 10 \\
\mathrm{~mA} \mathrm{~cm}\end{array}$ & [188] \\
\hline GNCNTs & ZIF-67 & Zn-air cathode & $\begin{array}{l}728 / 10 \\
\mathrm{~mA} \mathrm{~cm}\end{array}$ & $\begin{array}{l}801 / 5 \\
\mathrm{~mA} \mathrm{~cm}\end{array}$ & $\begin{array}{l}-/ 5 \\
\mathrm{~mA} \mathrm{~cm} \mathrm{~cm}^{-2} / 9000\end{array}$ & [190] \\
\hline $\mathrm{NC}-\mathrm{Co}_{3} \mathrm{O}_{4} / \mathrm{CC}$ & Co-MOF & Zn-air cathode & - & $\begin{array}{l}387 / 25 \\
\mathrm{~mA} \mathrm{~cm}^{-3}\end{array}$ & $\begin{array}{l}-/ 1 \\
\mathrm{~mA} \mathrm{~cm}-2 / 60\end{array}$ & [191] \\
\hline
\end{tabular}

${ }^{\mathrm{a}} \mathrm{DC}$ : discharge capacity $\left(\mathrm{mAh} \mathrm{g}^{-1}\right) ;{ }^{\mathrm{b}} \mathrm{CD}$ : current density; ${ }^{\mathrm{c}} \mathrm{CN}$ : cycle number

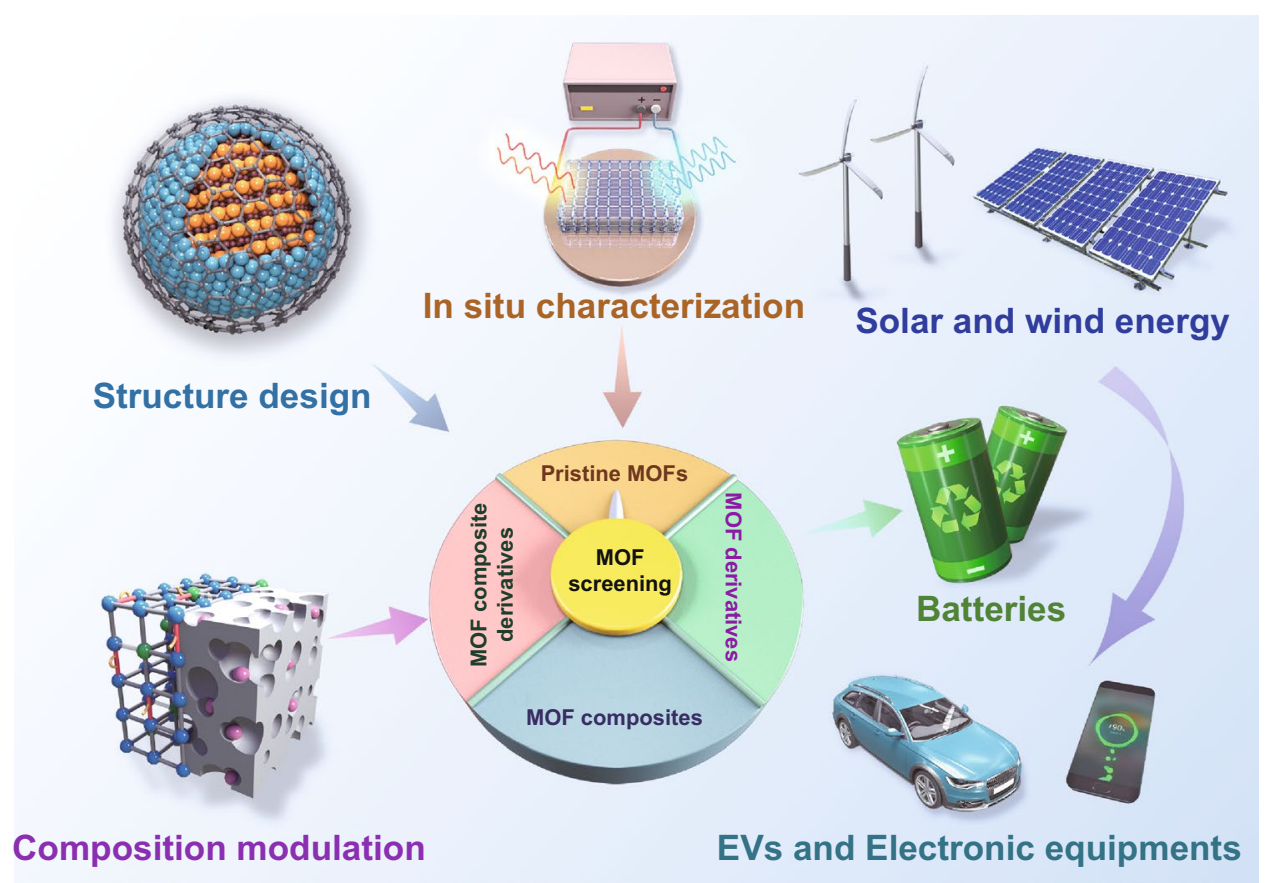

Fig. 7 Challenges of MOF-based materials for batteries, mainly including composition modulation and structure design, advanced in situ characterizations, rational MOFs screening, and practical applications

emphasized that developing efficient functional components, facile and scalable preparation procedures, and low synthetic costs would be the major challenges for MOF composite and their derivatives.

(2) Advanced in situ/operando characterization techniques are anticipated to play more significant roles in exploring the compositional and structural evolution of MOFs and revealing their charge/discharge mechanisms in new-generation batteries. To date, most reported characterizations of MOF-based batteries are ex situ characterizations. Considering the sensitivity of MOFs to air and moisture and variation of complicated battery systems, the realistic electrochemical processes (e.g., dynamic properties, interfacial reactions, and storage mechanisms) may not fully reflect under ex situ 
measurements. While the in situ characterization techniques could provide real-time information on structural evolution, valence changes, redox reaction mechanism, and SEI formation, during the operation of batteries, for example, in situ X-ray absorption or in situ infrared spectrum is used to investigate the realistic active sites, which would drive an in-depth understanding of MOF-based catalysts in $\mathrm{Li}-\mathrm{O}_{2}$ batteries and $\mathrm{Zn}$-air batteries. In situ Raman spectroscopy and in situ X-ray absorption can also be employed to investigate catalytic activity of MOFs, revealing the sulfur species conversion kinetics in $\mathrm{Li}-\mathrm{S}$ batteries.

(3) Rational screening of suitable MOFs (e.g., pristine MOFs/MOF composites and their derivatives) is of great importance for targeted next-generation battery applications. For Li-S batteries, MOFs consisting of Lewis acidic metal center ions and Lewis basic organic ligands are desirable for sulfur storage and polysulfides immobilization. MOFderived materials with polar and catalysis properties are more favorable for polysulfides confinement and transformation. The design and incorporation of multiple metal sites in MOFs or their derivatives can greatly improve catalytic activities toward ORR and OER, which are truly used as bifunctional catalyst $\mathrm{Li}-\mathrm{O}_{2}$ batteries and $\mathrm{Zn}$-air batteries. MOFs constructed with variable-valence metal center ions and redox-active organic ligands are beneficial for metal ions insertion in SIBs and PIBs, and ZIBs. For MOFs/MOF composite derivatives, integration of conductive carbon components and active metal-based species is an effective approach to prepare electrode materials for metal ion batteries. In addition, MOFs can protect the metal anode of $\mathrm{Li}$ - and Zn-based batteries. Both pristine MOFs with regular porous structure and MOF-based derivatives with lithiophilic active sites (e.g., $\mathrm{N}$ heteroatoms) can realize homogenous deposition and suppress dendrite formation of metal anode.

(4) Much more effort should be devoted to practical applications of MOF-based next-generation rechargeable batteries. Most of MOF-based energy materials can only be synthesized on the laboratory scale, which is complex and time-consuming. The development of facile and efficient approaches to the large-scale production of MOFs is still necessary. Moreover, the high cost and low yields of the MOF-based derivatives are disadvantageous to scalable production in practical applications. MOFs have shown great potential applications in new-generation batteries; however, the excellent electrochemical performance was mainly based on lab-scale (coin-type) cells. It is highly desirable to evaluate their real potentials in practical pouch cells. Although scientific researches and industrial applications of MOF-based batteries still faced challenges, it is undoubted that MOFs can serve as the high-capacity electrode materials, single ion conductor for solid-state electrolyte, or even protecting materials on metal anodes in next-generation batteries. In particular, some MOF-based materials can act as modified separators and functional interlayers to simultaneously inhibit the polysulfides and Li dendrites growth, largely facilitate the industrialization process of MOFs in Li-S battery applications [197, 198].

In conclusion, great progress of MOFs has been achieved in the field of next-generation batteries in recent years, the rational design of advanced MOF-based nanostructures/ architectures is still in the early stages of research. Most of the studies are limited to the ZIFs family (ZIF-8 and ZIF67) and PBAs. New strategies and preparation methods for synthesizing novel MOFs/MOF composites and their derivatives are more exploited for energy applications. Meanwhile, an in-depth investigation on fundamental mechanism in the electrochemical processes by in situ characterizations is highly required for future MOF-based material design and optimization. Moreover, the high cost and environmental damage of preparing MOFs still hinder their actual application, which needs further strenuous efforts in future researches. Although there are still several challenges, therefore, it is anticipated that the development of novel MOF chemistries and advanced technologies will provide numerous opportunities to achieve high-performance nextgeneration rechargeable batteries.

Acknowledgements This work was supported by the National Natural Science Foundation of China (51972030, 51772030), the S\&T Major Project of Inner Mongolia Autonomous Region in China (2020ZD0018), Beijing Outstanding Young Scientists Program (BJJWZYJH01201910007023) and Guangdong Key Laboratory of Battery Safety (2019B121203008).

Open Access This article is licensed under a Creative Commons Attribution 4.0 International License, which permits use, sharing, adaptation, distribution and reproduction in any medium or format, as long as you give appropriate credit to the original author(s) and the source, provide a link to the Creative Commons licence, and indicate if changes were made. The images or other third party material in this article are included in the article's Creative Commons licence, unless indicated otherwise in a credit line to the material. If material is not included in the article's Creative Commons licence and your intended use is not permitted by statutory regulation or exceeds the permitted use, you will need to obtain 
permission directly from the copyright holder. To view a copy of this licence, visit http://creativecommons.org/licenses/by/4.0/.

\section{References}

1. B. Dunn, H. Kamath, J.-M. Tarascon, Electrical energy storage for the grid: a battery of choices. Science 334(6058), 928-935 (2011). https://doi.org/10.1126/science.1212741

2. M.S. Whittingham, Ultimate limits to intercalation reactions for lithium batteries. Chem. Rev. 114(23), 11414-11443 (2014). https://doi.org/10.1021/cr5003003

3. P.G. Bruce, S.A. Freunberger, L.J. Hardwick, J.M. Tarascon, Li- $\mathrm{O}_{2}$ and Li-S batteries with high energy storage. Nat. Mater. 11(1), 19-29 (2012). https://doi.org/10.1038/nmat3191

4. C. Xia, C.Y. Kwok, L.F. Nazar, A high-energy-density lithium-oxygen battery based on a reversible four-electron conversion to lithium oxide. Science 361(6404), 777-781 (2018). https://doi.org/10.1126/science.aas9343

5. Y. Chen, Z. Wang, X. Li, X. Yao, C. Wang et al., Li metal deposition and stripping in a solid-state battery via coble creep. Nature 578(7794), 251-255 (2020). https://doi.org/ 10.1038/s41586-020-1972-y

6. A. Manthiram, Y.Z. Fu, S.H. Chung, C.X. Zu, Y.S. Su, Rechargeable lithium-sulfur batteries. Chem. Rev. 114(23), 11751-11787 (2014). https://doi.org/10.1021/cr500062v

7. L. Zhang, D. Liu, Z. Muhammad, F. Wan, W. Xie et al., Single nickel atoms on nitrogen-doped graphene enabling enhanced kinetics of lithium-sulfur batteries. Adv. Mater. 31(40), 1903955 (2019). https://doi.org/10.1002/adma.20190 3955

8. Z. Ye, Y. Jiang, T. Feng, Z. Wang, L. Li et al., Curbing polysulfide shuttling by synergistic engineering layer composed of supported $\mathrm{Sn}_{4} \mathrm{P}_{3}$ nanodots electrocatalyst in lithium-sulfur batteries. Nano Energy 70, 104532 (2020). https://doi.org/10. 1016/j.nanoen.2020.104532

9. J.-S. Lee, S. Tai Kim, R. Cao, N.-S. Choi, M. Liu et al., Metal-air batteries with high energy density: Li-air versus Zn-air. Adv. Energy Mater. 1(1), 34-50 (2011). https://doi. org/10.1002/aenm.201000010

10. L. Jiang, Y. Lu, C. Zhao, L. Liu, J. Zhang et al., Building aqueous K-ion batteries for energy storage. Nat. Energy 4(6), 495-503 (2019). https://doi.org/10.1038/s41560-019-0388-0

11. F. Wu, Y. Jiang, Z. Ye, Y. Huang, Z. Wang et al., A 3D flowerlike $\mathrm{VO}_{2}$ /Mxene hybrid architecture with superior anode performance for sodium ion batteries. J. Mater. Chem. A 7(3), 1315-1322 (2019). https://doi.org/10.1039/c8ta11419f

12. H.J. Huang, R. Xu, Y.Z. Feng, S.F. Zeng, Y. Jiang et al., Sodium/potassium-ion batteries: boosting the rate capability and cycle life by combining morphology, defect and structure engineering. Adv. Mater. 32(8), 1904320 (2020). https://doi. org/10.1002/adma.201904320

13. Y.-P. Deng, R. Liang, G. Jiang, Y. Jiang, A. Yu et al., The current state of aqueous $\mathrm{Zn}$-based rechargeable batteries. ACS
Energy Lett. 5(5), 1665-1675 (2020). https://doi.org/10.1021/ acsenergylett.0c00502

14. L.E. Blanc, D. Kundu, L.F. Nazar, Scientific challenges for the implementation of Zn-ion batteries. Joule 4(4), 771-799 (2020). https://doi.org/10.1016/j.joule.2020.03.002

15. H. Jia, Z. Wang, B. Tawiah, Y. Wang, C.-Y. Chan et al., Recent advances in zinc anodes for high-performance aqueous Zn-ion batteries. Nano Energy 70, 104523 (2020). https:// doi.org/10.1016/j.nanoen.2020.104523

16. H. Zheng, Y. Zhang, L. Liu, W. Wan, P. Guo et al., One-pot synthesis of metal organic frameworks with encapsulated target molecules and their applications for controlled drug delivery. J. Am. Chem. Soc. 138(3), 962-968 (2016). https:// doi.org/10.1021/jacs.5b11720

17. M.H. Teplensky, M. Fantham, C. Poudel, C. Hockings, M. $\mathrm{Lu}$ et al., A highly porous metal-organic framework system to deliver payloads for gene knockdown. Chem 5(11), 29262941 (2019). https://doi.org/10.1016/j.chempr.2019.08.015

18. S. Yuan, X. Sun, J. Pang, C. Lollar, J.-S. Qin et al., PCN250 under pressure: sequential phase transformation and the implications for MOF densification. Joule 1(4), 806-815 (2017). https://doi.org/10.1016/j.joule.2017.09.001

19. Y. Liu, G. Liu, C. Zhang, W. Qiu, S. Yi et al., Enhanced $\mathrm{CO}_{2} /$ $\mathrm{CH}_{4}$ separation performance of a mixed matrix membrane based on tailored MOF-polymer formulations. Adv. Sci. 5(9), 1800982 (2018). https://doi.org/10.1002/advs.201800982

20. C.-C. Hou, Q. Xu, Metal-organic frameworks for energy. Adv. Energy Mater. 9(23), 1801307 (2018). https://doi.org/ 10.1002/aenm.201801307

21. Z. Li, X. Ge, C. Li, S. Dong, R. Tang et al., Rational microstructure design on metal-organic framework composites for better electrochemical performances: design principle, synthetic strategy, and promotion mechanism. Small Methods 4(3), 1900756 (2020). https://doi.org/10.1002/smtd.20190 0756

22. J. Haoqing, L. Xiao-Chen, W. Yushan, S. Yufei, G. Xuan et al., Metal-organic frameworks for high charge-discharge rates in lithium-sulfur batteries. Angew. Chem. Int. Ed. 57(15), 3916-3921 (2018). https://doi.org/10.1002/anie. 201712872

23. S. Kitagawa, R. Kitaura, S.-I. Noro, Functional porous coordination polymers. Angew. Chem. Int. Ed. 43(18), 2334-2375 (2004). https://doi.org/10.1002/anie.200300610

24. J. Meng, X. Liu, C. Niu, Q. Pang, J. Li et al., Advances in metal-organic framework coatings: versatile synthesis and broad applications. Chem. Soc. Rev. 49, 3142-3186 (2020). https://doi.org/10.1039/c9cs00806c

25. S.H. Ahn, A. Manthiram, Cobalt phosphide coupled with heteroatom-doped nanocarbon hybrid electroctalysts for efficient, long-life rechargeable zinc-air batteries. Small 13(40), 1702068 (2017). https://doi.org/10.1002/smll.201702068

26. S. Dang, Q.-L. Zhu, Q. Xu, Nanomaterials derived from metal-organic frameworks. Nat. Rev. Mater. 3(1), 17075 (2017). https://doi.org/10.1038/natrevmats.2017.75 
27. Y. Li, R. Cao, L. Li, X. Tang, T. Chu et al., Simultaneously integrating single atomic cobalt sites and $\mathrm{Co}_{9} \mathrm{~S}_{8}$ nanoparticles into hollow carbon nanotubes as trifunctional electrocatalysts for $\mathrm{Zn}$-air batteries to drive water splitting. Small 16(10), 1906735 (2020). https://doi.org/10.1002/smll.201906735

28. R. Demir-Cakan, M. Morcrette, F. Nouar, C. Davoisne, T. Devic et al., Cathode composites for $\mathrm{Li}-\mathrm{S}$ batteries via the use of oxygenated porous architectures. J. Am. Chem. Soc. 133(40), 16154-16160 (2011). https://doi.org/10.1021/ja206 2659

29. J.M. Zheng, J. Tian, D.X. Wu, M. Gu, W. Xu et al., Lewis acid-base interactions between polysulfides and metal organic framework in lithium sulfur batteries. Nano Lett. 14(5), 2345-2352 (2014). https://doi.org/10.1021/nl404721h

30. Y. Zang, F. Pei, J. Huang, Z. Fu, G. Xu et al., Large-area preparation of crack-free crystalline microporous conductive membrane to upgrade high energy lithium-sulfur batteries. Adv. Energy Mater. 8(31), 1802052 (2018). https://doi.org/ 10.1002/aenm.201802052

31. M. Tian, F. Pei, M. Yao, Z. Fu, L. Lin et al., Ultrathin MOF nanosheet assembled highly oriented microporous membrane as an interlayer for lithium-sulfur batteries. Energy Storage Mater. 21, 14-21 (2019). https://doi.org/10.1016/j.ensm. 2018.12.016

32. Y. He, Z. Chang, S. Wu, Y. Qiao, S. Bai et al., Simultaneously inhibiting lithium dendrites growth and polysulfides shuttle by a flexible MOF-based membrane in Li-S batteries. Adv. Energy Mater. 8(34), 1802130 (2018). https://doi.org/ 10.1002/aenm.201802130

33. J. Qian, Y. Li, M. Zhang, R. Luo, F. Wang et al., Protecting lithium/sodium metal anode with metal-organic framework based compact and robust shield. Nano Energy 60, 866-874 (2019). https://doi.org/10.1016/j.nanoen.2019.04.030

34. M. Rana, H.A. Al-Fayaad, B. Luo, T. Lin, L. Ran et al., Oriented nanoporous MOFs to mitigate polysulfides migration in lithium-sulfur batteries. Nano Energy 75, 105009 (2020). https://doi.org/10.1016/j.nanoen.2020.105009

35. H. Zhang, W. Zhao, M. Zou, Y. Wang, Y. Chen et al., 3D, mutually embedded MOF@ carbon nanotube hybrid networks for high-performance lithium-sulfur batteries. Adv. Energy Mater. 8(19), 1800013 (2018). https://doi.org/10.1002/aenm. 201800013

36. S.Y. Bai, X.Z. Liu, K. Zhu, S.C. Wu, H.S. Zhou, Metalorganic framework-based separator for lithium-sulfur batteries. Nat. Energy 1, 6 (2016). https://doi.org/10.1038/nenergy. 2016.94

37. Y.Y. Mao, G.R. Li, Y. Guo, Z.P. Li, C.D. Liang et al., Foldable interpenetrated metal-organic frameworks/carbon nanotubes thin film for lithium-sulfur batteries. Nat. Commun. 8, 8 (2017). https://doi.org/10.1038/ncomms 14628

38. A.E. Baumann, J.R. Downing, D.A. Burns, M.C. Hersam, V.S. Thoi, Graphene-metal-organic framework composite sulfur electrodes for $\mathrm{Li}-\mathrm{S}$ batteries with high volumetric capacity. ACS Appl. Mater. Interfaces 12(33), 37173-37181 (2020). https://doi.org/10.1021/acsami.0c09622
39. C. Wu, S. Gu, Q. Zhang, Y. Bai, M. Li et al., Electrochemically activated spinel manganese oxide for rechargeable aqueous aluminum battery. Nat. Commun. 10(1), 73 (2019). https://doi.org/10.1038/s41467-018-07980-7

40. B. Liu, M. Taheri, J.F. Torres, Z. Fusco, T. Lu et al., Janus conductive/insulating microporous ion-sieving membranes for stable Li-S batteries. ACS Nano 14(10), 13852-13864 (2020). https://doi.org/10.1021/acsnano.0c06221

41. B. Liu, R. Bo, M. Taheri, I. Di Bernardo, N. Motta et al., Metal-organic frameworks/conducting polymer hydrogel integrated three-dimensional free-standing monoliths as ultrahigh loading Li-S battery electrodes. Nano Lett. 19(7), 4391-4399 (2019). https://doi.org/10.1021/acs.nanolett. $9 \mathrm{~b} 01033$

42. P. Chiochan, X. Yu, M. Sawangphruk, A. Manthiram, A metal organic framework derived solid electrolyte for lithium-sulfur batteries. Adv. Energy Mater. 10(27), 2001285 (2020). https://doi.org/10.1002/aenm.202001285

43. B. Liu, V.S. Thoi, Improving charge transfer in metal-organic frameworks through open site functionalization and porosity selection for Li-S batteries. Chem. Mater. 32(19), 8450-8459 (2020). https://doi.org/10.1021/acs.chemmater.0c02438

44. A.E. Baumann, X. Han, M.M. Butala, V.S. Thoi, Lithium thiophosphate functionalized zirconium MOFs for Li-S batteries with enhanced rate capabilities. J. Am. Chem. Soc. 141(44), 17891-17899 (2019). https://doi.org/10.1021/jacs.9b09538

45. Z. Chang, Y. Qiao, J. Wang, H. Deng, P. He et al., Fabricating better metal-organic frameworks separators for Li-S batteries: pore sizes effects inspired channel modification strategy. Energy Storage Mater. 25, 164-171 (2020). https://doi.org/ 10.1016/j.ensm.2019.10.018

46. Z. Wang, W. Huang, J. Hua, Y. Wang, H. Yi et al., An anionic-mof-based bifunctional separator for regulating lithium deposition and suppressing polysulfides shuttle in $\mathrm{Li}-\mathrm{S}$ batteries. Small Methods 4(7), 2000082 (2020). https://doi.org/ 10.1002/smtd.202000082

47. Y. Li, S. Lin, D. Wang, T. Gao, J. Song et al., Single atom array mimic on ultrathin MOF nanosheets boosts the safety and life of lithium-sulfur batteries. Adv. Mater. 32(8), 1906722 (2020). https://doi.org/10.1002/adma.201906722

48. G.K. Gao, Y.R. Wang, S.B. Wang, R.X. Yang, Y. Chen et al., Stepped channels integrated lithium-sulfur separator via photoinduced multidimensional fabrication of metal-organic frameworks. Angew. Chem. Int. Ed. 60(18), 10147-10154 (2021). https://doi.org/10.1002/anie.202016608

49. D.-D. Han, Z.-Y. Wang, G.-L. Pan, X.-P. Gao, Metal-organicframework-based gel polymer electrolyte with immobilized anions to stabilize a lithium anode for a quasi-solid-state lithium-sulfur battery. ACS Appl. Mater. Interfaces 11(20), 18427-18435 (2019). https://doi.org/10.1021/acsami.9b036 82

50. Y.J. Li, J.M. Fan, M.S. Zheng, Q.F. Dong, A novel synergistic composite with multi-functional effects for high-performance Li-S batteries. Energy Environ. Sci. 9(6), 1998-2004 (2016). https://doi.org/10.1039/c6ee00104a 
51. Y. Wu, X. Zhu, P. Li, T. Zhang, M. Li et al., Ultradispersed WxC nanoparticles enable fast polysulfide interconversion for high-performance Li-S batteries. Nano Energy 59, 636-643 (2019). https://doi.org/10.1016/j.nanoen.2019.03.015

52. G. Chen, Y. Li, W. Zhong, F. Zheng, J. Hu et al., MOFsderived porous $\mathrm{Mo}_{2} \mathrm{C}-\mathrm{C}$ nano-octahedrons enable high-performance lithium-sulfur batteries. Energy Storage Mater. 25, 547-554 (2020). https://doi.org/10.1016/j.ensm.2019.09.028

53. S.D. Seo, D. Park, S. Park, D.W. Kim, "Brain-coral-like" mesoporous hollow $\mathrm{CoS}_{2} @ \mathrm{~N}$-doped graphitic carbon nanoshells as efficient sulfur reservoirs for lithium-sulfur batteries. Adv. Funct. Mater. 29(38), 1903712 (2019). https:// doi.org/10.1002/adfm.201903712

54. Y.X. Tian, H.W. Huang, G.X. Liu, R. Bi, L. Zhang, Metalorganic framework derived yolk-shell $\mathrm{NiS}_{2} /$ carbon spheres for lithium-sulfur batteries with enhanced polysulfide redox kinetics. Chem. Commun. 55(22), 3243-3246 (2019). https:// doi.org/10.1039/c9cc00486f

55. Z. Sun, S. Vijay, H.H. Heenen, A.Y.S. Eng, W. Tu et al., Catalytic polysulfide conversion and physiochemical confinement for lithium-sulfur batteries. Adv. Energy Mater. 10(22), 1904010 (2020). https://doi.org/10.1002/aenm.201904010

56. Z. Ye, Y. Jiang, J. Qian, W. Li, T. Feng et al., Exceptional adsorption and catalysis effects of hollow polyhedra/carbon nanotube confined CoP nanoparticles superstructures for enhanced lithium-sulfur batteries. Nano Energy 64, 103965 (2019). https://doi.org/10.1016/j.nanoen.2019.103965

57. S.-D. Seo, C. Choi, D. Park, D.-Y. Lee, S. Park et al., Metalorganic-framework-derived 3D crumpled carbon nanosheets with self-assembled $\mathrm{Co}_{\mathrm{x}} \mathrm{S}_{\mathrm{y}}$ nanocatalysts as an interlayer for lithium-sulfur batteries. Chem. Eng. J. 400, 125959 (2020). https://doi.org/10.1016/j.cej.2020.125959

58. J. Cai, Y. Song, X. Chen, Z. Sun, Y. Yi et al., MOF-derived conductive carbon nitrides for separator-modified Li-S batteries and flexible supercapacitors. J. Mater. Chem. A 8(4), 1757-1766 (2020). https://doi.org/10.1039/C9TA11958B

59. J. He, Y. Chen, A. Manthiram, Vertical $\mathrm{Co}_{9} \mathrm{~S}_{8}$ hollow nanowall arrays grown on celgard separator as a multifunctional polysulfide barrier for high-performance Li-S batteries. Energy Environ. Sci. 11(9), 2560-2568 (2018). https://doi. org/10.1039/C8EE00893K

60. X.-J. Hong, C.-L. Song, Z.-M. Wu, Z.-H. Li, Y.-P. Cai et al., Sulfophilic and lithophilic sites in bimetal nickel-zinc carbide with fast conversion of polysulfides for high-rate Li-S battery. Chem. Eng. J. 404, 126566 (2021). https://doi.org/10.1016/j. cej.2020.126566

61. Y. Zhong, F. Lin, M. Wang, Y. Zhang, Q. Ma et al., Metal organic framework derivative improving lithium metal anode cycling. Adv. Funct. Mater. 30(10), 1907579 (2020). https:// doi.org/10.1002/adfm.201907579

62. K. Chen, Z. Sun, R. Fang, Y. Shi, H.-M. Cheng et al., Metalorganic frameworks (MOFs)-derived nitrogen-doped porous carbon anchored on graphene with multifunctional effects for lithium-sulfur batteries. Adv. Funct. Mater. 28(38), 1707592 (2018). https://doi.org/10.1002/adfm.201707592
63. D. Fang, Y. Wang, X. Liu, J. Yu, C. Qian et al., Spider-webinspired nanocomposite-modified separator: Structural and chemical cooperativity inhibiting the shuttle effect in Li-S batteries. ACS Nano 13(2), 1563-1573 (2019). https://doi. org/10.1021/acsnano.8b07491

64. R. Wang, J. Yang, X. Chen, Y. Zhao, W. Zhao et al., Highly dispersed cobalt clusters in nitrogen-doped porous carbon enable multiple effects for high-performance Li-S battery. Adv. Energy Mater. 10(9), 1903550 (2020). https://doi.org/ 10.1002/aenm.201903550

65. W. Cai, G. Li, D. Luo, G. Xiao, S. Zhu et al., The dual-play of $3 \mathrm{D}$ conductive scaffold embedded with $\mathrm{Co}, \mathrm{N}$ codoped hollow polyhedra toward high-performance $\mathrm{Li}-\mathrm{S}$ full cell. Adv. Energy Mater. 8(34), 1802561 (2018). https://doi.org/ 10.1002/aenm.201802561

66. W. Li, J. Qian, T. Zhao, Y. Ye, Y. Xing et al., Boosting highrate $\mathrm{Li}-\mathrm{S}$ batteries by an MOF-derived catalytic electrode with a layer-by-layer structure. Adv. Sci. 6(16), 1802362 (2019). https://doi.org/10.1002/advs.201802362

67. Z. Wang, J. Shen, J. Liu, X. Xu, Z. Liu et al., Self-supported and flexible sulfur cathode enabled via synergistic confinement for high-energy-density lithium-sulfur batteries. Adv. Mater. 31(33), 1902228 (2019). https://doi.org/10.1002/ adma.201902228

68. L. Zhang, Y. Liu, Z. Zhao, P. Jiang, T. Zhang et al., Enhanced polysulfide regulation via porous catalytic $\mathrm{V}_{2} \mathrm{O}_{3} / \mathrm{V}_{8} \mathrm{C}_{7}$ heterostructures derived from metal-organic frameworks toward high-performance Li-S batteries. ACS Nano 14(7), 84958507 (2020). https://doi.org/10.1021/acsnano.0c02762

69. X. Yang, X. Gao, Q. Sun, S.P. Jand, Y. Yu et al., Promoting the transformation of $\mathrm{Li}_{2} \mathrm{~S}_{2}$ to $\mathrm{Li}_{2} \mathrm{~S}$ : significantly increasing utilization of active materials for high-sulfur-loading Li-S batteries. Adv. Mater. 31(25), 1901220 (2019). https://doi. org/10.1002/adma.201901220

70. Z. Ye, Y. Jiang, L. Li, F. Wu, R. Chen, A high-efficiency CoSe electrocatalyst with hierarchical porous polyhedron nanoarchitecture for accelerating polysulfides conversion in Li-S batteries. Adv. Mater. 32(32), 2002168 (2020). https:// doi.org/10.1002/adma.202002168

71. Q. Wu, Z. Yao, X. Zhou, J. Xu, F. Cao et al., Built-in catalysis in confined nanoreactors for high-loading Li-S batteries. ACS Nano 14(3), 3365-3377 (2020). https://doi.org/10.1021/acsna no. 9 b09231

72. B. Fei, C. Zhang, D. Cai, J. Zheng, Q. Chen et al., Hierarchical nanoreactor with multiple adsorption and catalytic sites for robust lithium-sulfur batteries. ACS Nano 15(4), 68496860 (2021). https://doi.org/10.1021/acsnano.0c10603

73. Z. Ye, Y. Jiang, L. Li, F. Wu, R. Chen, Self-assembly of OD-2D heterostructure electrocatalyst from MOF and MXene for boosted lithium polysulfide conversion reaction. Adv. Mater. 33(33), 2101204 (2021). https://doi.org/10.1002/ adma.202101204

74. R. Liu, Z. Liu, W. Liu, Y. Liu, X. Lin et al., $\mathrm{TiO}_{2}$ and $\mathrm{Co}$ nanoparticle-decorated carbon polyhedra as efficient sulfur host for high-performance lithium-sulfur batteries. Small 
15(29), 1804533 (2019). https://doi.org/10.1002/smll.20180 4533

75. S. Chen, J. Luo, N. Li, X. Han, J. Wang et al., Multifunctional $\mathrm{LDH} / \mathrm{Co}_{9} \mathrm{~S}_{8}$ heterostructure nanocages as high-performance lithium-sulfur battery cathodes with ultralong lifespan. Energy Storage Mater. 30, 187-195 (2020). https://doi.org/ 10.1016/j.ensm.2020.05.002

76. J. Zhang, G. Li, Y. Zhang, W. Zhang, X. Wang et al., Vertically rooting multifunctional tentacles on carbon scaffold as efficient polysulfide barrier toward superior lithium-sulfur batteries. Nano Energy 64, 103905 (2019). https://doi.org/ 10.1016/j.nanoen.2019.103905

77. H. Li, Y. Wang, H. Chen, B. Niu, W. Zhang et al., Synergistic mediation of polysulfide immobilization and conversion by a catalytic and dual-adsorptive system for high performance lithium-sulfur batteries. Chem. Eng. J. 406, 126802 (2021). https://doi.org/10.1016/j.cej.2020.126802

78. B. Guan, Y. Zhang, L. Fan, X. Wu, M. Wang et al., Blocking polysulfide with $\mathrm{Co}_{2} \mathrm{~B} @ \mathrm{CNT}$ via "synergetic adsorptive effect" toward ultrahigh-rate capability and robust lithiumsulfur battery. ACS Nano 13(6), 6742-6750 (2019). https:// doi.org/10.1021/acsnano.9b01329

79. H. Shi, X. Ren, J. Lu, C. Dong, J. Liu et al., Dual-functional atomic zinc decorated hollow carbon nanoreactors for kinetically accelerated polysulfides conversion and dendrite free lithium sulfur batteries. Adv. Energy Mater. 10(39), 2002271 (2020). https://doi.org/10.1002/aenm.202002271

80. S.H. Liu, J. Li, X. Yan, Q.F. Su, Y.H. Lu et al., Superhierarchical cobalt-embedded nitrogen-doped porous carbon nanosheets as two-in-one hosts for high-performance lithiumsulfur batteries. Adv. Mater. 30(12), 9 (2018). https://doi.org/ 10.1002/adma.201706895

81. D. Wu, Z. Guo, X. Yin, Q. Pang, B. Tu et al., Metal-organic frameworks as cathode materials for $\mathrm{Li}-\mathrm{O}_{2}$ batteries. Adv. Mater. 26(20), 3258 (2014). https://doi.org/10.1002/adma. 201305492

82. S.H. Kim, Y.J. Lee, D.H. Kim, Y.J. Lee, Bimetallic metalorganic frameworks as efficient cathode catalysts for Li$\mathrm{O}_{2}$ batteries. ACS Appl. Mater. Interfaces 10(1), 660-667 (2018). https://doi.org/10.1021/acsami.7b15499

83. S. Yuan, J.L. Bao, J. Wei, Y. Xia, D.G. Truhlar et al., A versatile single-ion electrolyte with a grotthuss-like Li conduction mechanism for dendrite-free Li metal batteries. Energy Environ. Sci. 12(9), 2741-2750 (2019). https://doi.org/10. 1039/c9ee01473j

84. X. Zhang, P. Dong, J.-I. Lee, J.T. Gray, Y.-H. Cha et al., Enhanced cycling performance of rechargeable $\mathrm{Li}-\mathrm{O}_{2}$ batteries via $\mathrm{LiOH}$ formation and decomposition using high-performance MOF-74@CNTs hybrid catalysts. Energy Storage Mater. 17, 167-177 (2019). https://doi.org/10.1016/j.ensm. 2018.11.014

85. W.H. Choi, B.C. Moon, D.G. Park, J.W. Choi, K.H. Kim et al., Autogenous production and stabilization of highly loaded sub-nanometric particles within multishell hollow metal-organic frameworks and their utilization for high performance in $\mathrm{Li}-\mathrm{O}_{2}$ batteries. Adv. Sci. 7(9), 2000283 (2020). https://doi.org/10.1002/advs.202000283

86. L. Cao, F. Lv, Y. Liu, W. Wang, Y. Huo et al., A high performance $\mathrm{O}_{2}$ selective membrane based on CAU-L-NH $\mathrm{NH}_{2}$ polydopamine and the pmma polymer for $\mathrm{Li}$-air batteries. Chem. Commun. 51(21), 4364-4367 (2015). https://doi.org/ 10.1039/C4CC09281C

87. Y. Qiao, Y. He, S. Wu, K. Jiang, X. Li et al., MOF-based separator in an $\mathrm{Li}_{-} \mathrm{O}_{2}$ battery: an effective strategy to restrain the shuttling of dual redox mediators. ACS Energy Lett. 3(2), 463-468 (2018). https://doi.org/10.1021/acsenergylett.8b000 14

88. Q. Li, P. Xu, W. Gao, S. Ma, G. Zhang et al., Graphene/graphene-tube nanocomposites templated from cage-containing metal-organic frameworks for oxygen reduction in $\mathrm{Li}-\mathrm{O}_{2}$ batteries. Adv. Mater. 26(9), 1378-1386 (2014). https://doi.org/ 10.1002/adma.201304218

89. G. Tan, L. Chong, R. Amine, J. Lu, C. Liu et al., Toward highly efficient electrocatalyst for $\mathrm{Li}-\mathrm{O}_{2}$ batteries using biphasic N-doping cobalt@graphene multiple-capsule heterostructures. Nano Lett. 17(5), 2959-2966 (2017). https:// doi.org/10.1021/acs.nanolett.7b00207

90. J. Tang, S. Wu, T. Wang, H. Gong, H. Zhang et al., Cagetype highly graphitic porous carbon- $\mathrm{Co}_{3} \mathrm{O}_{4}$ polyhedron as the cathode of lithium-oxygen batteries. ACS Appl. Mater. Interfaces 8(4), 2796-2804 (2016). https://doi.org/10.1021/ acsami.5b11252

91. H. Gong, H. Xue, X. Lu, B. Gao, T. Wang et al., All solidstate lithium-oxygen batteries with MOF-derived nickel cobaltate nanoflake arrays as high-performance oxygen cathodes. Chem. Commun. 55(72), 10689-10692 (2019). https:// doi.org/10.1039/c9cc05685h

92. W. Yin, Y. Shen, F. Zou, X. Hu, B. Chi et al., Metal-organic framework derived $\mathrm{ZnO} / \mathrm{ZnFe}_{2} \mathrm{O}_{4} / \mathrm{C}$ nanocages as stable cathode material for reversible lithium-oxygen batteries. ACS Appl. Mater. Interfaces 7(8), 4947-4954 (2015). https://doi. org/10.1021/am509143t

93. Y. Dou, R. Lian, Y. Zhang, Y. Zhao, G. Chen et al., $\mathrm{Co}_{9} \mathrm{~S}_{8} @$ carbon porous nanocages derived from a metal-organic framework: a highly efficient bifunctional catalyst for aprotic Li-O $\mathrm{O}_{2}$ batteries. J. Mater. Chem. A 6(18), 8595-8603 (2018). https://doi.org/10.1039/C8TA01913D

94. H. Wang, F.-X. Yin, N. Liu, R.-H. Kou, X.-B. He et al., Engineering $\mathrm{Fe}-\mathrm{Fe}_{3} \mathrm{C} @ \mathrm{Fe}-\mathrm{N}-\mathrm{C}$ active sites and hybrid structures from dual metal-organic frameworks for oxygen reduction reaction in $\mathrm{H}_{2} \mathrm{O}_{2}$ fuel cell and $\mathrm{Li}-\mathrm{O}_{2}$ battery. Adv. Funct. Mater. 29(23), 1901531 (2019). https://doi.org/10.1002/adfm. 201901531

95. P. Wang, Y. Ren, R. Wang, P. Zhang, M. Ding et al., Atomically dispersed cobalt catalyst anchored on nitrogen-doped carbon nanosheets for lithium-oxygen batteries. Nat. Commun. 11(1), 1576 (2020). https://doi.org/10.1038/ s41467-020-15416-4

96. P. Hien Thi Thu, Y. Kim, Y.-J. Kim, J.-W. Lee, M.-S. Park, Robust design of dual-phasic carbon cathode for 
lithium-oxygen batteries. Adv. Funct. Mater. 29(31), 1902915 (2019). https://doi.org/10.1002/adfm.201902915

97. W.M. Zhang, X.Y. Yao, S.N. Zhou, X.W. Li, L. Li et al., ZIF-8/ZIF-67-derived Co- $\mathrm{N}_{\mathrm{x}}$-embedded 1D porous carbon nanofibers with graphitic carbon-encased Co nanoparticles as an efficient bifunctional electrocatalyst. Small 14(24), 1800423 (2018). https://doi.org/10.1002/smll.201800423

98. Z. Lyu, G.J.H. Lim, R. Guo, Z. Kou, T. Wang et al., 3D-printed MOF-derived hierarchically porous frameworks for practical high-energy density $\mathrm{Li}-\mathrm{O}_{2}$ batteries. Adv. Funct. Mater. 29(1), 1806658 (2019). https://doi.org/10.1002/adfm. 201806658

99. X. Hu, G. Luo, Q. Zhao, D. Wu, T. Yang et al., Ru single atoms on $\mathrm{N}$-doped carbon by spatial confinement and ionic substitution strategies for high-performance $\mathrm{Li}_{-} \mathrm{O}_{2}$ batteries. J. Am. Chem. Soc. 142(39), 16776-16786 (2020). https://doi. org/10.1021/jacs.0c07317

100. Y. Lu, L. Wang, J. Cheng, J.B. Goodenough, Prussian blue: A new framework of electrode materials for sodium batteries. Chem. Commun. 48(52), 6544-6546 (2012). https://doi.org/ 10.1039/C2CC31777J

101. L. Wang, Y. Lu, J. Liu, M. Xu, J. Cheng et al., A superior low-cost cathode for a Na-ion battery. Angew. Chem. In. Ed. 52(7), 1964-1967 (2013). https://doi.org/10.1002/anie.20120 6854

102. Y. You, X.-L. Wu, Y.-X. Yin, Y.-G. Guo, High-quality prussian blue crystals as superior cathode materials for roomtemperature sodium-ion batteries. Energy Environ. Sci. 7(5), 1643-1647 (2014). https://doi.org/10.1039/C3EE44004D

103. J. Song, L. Wang, Y. Lu, J. Liu, B. Guo et al., Removal of interstitial $\mathrm{H}_{2} \mathrm{O}$ in hexacyanometallates for a superior cathode of a sodium-ion battery. J. Am. Chem. Soc. 137(7), 26582664 (2015). https://doi.org/10.1021/ja512383b

104. X. Wu, W. Deng, J. Qian, Y. Cao, X. Ai et al., Single-crystal $\mathrm{FeFe}(\mathrm{CN})_{6}$ nanoparticles: a high capacity and high rate cathode for Na-ion batteries. J. Mater. Chem. A 1(35), 1013010134 (2013). https://doi.org/10.1039/C3TA12036H

105. Y. Ma, Y. Ma, S.L. Dreyer, Q. Wang, K. Wang et al., Highentropy metal-organic frameworks for highly reversible sodium storage. Adv. Mater. (2021). https://doi.org/10.1002/ adma.202101342

106. H.-W. Lee, R.Y. Wang, M. Pasta, S. Woo Lee, N. Liu et al., Manganese hexacyanomanganate open framework as a highcapacity positive electrode material for sodium-ion batteries. Nat. Commun. 5(1), 5280 (2014). https://doi.org/10.1038/ ncomms6280

107. Y. Yue, A.J. Binder, B. Guo, Z. Zhang, Z.A. Qiao et al., Mesoporous prussian blue analogues: template-free synthesis and sodium-ion battery applications. Angew. Chem. Int. Ed. 53(12), 3134-3137 (2014). https://doi.org/10.1002/anie. 201310679

108. Y. Tang, W. Li, P. Feng, M. Zhou, K. Wang et al., Highperformance manganese hexacyanoferrate with cubic structure as superior cathode material for sodium-ion batteries. Adv. Funct. Mater. 30(10), 1908754 (2020). https://doi.org/ 10.1002/adfm.201908754
109. C. Li, Q. Yang, M. Shen, J.Y. Ma, B.W. Hu, The electrochemical $\mathrm{Na}$ intercalation/extraction mechanism of ultrathin cobalt(ii) terephthalate-based MOF nanosheets revealed by synchrotron X-ray absorption spectroscopy. Energy Storage Mater. 14, 82-89 (2018). https://doi.org/10.1016/j.ensm. 2018.02.021

110. J. Park, M. Lee, D.W. Feng, Z.H. Huang, A.C. Hinckley et al., Stabilization of hexaaminobenzene in a 2D conductive metalorganic framework for high power sodium storage. J. Am. Chem. Soc. 140(32), 10315-10323 (2018). https://doi.org/ 10.1021/jacs.8b06020

111. Y. Liu, X. Zhao, C. Fang, Z. Ye, Y.-B. He et al., Activating aromatic rings as $\mathrm{Na}$-ion storage sites to achieve high capacity. Chem 4(10), 2463-2478 (2018). https://doi.org/10.1016/j. chempr.2018.08.015

112. Y. Jiang, S. Yu, B. Wang, Y. Li, W. Sun et al., Prussian blue@C composite as an ultrahigh-rate and long-life sodiumion battery cathode. Adv. Funct. Mater. 26(29), 5315-5321 (2016). https://doi.org/10.1002/adfm.201600747

113. Y. You, H.-R. Yao, S. Xin, Y.-X. Yin, T.-T. Zuo et al., Subzero-temperature cathode for a sodium-ion battery. Adv. Mater. 28(33), 7243-7248 (2016). https://doi.org/10.1002/ adma.201600846

114. J. Luo, S. Sun, J. Peng, B. Liu, Y. Huang et al., Graphene-rollwrapped prussian blue nanospheres as a high-performance binder-free cathode for sodium-ion batteries. ACS Appl. Mater. Interfaces 9(30), 25317-25322 (2017). https://doi. org/10.1021/acsami.7b06334

115. Y. Huang, C. Fang, R. Zeng, Y. Liu, W. Zhang et al., In situformed hierarchical metal-organic flexible cathode for highenergy sodium-ion batteries. Chemsuschem 10(23), 47044708 (2017). https://doi.org/10.1002/cssc.201701484

116. Y. Mao, Y. Chen, J. Qin, C. Shi, E. Liu et al., Capacitance controlled, hierarchical porous 3D ultra-thin carbon networks reinforced prussian blue for high performance Na-ion battery cathode. Nano Energy 58, 192-201 (2019). https://doi.org/10. 1016/j.nanoen.2019.01.048

117. Y. Tang, W. Zhang, L. Xue, X. Ding, T. Wang et al., Polypyrrole-promoted superior cyclability and rate capability of $\mathrm{Na}_{\mathrm{x}} \mathrm{Fe}\left[\mathrm{Fe}(\mathrm{CN})_{6}\right]$ cathodes for sodium-ion batteries. J. Mater. Chem. A 4(16), 6036-6041 (2016). https://doi.org/10.1039/ C6TA00876C

118. W.-J. Li, S.-L. Chou, J.-Z. Wang, J.-L. Wang, Q.-F. Gu et al., Multifunctional conducing polymer coated $\mathrm{Na}_{1+\mathrm{x}} \mathrm{MnFe}(\mathrm{CN})_{6}$ cathode for sodium-ion batteries with superior performance via a facile and one-step chemistry approach. Nano Energy 13, 200-207 (2015). https://doi.org/10.1016/j.nanoen.2015. 02.019

119. Q. Qu, J. Yun, Z. Wan, H. Zheng, T. Gao et al., MOF-derived microporous carbon as a better choice for Na-ion batteries than mesoporous CMK-3. RSC Adv. 4(110), 64692-64697 (2014). https://doi.org/10.1039/c4ra11009a

120. X. Shi, Y. Chen, Y. Lai, K. Zhang, J. Li et al., Metal organic frameworks templated sulfur-doped mesoporous carbons as anode materials for advanced sodium ion batteries. Carbon 
123, 250-258 (2017). https://doi.org/10.1016/j.carbon.2017. 07.056

121. S. Liu, J. Zhou, H. Song, 2D Zn-hexamine coordination frameworks and their derived $\mathrm{N}$-rich porous carbon nanosheets for ultrafast sodium storage. Adv. Energy Mater. 8(22), 1800569 (2018). https://doi.org/10.1002/aenm.20180 0569

122. Y. Xie, J. Hu, Z. Han, T. Wang, J. Zheng et al., Encapsulating sodium deposition into carbon rhombic dodecahedron guided by sodiophilic sites for dendrite-free Na metal batteries. Energy Storage Mater. 30, 1-8 (2020). https://doi.org/10. 1016/j.ensm.2020.05.008

123. M.Q. Zhu, S.M. Li, B. Li, Y.J. Gong, Z.G. Du et al., Homogeneous guiding deposition of sodium through main group II metals toward dendrite-free sodium anodes. Sci. Adv. 5(4), 8 (2019). https://doi.org/10.1126/sciadv.aau6264

124. H. Xu, Y. Liu, T. Qiang, L. Qin, J. Chen et al., Boosting sodium storage properties of titanium dioxide by a multiscale design based on MOF-derived strategy. Energy Storage Mater. 17, 126-135 (2019). https://doi.org/10.1016/j.ensm. 2018.07.023

125. H.-H. Li, Z.-Y. Li, X.-L. Wu, L.-L. Zhang, C.-Y. Fan et al., Shale-like $\mathrm{Co}_{3} \mathrm{O}_{4}$ for high performance lithium/sodium ion batteries. J. Mater. Chem. A 4(21), 8242-8248 (2016). https://doi.org/10.1039/C6TA02417C

126. Y. Cai, G. Fang, J. Zhou, S. Liu, Z. Luo et al., Metal-organic framework-derived porous shuttle-like vanadium oxides for sodium-ion battery application. Nano Res. 11(1), 449-463 (2018). https://doi.org/10.1007/s12274-017-1653-9

127. S. Fan, S. Huang, Y. Chen, Y. Shang, Y. Wang et al., Construction of complex NiS multi-shelled hollow structures with enhanced sodium storage. Energy Storage Mater. 23, 17-24 (2019). https://doi.org/10.1016/j.ensm.2019.05.043

128. X. Xu, J. Liu, J. Liu, L. Ouyang, R. Hu et al., A general metal-organic framework (MOF)-derived selenidation strategy for in situ carbon-encapsulated metal selenides as highrate anodes for Na-ion batteries. Adv. Funct. Mater. 28(16), 1707573 (2018). https://doi.org/10.1002/adfm.201707573

129. N. Shi, B. Xi, M. Huang, X. Ma, H. Li et al., Hierarchical octahedra constructed by $\mathrm{Cu}_{2} \mathrm{~S} / \mathrm{MoS}_{2}$ subsetcarbon framework with enhanced sodium storage. Small 16(23), 2000952 (2020). https://doi.org/10.1002/smll.202000952

130. X. Wang, Y. Chen, Y.J. Fang, J.T. Zhang, S.Y. Gao et al., Synthesis of cobalt sulfide multi-shelled nanoboxes with precisely controlled two to five shells for sodium-ion batteries. Angew. Chem. Int. Ed. 58(9), 2675-2679 (2019). https://doi. org/10.1002/anie.201812387

131. Y. Zhang, Q. Su, W. Xu, G. Cao, Y. Wang et al., A confined replacement synthesis of bismuth nanodots in MOF derived carbon arrays as binder-free anodes for sodium-ion batteries. Adv. Sci. 6(16), 1900162 (2019). https://doi.org/10.1002/ advs.201900162

132. W. Zhang, W. Yan, H. Jiang, C. Wang, Y. Zhou et al., Uniform $\mathrm{Bi}-\mathrm{Sb}$ alloy nanoparticles synthesized from MOFs by laser metallurgy for sodium-ion batteries. ACS Sustain.
Chem. Eng. 8(1), 335-342 (2019). https://doi.org/10.1021/ acssuschemeng.9b05474

133. X. Hu, X. Liu, K. Chen, G. Wang, H. Wang, Core-shell mofderived N-doped yolk-shell carbon nanocages homogenously filled with $\mathrm{ZnSe}$ and $\mathrm{CoSe}_{2}$ nanodots as excellent anode materials for lithium- and sodium-ion batteries. J. Mater. Chem. A 7(18), 11016-11037 (2019). https://doi.org/10.1039/c9ta0 $1999 \mathrm{e}$

134. G. Fang, Z. Wu, J. Zhou, C. Zhu, X. Cao et al., Observation of pseudocapacitive effect and fast ion diffusion in bimetallic sulfides as an advanced sodium-ion battery anode. Adv. Energy Mater. 8(19), 1703155 (2018). https://doi.org/10. 1002/aenm.201703155

135. G. Fang, Q. Wang, J. Zhou, Y. Lei, Z. Chen et al., Metal organic framework-templated synthesis of bimetallic selenides with rich phase boundaries for sodium-ion storage and oxygen evolution reaction. ACS Nano 13(5), 5635-5645 (2019). https://doi.org/10.1021/acsnano.9b00816

136. X. Liu, Y. Liu, M. Feng, L.-Z. Fan, MOF-derived and nitrogen-doped $\mathrm{ZnSe}$ polyhedra encapsulated by reduced graphene oxide as the anode for lithium and sodium storage. J. Mater. Chem. A 6(46), 23621-23627 (2018). https://doi.org/10. $1039 / \mathrm{c} 8 \mathrm{ta0} 0247 \mathrm{~h}$

137. W. Ren, H. Zhang, C. Guan, C. Cheng, Ultrathin $\mathrm{MoS}_{2}$ nanosheets@metal organic framework-derived N-doped carbon nanowall arrays as sodium ion battery anode with superior cycling life and rate capability. Adv. Funct. Mater. 27(32), 1702116 (2017). https://doi.org/10.1002/adfm.20170 2116

138. C. Chen, M. Wu, Z. Xu, T. Feng, J. Yang et al., Tailored $\mathrm{N}$-doped porous carbon nanocomposites through MOF selfassembling for $\mathrm{Li} / \mathrm{Na}$ ion batteries. J Colloid Interface Sci. 538, 267-276 (2019). https://doi.org/10.1016/j.jcis.2018.11. 101

139. D. Cao, W. Kang, W. Wang, K. Sun, Y. Wang et al., Okra-like $\mathrm{Fe}_{7} \mathrm{~S}_{8} / \mathrm{C} @ \mathrm{ZnS} / \mathrm{N}-\mathrm{C} @ \mathrm{C}$ with core-double-shelled structures as robust and high-rate sodium anode. Small 16(35), 1907641 (2020). https://doi.org/10.1002/smll.201907641

140. Y.M. Chen, X.Y. Li, K. Park, W. Lu, C. Wang et al., Nitrogen-doped carbon for sodium-ion battery anode by selfetching and graphitization of bimetallic MOF-based composite. Chem 3(1), 152-163 (2017). https://doi.org/10.1016/j. chempr.2017.05.021

141. N. Mubarak, M. Ihsan-Ul-Haq, H. Huang, J. Cui, S. Yao et al., Metal-organic framework-induced mesoporous carbon nanofibers as an ultrastable $\mathrm{Na}$ metal anode host. J. Mater. Chem. A 8(20), 10269-10282 (2020). https://doi.org/10. 1039/d0ta00359j

142. S. Dong, C. Li, X. Ge, Z. Li, X. Miao et al., ZnS-Sb $\mathrm{S}_{3} @ \mathrm{C}$ core-double shell polyhedron structure derived from metalorganic framework as anodes for high performance sodium ion batteries. ACS Nano 11(6), 6474-6482 (2017). https:// doi.org/10.1021/acsnano.7b03321

143. L.T. Yu, J. Liu, X.J. Xu, L.G. Zhang, R.Z. Hu et al., Ilmenite nanotubes for high stability and high rate sodium-ion battery 
anodes. ACS Nano 11(5), 5120-5129 (2017). https://doi.org/ 10.1021/acsnano.7b02136

144. S.H. Yang, S.-K. Park, J.K. Kim, Y.C. Kang, A mofmediated strategy for constructing human backbone-like $\mathrm{CoMoS}_{3} @ \mathrm{~N}$-doped carbon nanostructures with multiple voids as a superior anode for sodium-ion batteries. J. Mater. Chem. A 7(22), 13751-13761 (2019). https://doi.org/10. 1039/C9TA03873F

145. X. Bie, K. Kubota, T. Hosaka, K. Chihara, S. Komaba, A novel K-ion battery: hexacyanoferrate(ii)/graphite cell. J. Mater. Chem. A 5(9), 4325-4330 (2017). https://doi.org/10. 1039/C7TA00220C

146. L. Li, Z. Hu, Y. Lu, C. Wang, Q. Zhang et al., A low-strain potassium-rich prussian blue analogue cathode for high power potassium-ion batteries. Angew. Chem. Int. Ed. 60(23), 13050-13056 (2021). https://doi.org/10.1002/anie. 202103475

147. J.Y. Liao, Q. Hu, J.X. Mu, X.D. He, S. Wang et al., A vanadium-based metal-organic phosphate framework material $\mathrm{K}_{2}\left[(\mathrm{VO})_{2}\left(\mathrm{HPO}_{4}\right)_{2}\left(\mathrm{C}_{2} \mathrm{O}_{4}\right)\right]$ as a cathode for potassium-ion batteries. Chem. Commun. 55(5), 659-662 (2019). https:// doi.org/10.1039/c8cc08734b

148. Y.L. An, H.F. Fei, Z. Zhang, L.J. Ci, S.L. Xiong et al., A titanium-based metal-organic framework as an ultralong cyclelife anode for PIBs. Chemical Commun. 53(59), 8360-8363 (2017). https://doi.org/10.1039/c7cc03606j

149. C. Li, X.S. Hu, B.W. Hu, Cobalt(ii) dicarboxylate-based metal-organic framework for long-cycling and high-rate potassium-ion battery anode. Electrochim. Acta 253, 439444 (2017). https://doi.org/10.1016/j.electacta.2017.09.090

150. E. Nossol, V.H.R. Souza, A.J.G. Zarbin, Carbon nanotube/ prussian blue thin films as cathodes for flexible, transparent and ITO-free potassium secondary battery. J. Colloid Interface Sci. 478, 107-116 (2016). https://doi.org/10.1016/j.jcis. 2016.05.056

151. J. Li, H. Zhao, J. Wang, N. Li, M. Wu et al., Interplanar space-controllable carboxylate pillared metal organic framework ultrathin nanosheet for superhigh capacity rechargeable alkaline battery. Nano Energy 62, 876-882 (2019). https:// doi.org/10.1016/j.nanoen.2019.06.009

152. P. Xiao, S. Li, C. Yu, Y. Wang, Y. Xu, Interface engineering between the metal-organic framework nanocrystal and graphene toward ultrahigh potassium-ion storage performance. ACS Nano 14(8), 10210-10218 (2020). https://doi.org/10. 1021/acsnano.0c03488

153. Y.P. Li, C.H. Yang, F.H. Zheng, X. Ou, Q.C. Pan et al., High pyridine $\mathrm{N}$-doped porous carbon derived from metal-organic frameworks for boosting potassium-ion storage. J. Mater. Chem. A 6(37), 17959-17966 (2018). https://doi.org/10. $1039 / \mathrm{c} 8 \mathrm{ta0} 6652 \mathrm{c}$

154. J. Lu, C. Wang, H. Yu, S. Gong, G. Xia et al., Oxygen/fluorine dual-doped porous carbon nanopolyhedra enabled ultrafast and highly stable potassium storage. Adv. Funct. Mater. 29(49), 1906126 (2019). https://doi.org/10.1002/adfm.20190 6126
155. G.Y. Ma, C.J. Li, F. Liu, M.K. Majeed, Z.Y. Feng et al., Metal-organic framework-derived $\mathrm{Co}_{0.85}$ Se nanoparticles in $\mathrm{N}$-doped carbon as a high-rate and long-lifespan anode material for potassium ion batteries. Mater. Today Energy 10, 241-248 (2018). https://doi.org/10.1016/j.mtener.2018. 09.013

156. S.L. Su, Q. Liu, J. Wang, L. Fan, R.F. Ma et al., Control of SEI formation for stable potassium-ion battery anodes by BiMOF-derived nanocomposites. ACS Appl. Mater. Interfaces 11(25), 22474-22480 (2019). https://doi.org/10.1021/acsami. $9 \mathrm{~b} 06379$

157. J. Xie, X. Li, H. Lai, Z. Zhao, J. Li et al., A robust solid electrolyte interphase layer augments the ion storage capacity of bimetallic-sulfide-containing potassium-ion batteries. Angew. Chem. Int. Ed. 58(41), 14740-14747 (2019). https://doi.org/ 10.1002/anie. 201908542

158. C. Atangana Etogo, H. Huang, H. Hong, G. Liu, L. Zhang, Metal-organic-frameworks-engaged formation of $\mathrm{Co}_{0.85} \mathrm{Se} @ \mathrm{C}$ nanoboxes embedded in carbon nanofibers film for enhanced potassium-ion storage. Energy Storage Mater. 24, 167-176 (2020). https://doi.org/10.1016/j.ensm.2019.08. 022

159. X. Zhou, L. Chen, W. Zhang, J. Wang, Z. Liu et al., Threedimensional ordered macroporous metal-organic framework single crystal-derived nitrogen-doped hierarchical porous carbon for high-performance potassium-ion batteries. Nano Lett. 19(8), 4965-4973 (2019). https://doi.org/10.1021/acs. nanolett.9b01127

160. R. Trócoli, F. La Mantia, An aqueous zinc-ion battery based on copper hexacyanoferrate. Chemsuschem 8(3), 481-485 (2015). https://doi.org/10.1002/cssc.201403143

161. M.S. Chae, J.W. Heo, H.H. Kwak, H. Lee, S.-T. Hong, Organic electrolyte-based rechargeable zinc-ion batteries using potassium nickel hexacyanoferrate as a cathode material. J. Power Sources 337, 204-211 (2017). https://doi.org/ 10.1016/j.jpowsour.2016.10.083

162. X.-W. Lou, Construction of Co-Mn prussian blue analog hollow spheres for efficient aqueous $\mathrm{Zn}$-ion batteries. Angew. Chem. Int. Ed. (2021). https://doi.org/10.1002/anie.20210 7697

163. L. Zhang, L. Chen, X. Zhou, Z. Liu, Towards high-voltage aqueous metal-ion batteries beyond $1.5 \mathrm{~V}$ : the zinc/zinc hexacyanoferrate system. Adv. Energy Mater. 5(2), 1400930 (2015). https://doi.org/10.1002/aenm.201400930

164. K.W. Nam, S.S. Park, R. dos Reis, V.P. Dravid, H. Kim et al., Conductive 2D metal-organic framework for highperformance cathodes in aqueous rechargeable zinc batteries. Nat. Commun. 10, 4948 (2019). https://doi.org/10.1038/ s41467-019-12857-4

165. H. Yang, Z. Chang, Y. Qiao, H. Deng, X. Mu et al., Constructing a super-saturated electrolyte front surface for stable rechargeable aqueous zinc batteries. Angew. Chem. Int. Ed. 59(24), 9377-9381 (2020). https://doi.org/10.1002/anie. 202001844

166. X. Pu, B. Jiang, X. Wang, W. Liu, L. Dong et al., High-performance aqueous zinc-ion batteries realized by MOF materials. 
Nano-Micro Lett. 12(1), 152 (2020). https://doi.org/10.1007/ s40820-020-00487-1

167. B. He, Q. Zhang, P. Man, Z. Zhou, C. Li et al., Self-sacrificed synthesis of conductive vanadium-based metal-organic framework nanowire-bundle arrays as binder-free cathodes for high-rate and high-energy-density wearable $\mathrm{Zn}$-ion batteries. Nano Energy 64, 103935 (2019). https://doi.org/10. 1016/j.nanoen.2019.103935

168. Z. Wang, J. Hu, L. Han, Z. Wang, H. Wang et al., A MOFbased single-ion $\mathrm{Zn}^{2+}$ solid electrolyte leading to dendritefree rechargeable Zn batteries. Nano Energy 56, 92-99 (2019). https://doi.org/10.1016/j.nanoen.2018.11.038

169. C.C. Hou, Y. Wang, L. Zou, M. Wang, H. Liu et al., A gassteamed MOF route to P-doped open carbon cages with enhanced $\mathrm{Zn}$-ion energy storage capability and ultrastability. Adv. Mater. (2021). https://doi.org/10.1002/adma.202101698

170. S. Deng, Z. Yuan, Z. Tie, C. Wang, L. Song et al., Electrochemically induced MOF-derived amorphous $\mathrm{V}_{2} \mathrm{O}_{5}$ for superior rate aqueous $\mathrm{Zn}$-ion batteries. Angew. Chem. Int. Ed. 59(49), 22002-22006 (2020). https://doi.org/10.1002/anie. 202010287

171. Z. Wang, J.H. Huang, Z.W. Guo, X.L. Dong, Y. Liu et al., A metal-organic framework host for highly reversible dendritefree zinc metal anodes. Joule 3(5), 1289-1300 (2019). https:// doi.org/10.1016/j.joule.2019.02.012

172. R. Yuksel, O. Buyukcakir, W.K. Seong, R.S. Ruoff, Metalorganic framework integrated anodes for aqueous zinc-ion batteries. Adv. Energy Mater. 10(16), 1904215 (2020). https://doi.org/10.1002/aenm.201904215

173. Y. Fu, Q. Wei, G. Zhang, X. Wang, J. Zhang et al., High-performance reversible aqueous $\mathrm{Zn}$-ion battery based on porous $\mathrm{MnO}_{\mathrm{x}}$ nanorods coated by MOF-derived N-doped carbon. Adv. Energy Mater. 8(26), 1801445 (2018). https://doi.org/ 10.1002/aenm.201801445

174. Q. Tan, X. Li, B. Zhang, X. Chen, Y. Tian et al., Valence engineering via in situ carbon reduction on octahedron sites $\mathrm{Mn}_{3} \mathrm{O}_{4}$ for ultra-long cycle life aqueous $\mathrm{Zn}$-ion battery. Adv. Energy Mater. 10(38), 2001050 (2020). https://doi.org/10. 1002/aenm.202001050

175. J.-H. Lee, R. Kim, S. Kim, J. Heo, H. Kwon et al., Dendritefree $\mathrm{Zn}$ electrodeposition triggered by interatomic orbital hybridization of $\mathrm{Zn}$ and single vacancy carbon defects for aqueous zn-based flow batteries. Energy Environ. Sci. 13, 2839-2848 (2020). https://doi.org/10.1039/d0ee00723d

176. S.S. Shinde, C.H. Lee, J.-Y. Jung, N.K. Wagh, S.-H. Kim et al., Unveiling dual-linkage 3D hexaiminobenzene metalorganic frameworks towards long-lasting advanced reversible Zn-air batteries. Energy Environ. Sci. 12(2), 727-738 (2019). https://doi.org/10.1039/c8ee02679c

177. H. Pourfarzad, M. Shabani-Nooshabadi, M.R. Ganjali, Novel bi-functional electrocatalysts based on the electrochemical synthesized bimetallicmetal organic frameworks: Towards high energy advanced reversible zinc-air batteries. J. Power Sources 451, 227768 (2020). https://doi.org/10.1016/j.jpows our.2020.227768
178. G. Chen, J. Zhang, F. Wang, L. Wang, Z. Liao et al., Cobaltbased metal-organic framework nanoarrays as bifunctional oxygen electrocatalysts for rechargeable $\mathrm{Zn}$-air batteries. Chem. Eur. J. 24(69), 18413-18418 (2018). https://doi.org/ 10.1002/chem.201804339

179. X. Zheng, Y. Cao, D. Liu, M. Cai, J. Ding et al., Bimetallic metal-organic-framework/reduced graphene oxide composites as bifunctional electrocatalysts for rechargeable $\mathrm{Zn}$-air batteries. ACS Appl. Mater. Interfaces 11(17), 15662-15669 (2019). https://doi.org/10.1021/acsami.9b02859

180. Y. Jiang, Y.-P. Deng, R. Liang, J. Fu, R. Gao et al., d-Orbital steered active sites through ligand editing on heterometal imidazole frameworks for rechargeable zinc-air battery. Nat. Commun. 11(1), 5858 (2020). https://doi.org/10.1038/ s41467-020-19709-6

181. F. Yang, J. Xie, X. Liu, G. Wang, X. Lu, Linker defects triggering boosted oxygen reduction activity of $\mathrm{Co} / \mathrm{Zn}$-ZIF nanosheet arrays for rechargeable $\mathrm{Zn}$-air batteries. Small 17(3), 2007085 (2021). https://doi.org/10.1002/smll.20200 7085

182. L. Zhao, B. Dong, S. Li, L. Zhou, L. Lai et al., Interdiffusion reaction-assisted hybridization of two-dimensional metalorganic frameworks and $\mathrm{Ti}_{3} \mathrm{C}_{2} \mathrm{~T}_{\mathrm{x}}$ nanosheets for electrocatalytic oxygen evolution. ACS Nano 11(6), 5800-5807 (2017). https://doi.org/10.1021/acsnano.7b01409

183. Z. Liang, H. Guo, G. Zhou, K. Guo, B. Wang et al., Metalorganic-framework-supported molecular electrocatalysis for the oxygen reduction reaction. Angew. Chem. Int. Ed. 60(15), 8472-8476 (2021). https://doi.org/10.1002/anie.202016024

184. Y. Qian, Z. Hu, X. Ge, S. Yang, Y. Peng et al., A metal-free ORR/OER bifunctional electrocatalyst derived from metalorganic frameworks for rechargeable $\mathrm{Zn}$-air batteries. Carbon 111, 641-650 (2017). https://doi.org/10.1016/j.carbon.2016. 10.046

185. A.I. Douka, Y. Xu, H. Yang, S. Zaman, Y. Yan et al., A zeolitic-imidazole frameworks-derived interconnected macroporous carbon matrix for efficient oxygen electrocatalysis in rechargeable zinc-air batteries. Adv. Mater. 32(28), 2002170 (2020). https://doi.org/10.1002/adma.202002170

186. Z. Wu, H. Wu, T. Niu, S. Wang, G. Fu et al., Sulfurated metal-organic framework-derived nanocomposites for efficient bifunctional oxygen electrocatalysis and rechargeable Zn-air battery. ACS Sustain. Chem. Eng. 8(24), 9226-9234 (2020). https://doi.org/10.1021/acssuschemeng.0c03570

187. M. Zhang, Q. Dai, H. Zheng, M. Chen, L. Dai, Novel MOFderived Co@N-C bifunctional catalysts for highly efficient $\mathrm{Zn}$-air batteries and water splitting. Adv. Mater. 30(10), 1705431 (2018). https://doi.org/10.1002/adma.201705431

188. X.F. Lu, Y. Chen, S. Wang, S. Gao, X.W. Lou, Interfacing manganese oxide and cobalt in porous graphitic carbon polyhedrons boosts oxygen electrocatalysis for $\mathrm{Zn}$-air batteries. Adv. Mater. 31(39), 1902339 (2019). https://doi.org/10.1002/ adma.201902339

189. D. Ren, J. Ying, M. Xiao, Y.P. Deng, J. Ou et al., Hierarchically porous multimetal-based carbon nanorod hybrid as an efficient oxygen catalyst for rechargeable zinc-air batteries. 
Adv. Funct. Mater. 30(7), 1908167 (2019). https://doi.org/10. 1002/adfm.201908167

190. Y. Xu, P. Deng, G. Chen, J. Chen, Y. Yan et al., 2D nitrogendoped carbon nanotubes/graphene hybrid as bifunctional oxygen electrocatalyst for long-life rechargeable $\mathrm{Zn}$-air batteries. Adv. Funct. Mater. 30(6), 1906081 (2020). https://doi.org/10. 1002/adfm.201906081

191. C. Guan, A. Sumboja, H. Wu, W. Ren, X. Liu et al., Hollow $\mathrm{Co}_{3} \mathrm{O}_{4}$ nanosphere embedded in carbon arrays for stable and flexible solid-state zinc-air batteries. Adv. Mater. 29(44), 1704117 (2017). https://doi.org/10.1002/adma.201704117

192. Q. Zhou, Z. Zhang, J. Cai, B. Liu, Y. Zhang et al., Templateguided synthesis of Co nanoparticles embedded in hollow nitrogen doped carbon tubes as a highly efficient catalyst for rechargeable Zn-air batteries. Nano Energy 71, 104592 (2020). https://doi.org/10.1016/j.nanoen.2020.104592

193. D. Ji, L. Fan, L. Li, S. Peng, D. Yu et al., Atomically transition metals on self-supported porous carbon flake arrays as binder-free air cathode for wearable zinc-air batteries. Adv. Mater. 31(16), 1808267 (2019). https://doi.org/10.1002/ adma.201808267

194. Y. Arafat, M.R. Azhar, Y. Zhong, X. Xu, M.O. Tadé et al., A porous nano-micro-composite as a high-performance bi-functional air electrode with remarkable stability for rechargeable zinc-air batteries. Nano-Micro Lett. 12, 130 (2020). https:// doi.org/10.1007/s40820-020-00468-4

195. D. Chen, X. Chen, Z. Cui, G. Li, B. Han et al., Dual-activesite hierarchical architecture containing NiFe-LDH and ZIF-derived carbon-based framework composite as efficient bifunctional oxygen electrocatalysts for durable rechargeable Zn-air batteries. Chem. Eng. J. 399, 125718 (2020). https:// doi.org/10.1016/j.cej.2020.125718

196. Y.-N. Chen, Y. Guo, H. Cui, Z. Xie, X. Zhang et al., Bifunctional electrocatalysts of MOF-derived Co-N/C on bamboolike $\mathrm{MnO}$ nanowires for high-performance liquid- and solidstate Zn-air batteries. J. Mater. Chem. A 6(20), 9716-9722 (2018). https://doi.org/10.1039/c8ta01859f

197. X. Gao, Y. Du, J. Zhou, S. Li, P. Qi et al., Large-scale production of MOF-derived coatings for functional interlayers in high-performance Li-S batteries. ACS Appl. Energy Mater. 1(12), 6986-6991 (2018). https://doi.org/10.1021/acsaem. $8 \mathrm{~b} 01401$

198. G.K. Gao, Y.R. Wang, H.J. Zhu, Y. Chen, R.X. Yang et al., Rapid production of metal-organic frameworks based separators in industrial-level efficiency. Adv. Sci. 7(24), 2002190 (2020). https://doi.org/10.1002/advs.202002190 